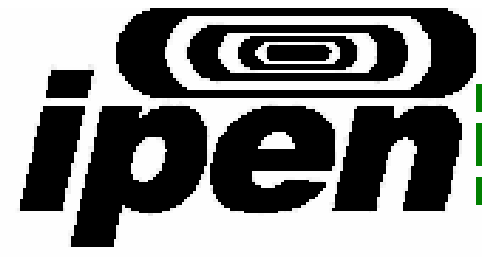

AUTARQUIA ASSOCIAD A A

UIIIERSIDADE DE SÄO PAULO

\title{
DESENVOLVIMENTO DE UM SISTEMA BASEADO NA WEB PARA SUPORTE AO PROGRAMA DE MONITORAÇÃO INDIVIDUAL INTERNA DO IPEN
}

\author{
VANESSA ROGÉRIA DE LIMA
}

Dissertação apresentada como parte dos requisitos para obtenção do Grau de Mestre em Ciências na Área de Tecnologia Nuclear - Aplicações.

Orientador:

Dr. Alberto Saburo Todo

SÃO PAULO 2007 
INSTITUTO DE PESQUISAS ENERGÉTICAS E NUCLEARES Autarquia Associada à Universidade de São Paulo

\title{
DESENVOLVIMENTO DE UM SISTEMA BASEADO NA WEB PARA SUPORTE AO PROGRAMA DE MONITORAÇÃO INDIVIDUAL INTERNA DO IPEN
}

\section{VANESSA ROGÉRIA DE LIMA}

\begin{abstract}
Dissertação apresentada como parte dos requisitos para obtenção do Grau de Mestre em Ciências na Área de Tecnologia Nuclear - Aplicações.
\end{abstract}

Orientador:

Dr. Alberto Saburo Todo 
Aos meus pais, Antônio e Nilza, sempre presentes na minha vida e apoio constante. À memória de meu irmão Celso e minha avó Joaquina. Ao meu marido, Rodrigo, pelo amor, paciência e incentivo. 


\section{AGRADECIMENTOS}

Aos meus pais, Sr. Antônio Francisco da Silva Lima e Sra. Nilza do Rosário Lima, pelo exemplo de vida, dedicação e apoio incondicional.

Ao meu irmão, Celso Ricardo de Lima (in memorian), e minha avó Joaquina Neves do Rosário (in memorian), que sempre estiveram e estarão ao meu lado.

Ao meu Orientador, Dr. Alberto Saburo Todo, pelo conhecimento, dedicação, amizade e valiosos conselhos e conversas durante esse trajeto.

Ao Dr. Orlando Rodrigues Junior, pelo incentivo, ensinamento e co-orientação para a qualificação deste trabalho.

Ao meu marido e companheiro Rodrigo da Costa Alexandre, que sempre me apoiou e motivou a perseguir meus objetivos, com disciplina e determinação.

À minha eterna amiga Sybele Guedes de Paulo Groff, que colaborou direta e indiretamente em diversos aspectos desta dissertação.

À minha família por entender minha ausência durante a realização desta pesquisa.

À Universidade do Estado de São Paulo e ao Instituto de Pesquisa Energéticas e Nucleares, por todas as oportunidades que me proporcionaram.

A todos que, direta ou indiretamente, contribuíram para a realização desta pesquisa. 
Jamais desencoraje alguém que faz progressos contínuos, não importa o quanto sejam lentos

Platão

O único homem que está isento de erros é aquele que não arrisca acertar. Albert Einstein 


\title{
DESENVOLVIMENTO DE UM SISTEMA BASEADO NA WEB PARA SUPORTE AO PROGRAMA DE MONITORAÇÃO INDIVIDUAL INTERNA DO IPEN
}

\author{
Vanessa Rogéria de Lima
}

\section{RESUMO}

O propósito geral da monitoração interna é verificar e documentar que o trabalhador está protegido adequadamente contra os riscos de incorporação de radionuclídeos e que esta proteção obedece as exigências legais. Portanto, um programa de proteção radiológica inicia-se com a identificação de situações de trabalho nas quais há um risco de contaminação interna de trabalhadores, além de quantificar a provável incorporação de material radioativo e a dose efetiva comprometida resultante. Como parte de uma melhoria contínua do programa de monitoração para os trabalhadores ocupacionalmente expostos no IPEN, está sendo proposto um sistema baseado na Web para acessar a base de dados da dosimetria interna. O sistema é baseado na linguagem de programação Hypertext Preprocessor, PHP e a base de dados PostgreSQL. Este sistema introduzirá um novo paradigma na rotina do serviço de dosimetria interna, proporcionando um acesso rápido à informação entre os laboratórios de medida, grupo de cálculo de dose e supervisores de radioproteção. A base de dados mantém informação sobre a identificação do trabalhador, características físicas e químicas do radionuclídeo, tipo de monitoração, dados de medida e a dose. Além disso, esta informação estará prontamente disponível para prover apoio aos órgãos reguladores e às exigências de controle de qualidade. 


\title{
DEVELOPEMENT OF WEB BASED SYSTEM FOR INDIVIDUAL INTERNAL MONITORING PROGRAMME
}

\author{
Vanessa Rogéria de Lima
}

\begin{abstract}
The purposes of the internal monitoring, in general, are to verify and document that each worker is protected adequately against risks from radionuclide intakes and the protection complies with legal requirements. Therefore, an overall radiation protection programme, starts with an assessment to identify work situations in which there is a risk of internal contamination of workers and to quantify the likely intake of radioactive material and the resulting committed effective dose. As a part of a continuous improvement of the monitoring programme for occupationally exposed workers at IPEN, it is being developed a Web based system to access the internal dosimetry database. The system was implemented using Hypertext Preprocessor, PHP, and a PostgreSQL database. This system will introduce a new paradigm in the routine of the internal dosimetry service, providing a fast access to the information among the measurement laboratories staff, dose evaluation group and the radiation protection supervisor. The database maintains information about worker identification, physical and chemical characteristics of the radionuclide, type of monitoring, measurement data and the dose. Moreover, this information will be readily available to provide support for regulatory compliance and quality control requirements.
\end{abstract}




\section{LISTA DE FIGURAS}

FIGURA 2.1 - Diagrama do programa de monitoração interna ................................6

FIGURA 2.2 - Modelo Cascata - O andamento do processo flui de cima para baixo, como uma cascata.....................................................13

FIGURA 2.3 - Modelo Protótipo - Apropriado quando o cliente define apenas objetivos gerais (sem requisitos detalhados de entrada,

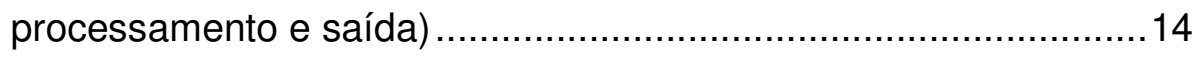

FIGURA 2.4 - Modelo Espiral completo descrito por Boehm …….......................15

FIGURA 2.5 - Diagrama representativo Cliente-Servidor...................................17

FIGURA 3.1 - Modelo atual do fluxo de informações ........................................22

FIGURA 3.2 - Modelo do fluxo de informações proposto a partir do

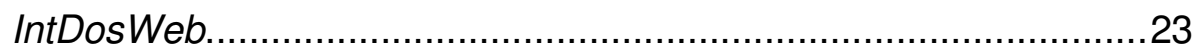

FIGURA 3.3 - Modelo complexo do fluxo de informações da

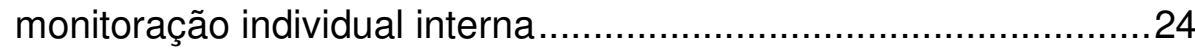

FIGURA 3.4 - Modelagem do banco de dados - Usuário ....................................26

FIGURA 3.5 - Modelagem do banco de dados - Trabalhador .............................27

FIGURA 3.6 - Modelagem do banco de dados - Monitoração In Vivo,

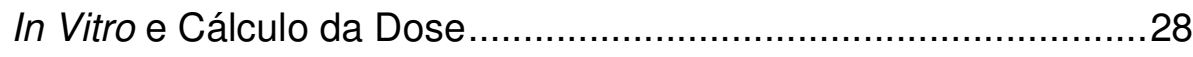

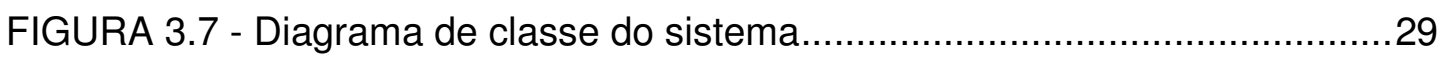

FIGURA 3.8 - Diagrama de caso de uso para o Administrador...............................30

FIGURA 3.9 - Diagrama de caso de uso para o Grupo de Cálculo de Dose .........31

FIGURA 3.10 - Diagrama de caso de uso para o Laboratório de Monitoração In Vivo.

FIGURA 3.11 - Diagrama de caso de uso para o Laboratório de

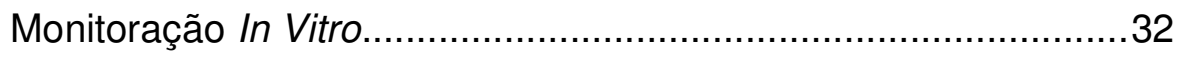

FIGURA 3.12 - Diagrama de caso de uso para o Supervisor ...............................32

FIGURA 3.13 - Diagrama de caso de uso para o Trabalhador ..............................33

FIGURA 4.1 - Representação gráfica do IntDosWeb baseado na troca de informações utilizando Intranet por meio de um único banco de dados. 
Página

FIGURA 4.2 - Fluxograma de acesso ao sistema IntDosWeb …..........................37

FIGURA 4.3 - Fluxograma de acesso ao sistema IntDosWeb - continuação........38

FIGURA 4.4 - Representação gráfica do menu de acesso ao perfil Administrador

FIGURA 4.5 - Representação gráfica do menu de acesso ao perfil Grupo de Cálculo de Dose

FIGURA 4.6 - Representação gráfica do menu de acesso ao perfil Laboratório de Monitoração In Vivo. .45

FIGURA 4.7 - Representação gráfica do menu de acesso ao perfil Laboratório de Monitoração In Vitro 46

FIGURA 4.8 - Representação gráfica do menu de acesso ao perfil Supervisor

FIGURA 4.9 - Representação gráfica do menu de acesso ao perfil Trabalhador..... .48

FIGURA 4.10 - Formulário de cadastro de usuários 49

FIGURA 4.11 - Formulário de relação supervisor $x$ setor ....................................50

FIGURA 4.12 - Formulário de cadastro de trabalhador - primeiro passo ...............51

FIGURA 4.13 - Formulário de cadastro de trabalhador - segundo passo .............52

FIGURA 4.14 - Formulário de cadastro de trabalhador - terceiro passo …............52

FIGURA 4.15 - Formulário de cadastro de trabalhador - quarto passo ...................53

FIGURA 4.16 - Formulário de cadastro de trabalhador - quinto passo ..................53

FIGURA 4.17 - Formulário de monitoração in vivo - pesquisa de trabalhador ......54

FIGURA 4.18 - Formulário de monitoração in vivo - inserção dos dados da monitoração .56

FIGURA 4.19 - Formulário de monitoração in vitro - pesquisa de trabalhador ......57

FIGURA 4.20 - Formulário de monitoração in vitro - inserção dos dados da monitoração in vitro para o método de análise tório

FIGURA 4.21 - Formulário de monitoração in vitro - inserção dos dados da monitoração in vitro para o método de análise trítio 
Página

FIGURA 4.22 - Formulário de monitoração in vitro - inserção dos dados da monitoração in vitro para o método actinídeos........62

FIGURA 4.23 - Formulário de pesquisa de monitoração para cálculo da dose.....63

FIGURA 4.24 - Mensagem de erro - pesquisa de monitoração para cálculo da dose. .64

FIGURA 4.25 - Formulário para pesquisar o registro do trabalhador e monitoração .65

FIGURA 4.26 - Formulário para inserir resultado da dose .66

FIGURA 4.27 - Formulário para gerar o relatório do cálculo de dose da monitoração in vivo e in vitro .68

FIGURA 5.1 - Formulário de autenticação de usuários 69

FIGURA 5.2 - Pesquisa de usuários, parte do formulário cadastro de usuários ...70 FIGURA 5.3 - Formulário para alteração de dados do usuário .............................71

FIGURA 5.4 - Formulário para alteração de dados do trabalhador........................72

FIGURA 5.5 - Formulário para alteração de dados do trabalhador - instituição ....73

FIGURA 5.6 - Formulário para alteração de dados do trabalhador - material radioativo

FIGURA 5.7 - Formulário para alteração de dados do trabalhador - radioisótopo

FIGURA 5.8 - Formulário para alteração de dados do trabalhador - tipo de monitoração. .74

FIGURA 5.9 - Formulário de impressão da ficha cadastral do trabalhador. .75

FIGURA 5.10 - Formulário de pesquisa relação supervisor $x$ setor .......................76

FIGURA 5.11 - Histórico de monitoração individual interna in vivo ........................77

FIGURA 5.12 - Formulário para alteração de dados da monitoração in vivo ........78

FIGURA 5.13 - Histórico da monitoração individual interna in vitro........................79

FIGURA 5.14 - Formulário para alteração de dados da monitoração in vitro - trítio

FIGURA 5.15 - Pesquisa de monitoração realizada para efetuar cálculo de dose.

FIGURA 5.16 - Resultado da pesquisa de monitoração salva em planilha Excel 
Página

FIGURA 5.17 - Formulário de pesquisa registro de dose …...............................82

FIGURA 5.18 - Formulário para alteração de dados do registro de dose .............84

FIGURA 5.19 - Impressão do relatório monitoração interna

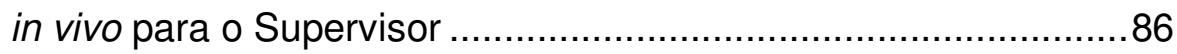

FIGURA 5.20 - Impressão do Relatório Monitoração Interna

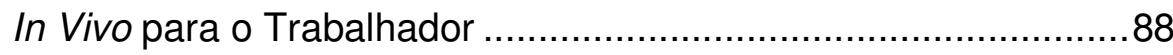

FIGURA 5.21 - Impressão do Relatório Monitoração Interna

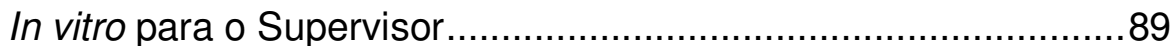

FIGURA 5.22 - Impressão do relatório monitoração interna in vitro para o Trabalhador. 90 


\section{LISTA DE TABELAS}

TABELA 2.1 - Principais radionuclídeos selecionados para monitoração

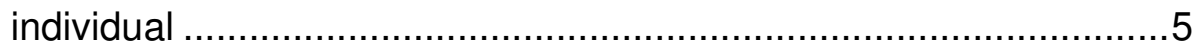

TABELA 2.2 - Período de retenção do registro de dose .....................................10

TABELA 4.1 - Formulário de monitoração in vivo - resultado da pesquisa de trabalhador... .55

TABELA 4.2 - Formulário de monitoração in vitro - resultado da

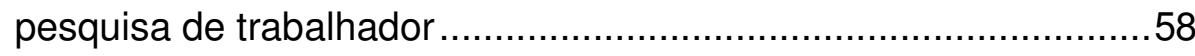

TABELA 4.3 - Resultado da pesquisa de monitoração para cálculo da dose .......65

TABELA 5.1 - Pesquisa de usuários de acesso efetuada por nome ......................70

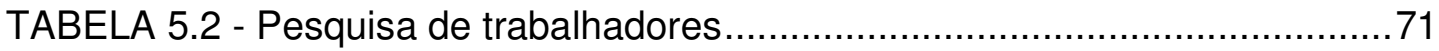

TABELA 5.3 - Resultado da pesquisa do registro de dose …...............................83

TABELA 5.4 - Relatório da monitoração interna in vivo para o Supervisor ............85

TABELA 5.5 - Relatório da monitoração interna in vivo para o Trabalhador ..........87

TABELA 5.6 - Relatório da monitoração interna in vitro para o Supervisor............89

TABELA 5.7 - Relatório da monitoração interna in vitro para o Trabalhador .........90 


\section{LISTA DE SIGLAS}

AIEA - International Atomic Energy Agency, Agência Internacional de Energia Atômica

AMAD - Activity Median Aerodynamic Diameter, Diâmetro Aerodinâmico Mediano em Atividade (DAMA)

ARCAL - Acordo Regional de Cooperação para a Promoção da Ciência e Tecnologia Nucleares na America Latina e Caribe

$\mathrm{Bq}$ - Bequerel

CAC - Centro de Aceleradores Ciclotron

CCN - Ciclo do Combustível Nuclear

CMR - Centro de Metrologia das Radiações

CNEN - Comissão Nacional de Energia Nuclear

CP - Contaminação Através da Pele

CPD - Centro de Processamento de Dados

CR - Centro de Radiofarmácia

$\mathrm{CRPq}$ - Centro do Reator de Pesquisa

FAQ - Frequently Asked Questions, Perguntas Freqüentes

FSS - Ficha de Solicitação de Serviço

GCD - Grupo de Cálculo de Dose

$\mathrm{IH}$ - Inalação

IG - Ingestão

IOE - Indivíduo Ocupacionalmente Exposto

HATM - Human Alimentary Tract Model, Modelo do Trato Alimentar Humano

HRTM - Human Respiratory Ttract Model, Modelo do Trato Respiratório Humano

HTTP - Hypertext Transfer Protocol, Protocolo de Transferência de Hipertexto

HTTPS - Hypertext Transfer Protocol Secure, Protocolo de Transferência de Hipertexto Seguro 
HTML - Hypertext Markup Language, Linguagem de Marcação de Hipertexto

ICRP - International Commission on Radiological Protection, Comissão Internacional de Proteção Radiológica

IP - Internet Protocol, Protocolo de Internet

IPEN - Instituto de Pesquisas Energéticas e Nucleares

LMIV - Laboratório de Monitoração in Vivo

LNR - Laboratório de Rejeitos Radioativos

mSv - Milesiervert

NATO - Conference on Software Engineering, Conferência sobre Engenharia de Software da OTAN

PHP - Hypertext Preprocessor

SGBD - Sistema Gerenciador de Banco de Dados

SQL - Structured Query Language

URL - Uniform Resource Locator, Localizador Uniforme de Recursos

WWW - World Wide Web 


\section{SUMÁRIO}

Página

1 INTRODUÇÃO

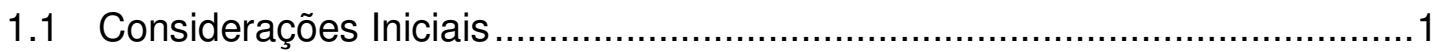

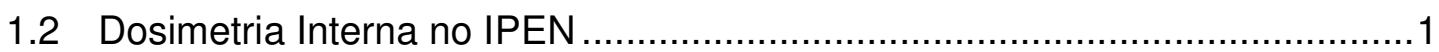

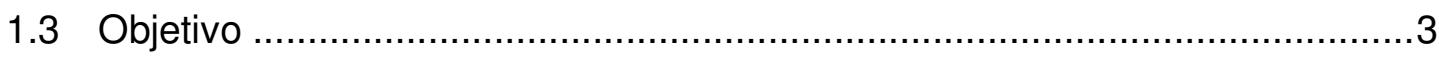

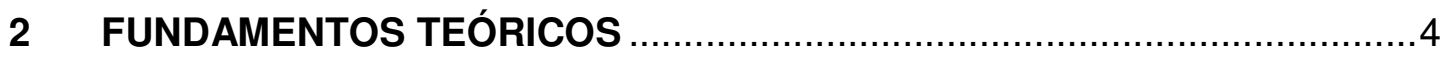

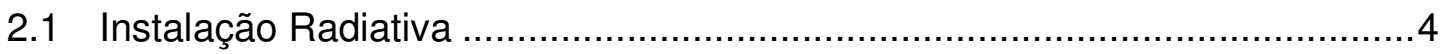

2.2 Fundamentos do Programa de Monitoração ………………………….......

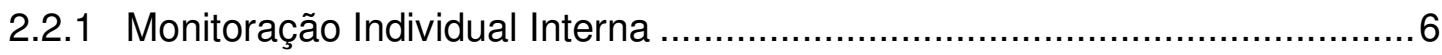

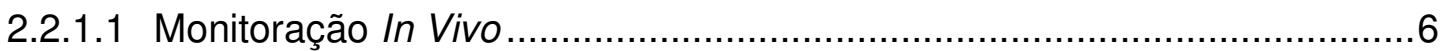

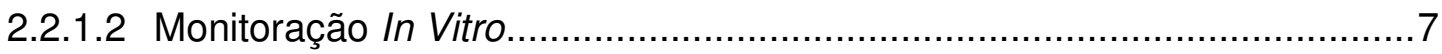

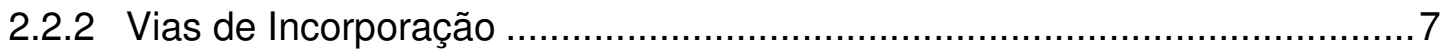

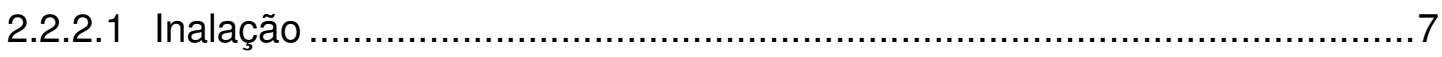

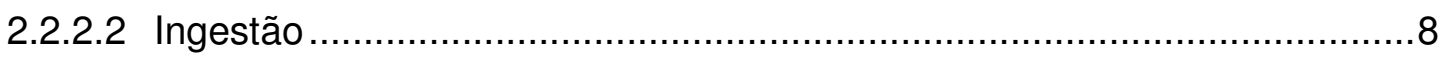

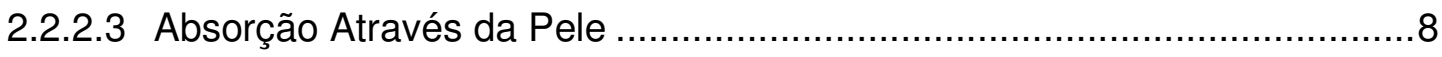

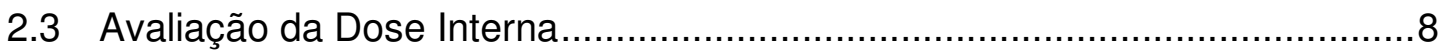

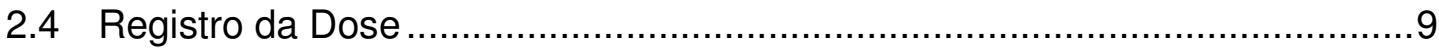

2.5 Fundamentos de Tecnologia da Informação ............................................11

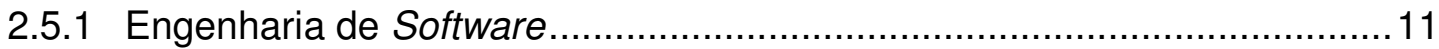

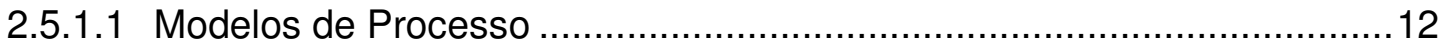

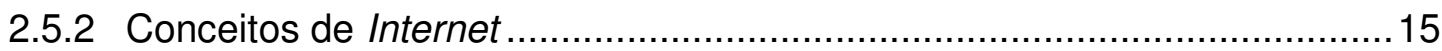

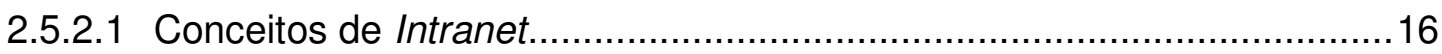

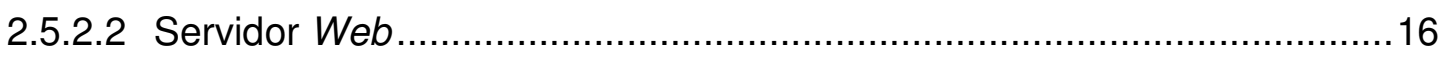

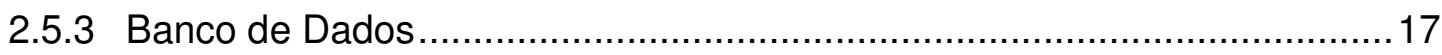

2.5.3.1 Sistema Gerenciador de Banco de Dados..........................................18

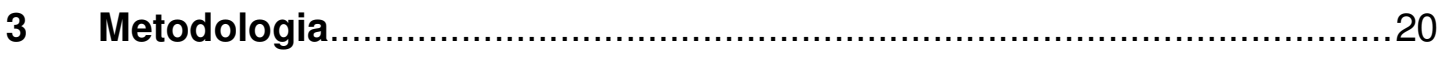


Página

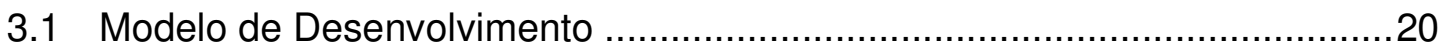

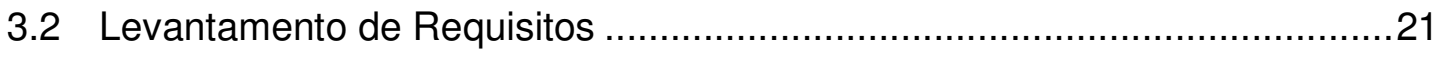

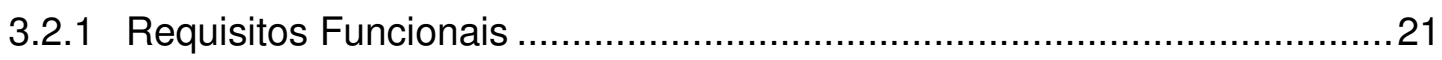

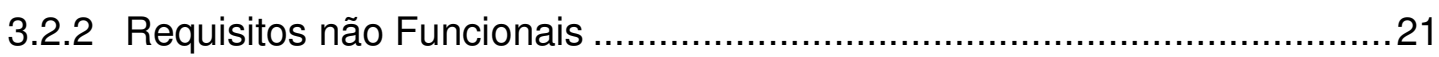

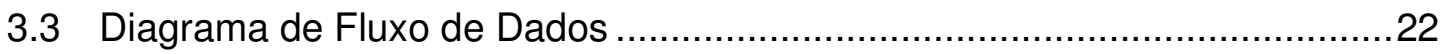

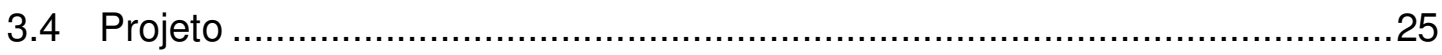

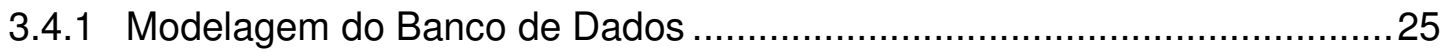

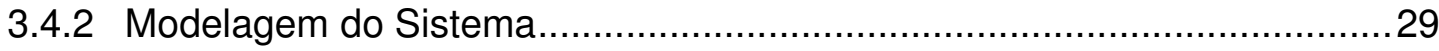

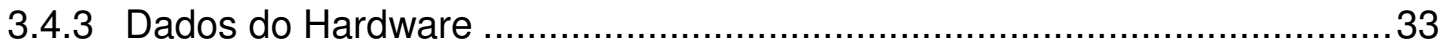

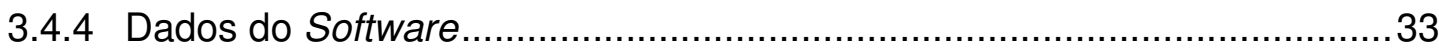

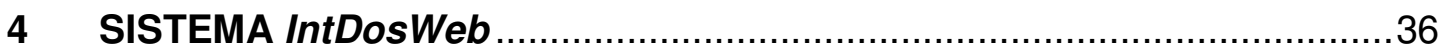

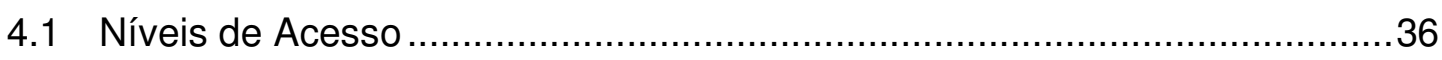

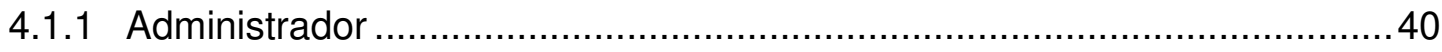

4.1.2 Grupo de Cálculo de Dose ............................................................. 42

4.1.3 Laboratório de Monitoração In Vivo.........................................................44

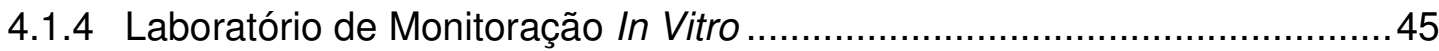

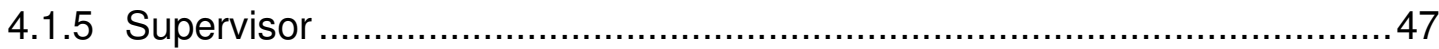

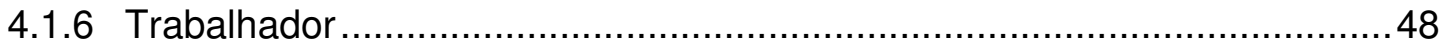

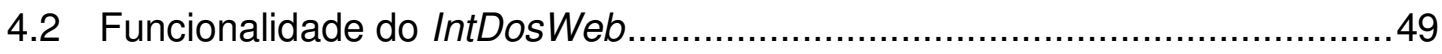

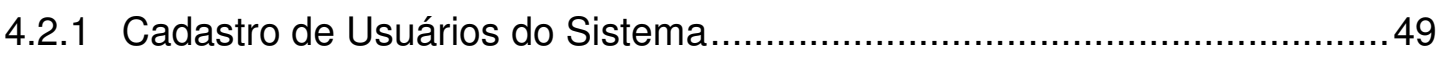

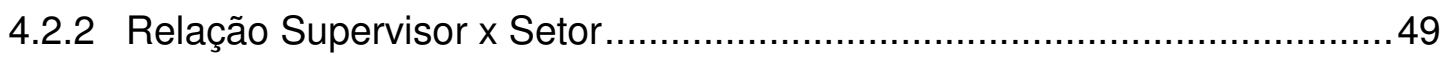

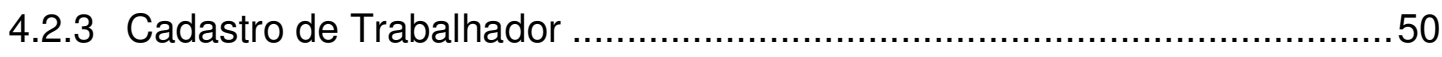

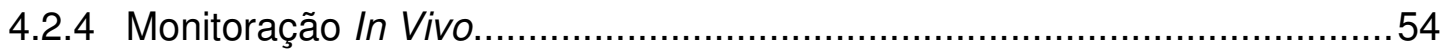

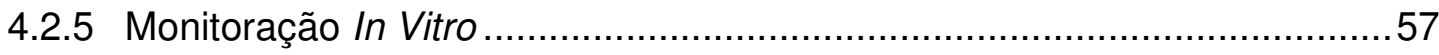

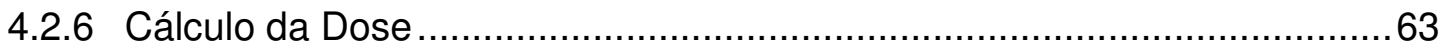

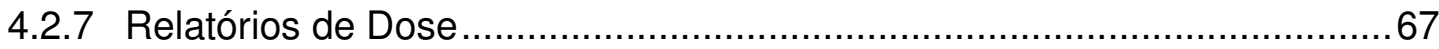

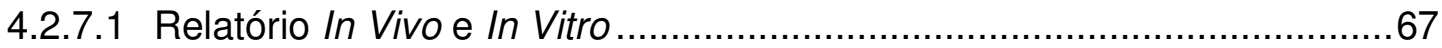

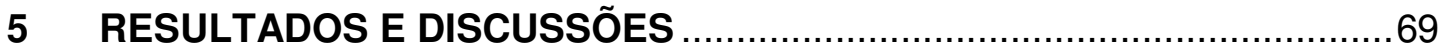

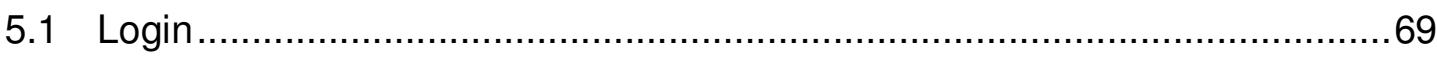

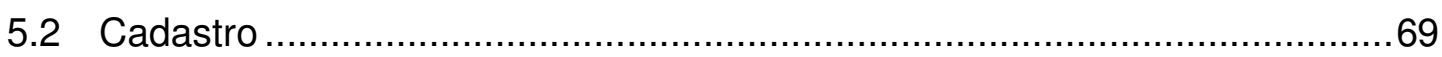

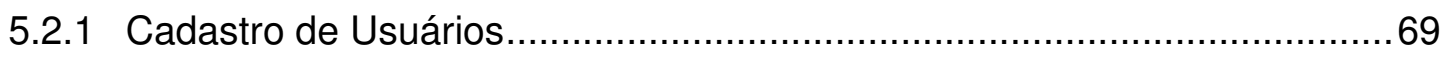

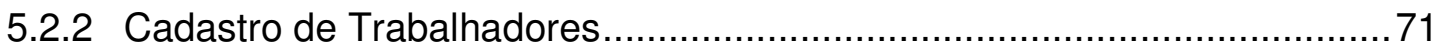


Página

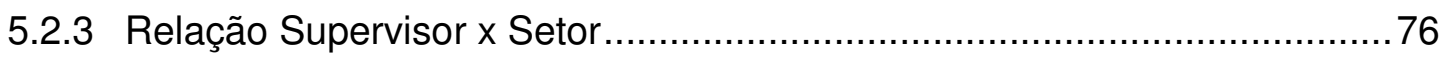

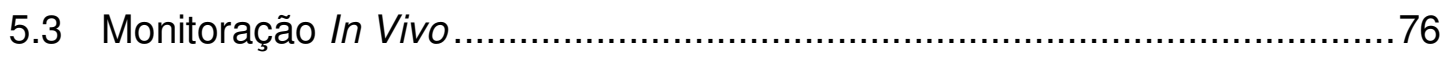

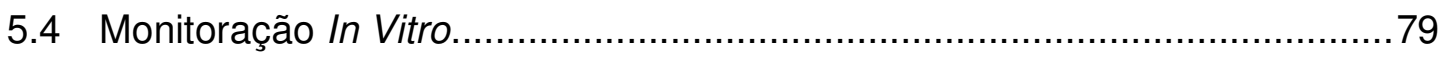

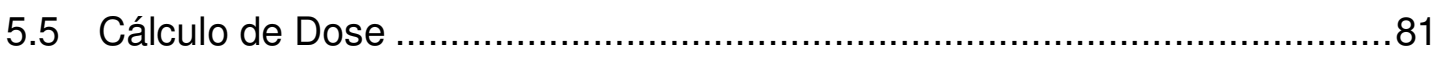

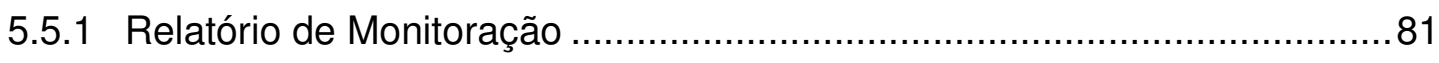

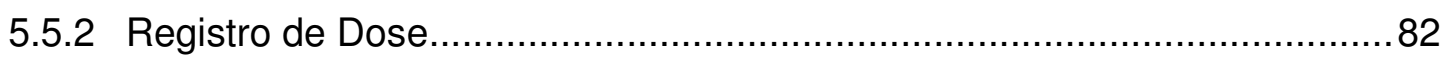

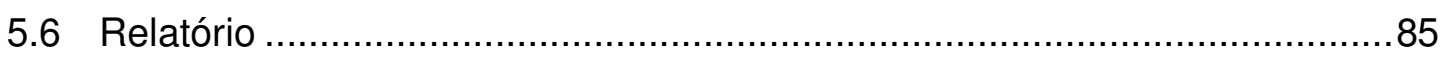

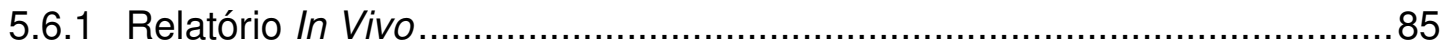

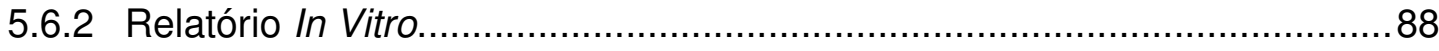

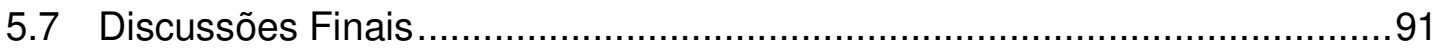

6 CONCLUSÃO

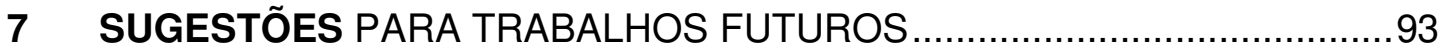

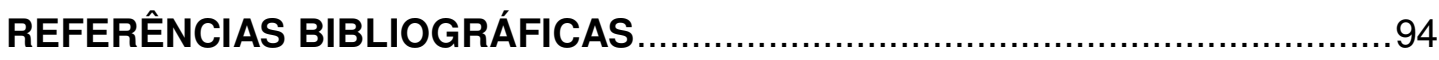




\section{INTRODUÇÃO}

\subsection{Considerações Iniciais}

A avaliação da dose devido à incorporação de radionuclídeos no local de trabalho é parte integrante de um programa de proteção radiológica ocupacional. Na prática, este programa é administrado pelo supervisor de radioproteção da instalação com a participação do serviço de dosimetria interna. Portanto, a dosimetria faz parte do programa de proteção radiológica que se inicia com a identificação das situações de trabalho nas quais há um risco de contaminação interna de trabalhadores, passa pela medição do material radioativo incorporado e é finalizada com a avaliação da dose efetiva comprometida.

Em geral, o contato direto entre o serviço de dosimetria, o trabalhador e o administrador da instalação é limitado. Normalmente, a comunicação de qualquer dado dosimétrico relevante é efetuada pelo supervisor de radioproteção da instalação aos integrantes do programa de monitoração. Existem situações em que o resultado da monitoração é utilizado pelo administrador da instalação para se aconselhar com o supervisor da radioproteção, quando é necessária a intervenção no trabalhador como a realização de novos exames ou restrição no trabalho. Consequentemente, a cooperação mútua é necessária entre as diferentes partes envolvidas na monitoração e no programa de radioproteção.

A exposição do indivíduo à fonte de radiação resultante da combinação de todas as práticas pertinentes deve estar sujeita aos limites de dose e os registros de avaliação devem ser preservados.

\subsection{Dosimetria Interna no IPEN}

O serviço de dosimetria interna do Instituto de Pesquisas Energéticas e Nucleares (IPEN) é operado pelo Laboratório de Medida In Vivo, Laboratório de Medida In Vitro e o Grupo de Cálculo de Dose. Atualmente, todos os dados 
dosimétricos são mantidos independentemente em cada laboratório em sua própria base de dados.

Esta é uma situação clara que a proposta de um sistema de dosimetria interna integrada é altamente desejada para administrar as informações comuns relacionadas às instalações radiativas e nucleares, aos trabalhadores, aos laboratórios de medidas e à avaliação da dose.

Para tornar possível o desenvolvimento de uma proposta desta natureza, é necessário um amplo estudo e pesquisa em proteção radiológica e dosimetria interna.

Na fase inicial é importante adquirir conhecimentos das instalações no que concerne à caracterização dos materiais que são manuseados além das atividades dos supervisores de radioproteção.

As instalações do IPEN que requerem um programa de monitoração interna para os trabalhadores podem ser divididas em dois grupos identificados como instalações radiativas e instalações nucleares do ciclo do combustível. Em todas essas instalações o supervisor de proteção radiológica é encarregado de estabelecer um programa de monitoração individual rotineira ou uma monitoração especial para casos de incidentes ou acidentes. Assim, é importante efetuar a caracterização do radionuclídeo presente na instalação quanto ao seu tipo, à sua forma física e química para que o método da monitoração individual interna possa ser estabelecido para os trabalhadores.

Posteriormente, é importante efetuar coletas de informações das atividades dos laboratórios de monitoração individual interna in vivo e in vitro e também do grupo de cálculo de dose do IPEN. Sabe-se que os resultados das medidas in vivo ou in vitro são utilizados para avaliar a dose efetiva comprometida de acordo com o padrão de incorporação(1). Todos esses dados deverão ser registrados em um banco de dados durante cada etapa do programa monitoração interna. 
Dessa forma, é possível ter uma noção geral das atividades e do fluxo de informações para o desenvolvimento desta proposta.

Nesse contexto, procurou-se por soluções que atenda ao problema específico de dosimetria interna aplicada aos trabalhadores que manuseiam materiais radioativos na forma não selada, nas instalações do IPEN. Uma das idéias foi a de unir a versatilidade da Internet para ter um rápido acesso às informações e permitir que os dados comuns e de interesse em dosimetria interna fosse gerenciada de forma integrada.

\subsection{Objetivo}

O trabalho proposto tem como objetivo a criação de uma nova base de dados para a dosimetria interna e o desenvolvimento de um sistema baseado na Web, denominado IntDosWeb, como parte do programa de melhoria da qualidade do serviço de monitoração interna para os trabalhadores ocupacionalmente expostos (IOE) no IPEN.

Pretende-se que os usuários desse sistema tenham acesso ao IntDosWeb em qualquer ambiente do IPEN por meio da Intranet, desde que os computadores estejam conectados à rede. $\mathrm{O}$ acesso aos dados dosimétricos dos trabalhadores disponibilizada por meio da Intranet beneficiaria a interação entre os Laboratórios de Monitoração In Vivo e In Vitro, o Grupo de Cálculo de Dose e o Supervisor de Proteção Radiológica, uma vez que a informação será compartilhada em uma única base de dados. 


\section{FUNDAMENTOS TEÓRICOS}

\subsection{Instalação Radiativa}

O IPEN é uma instituição de pesquisa nuclear onde são manuseados diferentes tipos, formas e quantidades de materiais radioativos. Dessa forma, existe uma variedade de situações nas quais os trabalhadores são expostos à radiação ionizante. Esses incluem atividades relacionadas a manuseio de materiais radioativos nos laboratórios de pesquisa, produção de radiofármacos, ou até trabalhos em instalações do ciclo de combustível nuclear. Os programas de monitorações internas elaborados pelos supervisores de proteção radiológica possuem as suas particularidades em virtude dessas diferenças.

Presentemente, os trabalhadores do IPEN que executam atividades em instalações ou laboratórios que manuseiam material radioativo em forma não selada estão sujeitas a serem monitorados ao menos uma vez por ano.

Entre as instalações radiativas do IPEN que fazem parte do programa de monitoração interna para os trabalhadores destacam-se alguns como o setor de produção de radioisótopos do Centro de Radiofarmácia (CR), Centro de Aceleradores Cíclotron (CAC), Ciclo do Combustível Nuclear (CCN), Laboratório de Rejeitos Radioativos (LRR), e o Centro do Reator de Pesquisa (CRPq). Os principais radionuclídeos manuseados nestas instalações são apresentados na TAB. 2.1. Ressalta-se que existem alguns outros laboratórios que também fazem parte do programa de monitoração interna, mas que manuseiam quantidades pequenas de material radioativo. 
TABELA 2.1 - Principais radionuclídeos selecionados para monitoração individual $^{(2)}$

\begin{tabular}{c|c|c}
\hline Instalação & Radionuclídeo & Método de Análise \\
\hline $\mathrm{CR}$ & ${ }^{153} \mathrm{Sm}$ & Corpo Inteiro \\
\hline $\mathrm{CR}, \mathrm{CAC}$ & ${ }^{67} \mathrm{Ga} ;{ }^{99} \mathrm{Mo} /{ }^{99 \mathrm{~m}} \mathrm{Tc} ;{ }^{131} \mathrm{I}$ & Corpo Inteiro, Tireóide \\
\hline $\mathrm{CR}, \mathrm{CAC}$ & ${ }^{3} \mathrm{H},{ }^{32} \mathrm{P}$ & Cintilação líquida, beta \\
\hline \multirow{3}{*}{$\mathrm{CCN}$} & Isótopos de U $\left({ }^{234} \mathrm{U} ;{ }^{235} \mathrm{U} ;{ }^{238} \mathrm{U}\right)$ & Espectrometria alfa \\
\cline { 2 - 3 } & $\mathrm{U}$-natural & Fluorimetria \\
\cline { 2 - 3 } & ${ }^{232} \mathrm{Th}$ & Análise por ativação \\
\cline { 2 - 3 } $\mathrm{NR}$ & Isótopos de $\mathrm{Pu}\left({ }^{238} \mathrm{Pu},{ }^{239} \mathrm{Pu}\right) ;{ }^{241} \mathrm{Am}$ & Espectrometria alfa \\
\hline $\mathrm{CRPq}$ & ${ }^{131} \mathrm{I},{ }^{60} \mathrm{Co},{ }^{13 /} \mathrm{Cs}$ & Corpo Inteiro \\
\hline
\end{tabular}

\subsection{Fundamentos do Programa de Monitoração}

O manuseio de materiais radioativos sob a forma não selada contribui para o aumento do risco de contaminação. A forma de contaminação pode ser externa, para a situação em que o material está em contato com a pele, ou pode ser interna, quando o material encontra-se dentro do corpo. O programa de monitoração é conduzido pelo supervisor de radioproteção da instalação com o apoio do serviço de dosimetria do IPEN.

A FIG. 2.1 representa o diagrama do programa de monitoração interna. O supervisor de radioproteção é responsável pela segurança radiológica do IOE que manuseia o material radioativo sob a forma não selada e a sua preocupação é com a possível incorporação deste material pôr: Inalação, Ingestão e Contaminação da Pele. O controle da incorporação é efetuado por um programa de monitoração rotineira, um programa de monitoração relacionada à tarefa e um programa de monitoração especial (em caso de acidentes e incidentes). Para efetuar a medição da contaminação o supervisor encaminha o IOE para o Centro de Metrologia das Radiações (CMR) para a identificação de uma possível contaminação interna onde o IOE passa por uma avaliação da contaminação pela técnica de medida in vivo ou in vitro. 


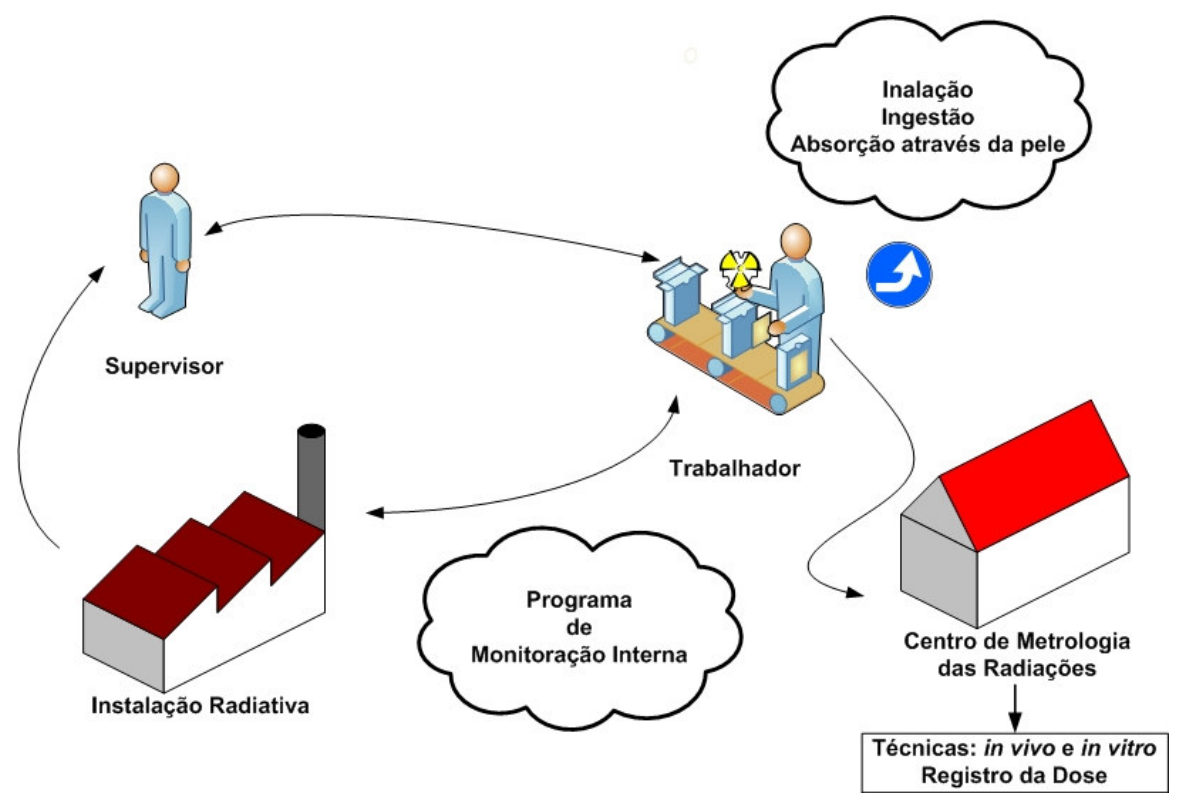

FIGURA 2.1 - Diagrama do programa de monitoração interna

\subsubsection{Monitoração Individual Interna}

A monitoração individual interna é utilizada para determinar a quantidade de radionuclídeo incorporado pelo indivíduo e avalia a dose efetiva comprometida para o mesmo. A medida da contaminação interna pode ser realizada pela técnica de análise in vivo ou in vitro.

\subsubsection{Monitoração In Vivo}

A monitoração in vivo ${ }^{(3,4)}$ consiste basicamente na medida direta da atividade do radionuclídeo existente no corpo, ou em um órgão específico, por meio de detectores de radiação acoplados a equipamentos de aquisição de dados. Esses sistemas são denominados contadores de corpo inteiro.

A medida in vivo apresenta uma boa eficiência na detecção de materiais radioativos emissores gama, apresentando menor eficiência na detecção de emissores beta e alfa. Uma das vantagens desse método é o de fornecer os resultados das avaliações rapidamente, uma vez que as quantidades são medidas diretamente no corpo. 


\subsubsection{Monitoração In Vitro}

A dosimetria in vitro ${ }^{(5,6)}$ é baseada na avaliação indireta da quantidade do material radioativo presente no corpo por meio de análise de amostras de material biológico do indivíduo como, por exemplo, sangue, urina e fezes. Em geral as análises em amostras de excretas, como urina e fezes, são as mais utilizadas rotineiramente.

A dosimetria interna in vitro possui a vantagem de ser aplicável a todos os radionuclídeos, mesmo aqueles emissores alfa, beta ou da radiação gama de baixa energia. A desvantagem é que o método de separação química do elemento radioativo das excretas pode envolver técnicas complexas e demoradas.

\subsubsection{Vias de Incorporação}

Define-se como vias de incorporação a passagem do material radioativo pelos sistemas respiratórios, trato gastrintestinal e pele, ou seja, inalação, ingestão, ou absorção através da pele intacta ou ferida.

\subsubsection{Inalação}

A incorporação por inalação é a via mais importante de contaminação interna em ambiente de trabalho. As partículas do material radioativo em suspensão no ar, os gases e os aerossóis podem ser inalados e depositar inicialmente no pulmão e posteriormente ser transferidos para outros órgãos do corpo humano.

A Comissão Internacional de Proteção Radiológica (ICRP) apresenta o modelo do trato respiratório humano, $\operatorname{HRTM}^{(7,8)}$, que descreve os aspectos anatômicos e fisiológicos dos órgãos e a cinética do radionuclídeo inalado para ser utilizado na avaliação da dose interna. Esta descrição inclui aspectos como o percentual do ar inalado que entra pelas narinas e pela boca, a quantidade de 
material radioativo que é depositado no pulmão e também como ocorre à absorção deste material para o sangue.

A contaminação pode ser minimizada ou evitada protegendo o indivíduo com a utilização de equipamentos de proteção individual ou fazendo o controle de acesso às áreas contaminadas. Quando as substâncias radioativas forem voláteis ou gasosas deve-se utilizar capelas, máscaras ou outros equipamentos de proteção adequados ao processo a ser realizado.

\subsubsection{Ingestão}

A contaminação radioativa por ingestão pode ser facilmente evitada obedecendo as medidas de higiene de trabalho, como não fumar, não comer, não beber nem utilizar cosméticos nas áreas restritas que envolva o manuseio de material radioativo.

O modelo do trato alimentar humano, $\operatorname{HATM}^{(9,14)}$, da ICRP é utilizado, em proteção radiológica, para a avaliação da dose interna por ingestão. O HATM é aplicado em todas as situações em que ocorre a incorporação por ingestão e em muitas situações é usado concomitantemente com o modelo do trato respiratório humano.

\subsubsection{Absorção Através da Pele}

A absorção é a passagem do material radioativo para os fluidos como o sangue, e pode ocorrer por meio da pele intacta ou ferida. Em trabalhos que envolvam tais riscos deve-se utilizar aventais, macacões, luvas e botas apropriadas. A pele intacta é uma barreira eficaz para evitar a incorporação do material radioativo.

\subsection{Avaliação da Dose Interna}

A metodologia utilizada para a avaliação da dose interna segue as recomendações da $\operatorname{ICRP}^{(4,10,12,13)}$. 
Sabe-se que todos os resultados de medidas de uma monitoração interna de trabalhadores são interpretados com relação às atividades dos radionuclídeos encontrados nos órgãos ou distribuídos no corpo ou presente nas excretas.

É importante observar que somente o conhecimento da medida da atividade no corpo ou distribuídos no corpo ou da taxa de excreção do organismo humano não é suficiente para calcular a incorporação. Para o cálculo da incorporação são necessários o conhecimento da natureza, a forma química e o tipo da radiação. Além disso, outros parâmetros como as vias e a forma de incorporação, o momento da ocorrência da incorporação e o conhecimento do modelo metabólico do radionuclídeo em questão também são indispensáveis.

Dessa forma, as medidas são utilizadas para calcular a atividade incorporada de um radionuclídeo que, por sua vez, quando multiplicado por coeficientes de dose adequados levam à estimativa da dose efetiva comprometida. Os coeficientes de dose são valores conhecidos para uma grande variedade de radionuclídeos e encontram-se disponíveis na literatura ${ }^{(5)}$. A dose efetiva comprometida (50 anos), atribuída a um ano de incorporação, é utilizada como base para atendimento às necessidades da monitoração e do sistema de limitação de dose.

\subsection{Registro da Dose}

Uma vez determinada as doses dos trabalhadores, estas precisam ser registradas e arquivadas. Em geral, os períodos de retenção dos registros são especificados pela CNEN ${ }^{(3,11)}$. A TAB. 2.2 apresenta os períodos de retenção do registro de dose. 
TABELA 2.2 - Período de retenção do registro de dose ${ }^{(3,11)}$

\begin{tabular}{c|c}
\hline \multicolumn{2}{c}{ Retenção de Registro } \\
\hline Tipo de Registro & Período de retenção sugerido \\
\hline $\begin{array}{c}\text { Monitoração do local de trabalho, } \\
\text { calibração dos instrumentos de } \\
\text { medidas. }\end{array}$ & 5 anos \\
\hline $\begin{array}{c}\text { Exposição ocupacional do trabalhador, } \\
\text { calibração do equipamento de } \\
\text { monitoração individual. }\end{array}$ & $\begin{array}{c}\text { Até que o trabalhador atinja a idade de } \\
75 \text { anos ou por } 30 \text { anos após o termino } \\
\text { das atividades ocupacionais. }\end{array}$ \\
\hline
\end{tabular}

A necessidade de mostrar a conformidade com limites de doses e a retenção desses registros são importantes por quatro razões adicionais:

- Fornecer dados para a análise das distribuições de doses;

- Avaliar as tendências de exposição que um grupo coletivo de trabalhadores pode receber;

- Aperfeiçoar a eficácia do programa de monitoração; e

- Fornecer dados para estudos epidemiológicos.

Os dados dos registros também devem estar acessíveis aos trabalhadores, aos supervisores, aos empregadores e à autoridade regulatória. Os trabalhadores devem ser informados por meio de relatórios com resumos de suas exposições anuais e exposições cumulativas individuais, quando solicitados pelos mesmos ou quando especificado pelo regulamento. 


\subsection{Fundamentos de Tecnologia da Informação}

\subsubsection{Engenharia de Software}

Segundo Friedrich Ludwig Bauer, "Engenharia de Software é a criação e a utilização de sólidos princípios de engenharia a fim de obter software de maneira econômica, que seja confiável e que trabalhe eficientemente em máquinas reais" ${ }^{\prime \prime 25,26)}$.

A engenharia de software se concentra nos aspectos práticos da produção de um sistema de software, enquanto a ciência da computação estuda os fundamentos teóricos dos aspectos computacionais. O termo foi cunhado na década de 1960 e utilizado oficialmente em 1968 na NATO Conference on Software Engineering (Conferência sobre Engenharia de Software da OTAN) ${ }^{(26)}$.

O processo de desenvolvimento de um software começa com um problema que o usuário quer resolver. $O$ processo de desenvolvimento de software é um conjunto de atividades, parcialmente ordenadas, com a finalidade de obter um produto de software estudado dentro da área de Engenharia de Software.

Processo de desenvolvimento:

- Definição: O que será desenvolvido;

- Desenvolvimento: Como será desenvolvido;

- Manutenção: Que mudanças ocorrerão depois.

Atividades no processo de desenvolvimento:

- Levantamento dos Requisitos

- Qual é o problema a ser resolvido? Quais são as limitações? Definição detalhada do domínio da informação e da função do software; 
- Análise de Sistemas

- Define o papel de cada elemento em um sistema baseado em computador.

- Planejamento do Projeto

- Definição detalhada da futura implementação: interfaces e procedimentos de utilização.

- Implementação

- Define a implementação (em geral: por programação) do sistema definido na atividade precedente e de verificar o bom funcionamento dos programas (testes).

\subsubsection{Modelos de Processo}

Existem alguns modelos de processo que buscam descrever a forma com que as fases seguem e interagem. Todo modelo de software deve levar em consideração as fases descritas, no entanto, cada um organiza estas fases de uma forma particular de acordo com sua filosofia de organização. A seguir apresenta-se alguns dos modelos mais conhecidos. ${ }^{(27,28,29,30,31,32)}$

Modelo Cascata: O modelo cascata, idealizado por Royce ${ }^{(27)}$ em 1970, também conhecido como abordagem top-down, tem como principal característica a seqüência de atividades de forma que uma atividade só poderá ter início quando a anterior tiver terminada, a saída da primeira etapa "flui" para a segunda etapa e a saída da segunda etapa "flui" para a terceira e assim por diante. O modelo cascata sofreu diversos ajustes e aprimoramentos sendo muito utilizado nos dias atuais. A FIG. 2.2 apresenta a descrição visual do modelo cascata. 


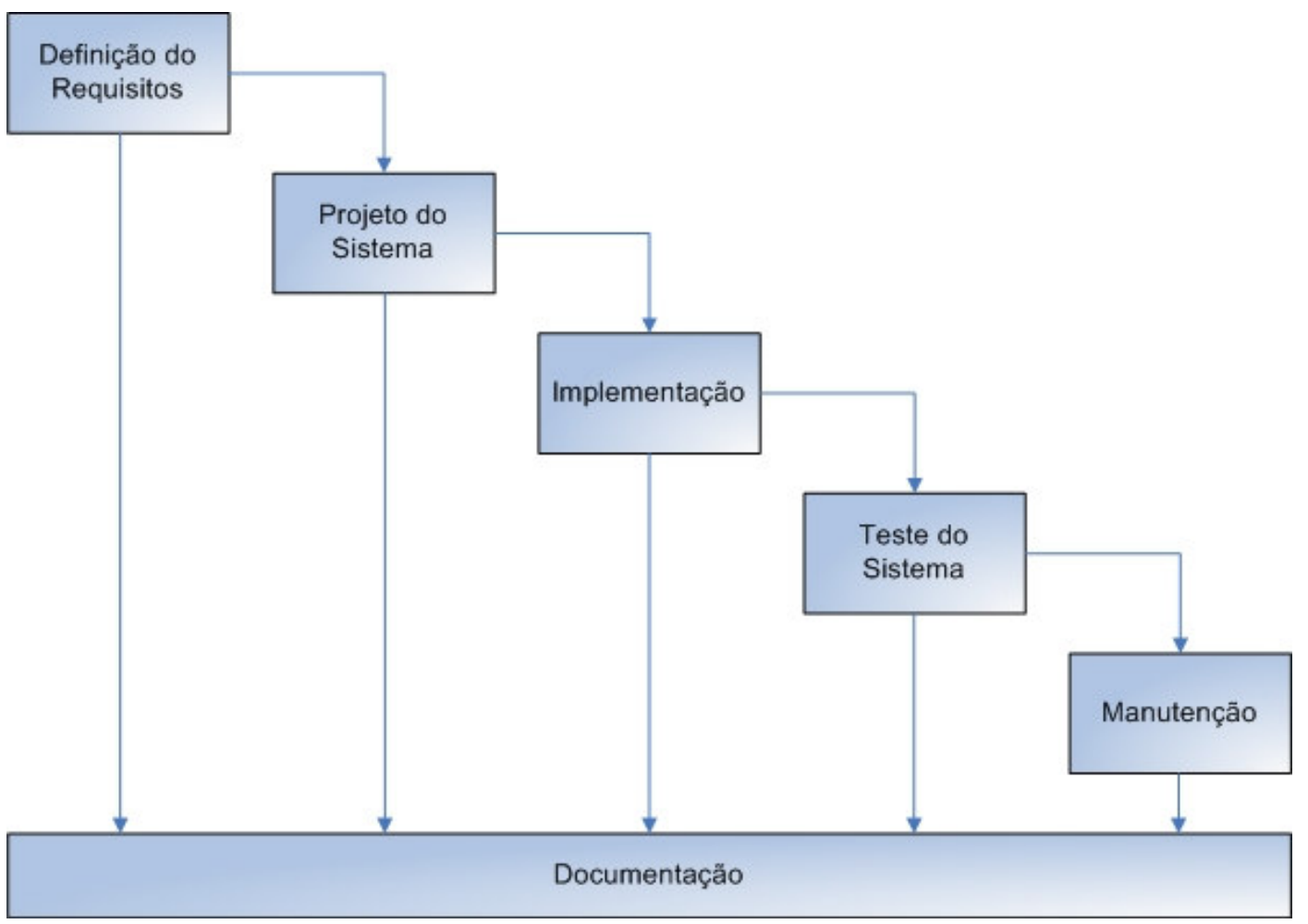

FIGURA 2.2 - Modelo Cascata - O andamento do processo flui de cima para baixo, como uma cascata ${ }^{(27,29,30)}$

- Modelo Protótipo: O objetivo do modelo protótipo é entender os requisitos do usuário e assim, obter uma melhor definição dos requisitos do sistema possibilitando que o desenvolvedor crie um modelo (protótipo) do software que deve ser construído. A FIG. 2.3 apresenta a descrição visual do modelo espiral.

Preece $^{(28)}$ e Sommerville ${ }^{(29)}$ apresentam alguns modelos de Prototipação, entre eles podem-se citar:

a. Prototipação Descartável, que enfatiza o desenvolvimento do protótipo e a sua avaliação, descartando-o quando os requisitos se tornam mais claros para então desenvolver o sistema final;

b. Prototipação Evolucionária, cujo protótipo é desenvolvido em partes com as funcionalidades, modificado-o e acrescentando requisitos até satisfazer o cliente. A última versão do protótipo é o sistema final; 
c. Prototipação Incremental, em que o protótipo é construído incrementalmente, sendo elaborado um projeto que considere todos os aspectos sem que as funcionalidades estejam completas.

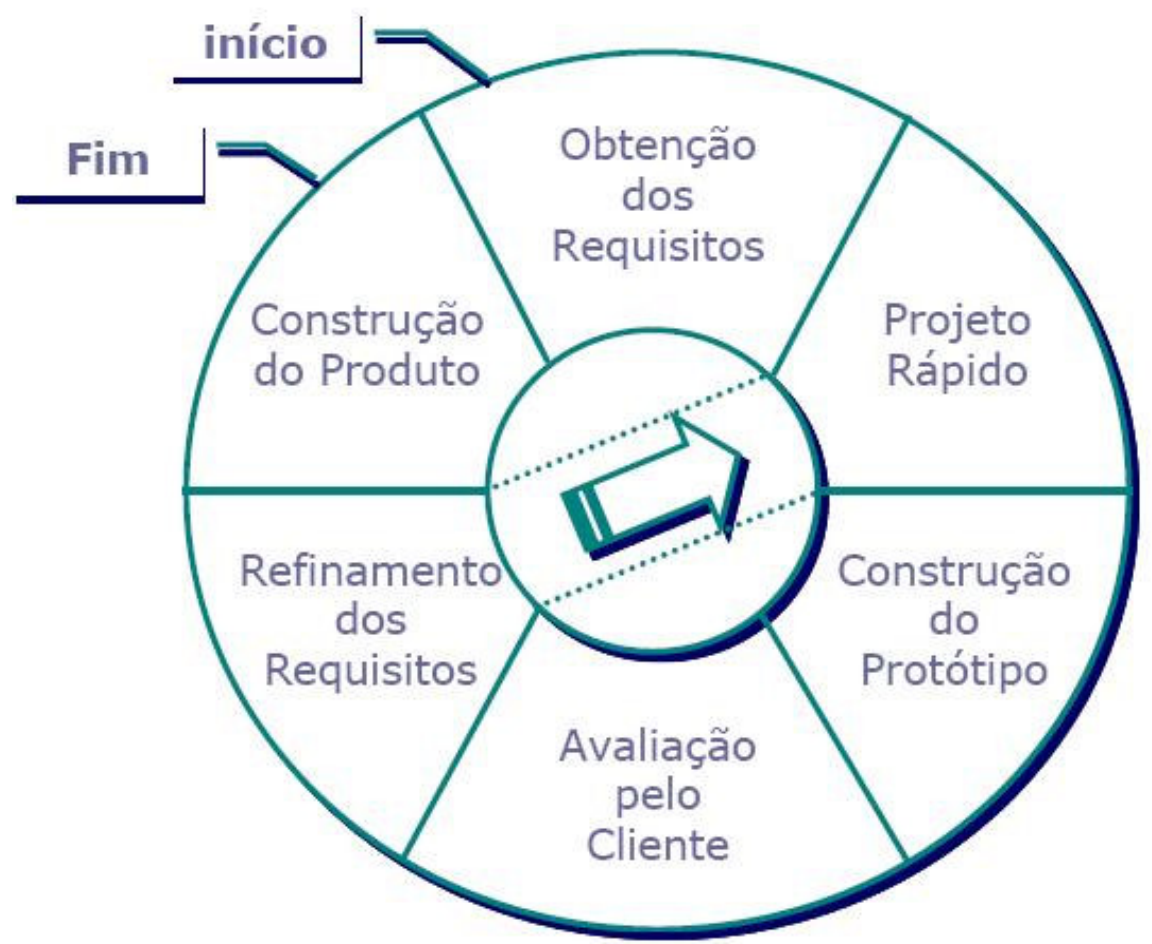

FIGURA 2.3 - Modelo Protótipo - Apropriado quando o cliente define apenas objetivos gerais (sem requisitos detalhados de entrada, processamento e saída) $)^{(28,29,30)}$

- Modelo Espiral: O modelo espiral foi proposto por Boehm ${ }^{(30)} \mathrm{em}$ 1988 como forma de integrar os diversos modelos existentes à época, eliminando suas dificuldades e explorando seus pontos fortes. Este modelo foi desenvolvido para abranger as melhores características tanto do ciclo de vida clássico como da prototipação, acrescentando, ao mesmo tempo, um novo elemento (a análise de riscos) que falta a esses paradigmas. A FIG. 2.4 apresenta a descrição visual do modelo espiral. 


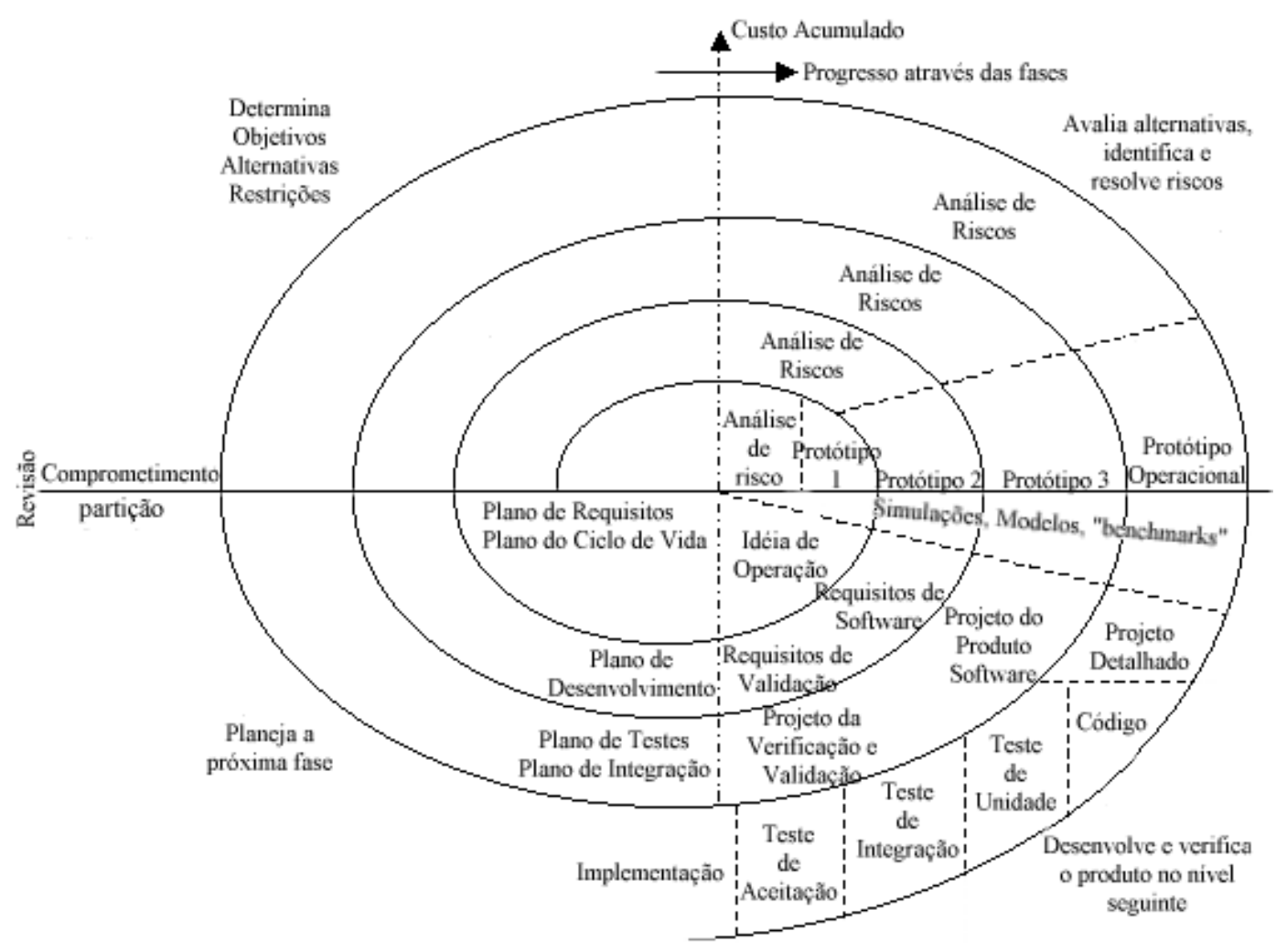

FIGURA 2.4 - Modelo Espiral completo descrito por Boehm ${ }^{(28,29,30,31)}$

\subsubsection{Conceitos de Internet}

A Internet ${ }^{(33,34)}$ surgiu na década de 60, num panorama mundial cercado pela Guerra Fria. O departamento de Defesa norte-americano queria ter posse de um meio de comunicação que não sofresse danos em um suposto ataque nuclear da URSS aos EUA. A descentralização seria uma das principais características, pois as informações poderiam ser transmitidas de vários pontos do território americano, e mesmo que um deles fosse atingido esta rede ainda estaria funcionando.

$\mathrm{Na}$ década de 70, a rede foi apropriada pelas universidades e centros de pesquisa, e daí tornou-se um meio não só de troca de informações militares, mas de resultados científicos, recados e piadas. Assim, iniciava-se uma apropriação mais popular da rede. 


\subsubsection{Conceitos de Intranet}

A Intranet ${ }^{(34)}$ é uma rede fechada que funciona interligando os computadores de uma mesma empresa, no mesmo local físico. As Intranets são utilizadas, por exemplo, em empresas para que todos os trabalhadores possam utilizar um mesmo sistema e compartilhar informações com outros usuários daquela rede.

\subsubsection{Servidor Web}

A Internet é baseada no relacionamento cliente-servidor, onde o cliente é o navegador, comumente chamado de browser. O servidor Web é normalmente acessado por meio do protocolo HyperText Transfer Protocol (HTTP), que permite o tráfego das informações desejadas por meio de uma conexão.

O servidor Web, também chamado de servidor HTTP, é o computador conectado na rede com um endereço Internet Protocol (IP) e um software específico, conhecido como Web Server, visando garantir o acesso a Internet dia e noite.

O processo inicia-se a partir do computador do usuário que, por meio de um browser utilizando formulários HTML, solicita informações ao servidor Web. O browser repassa as informações ao servidor Web que recebe as informações, lê, formata e retorna a informação para o usuário.

A principal funcionalidade do servidor Web é tratar as requisições HTTP e ligar os dados HTML gerados no cliente com o banco de dados relacional ao servidor de banco de dados e vice-versa, a FIG. 2.5 representa o diagrama cliente-servidor. 


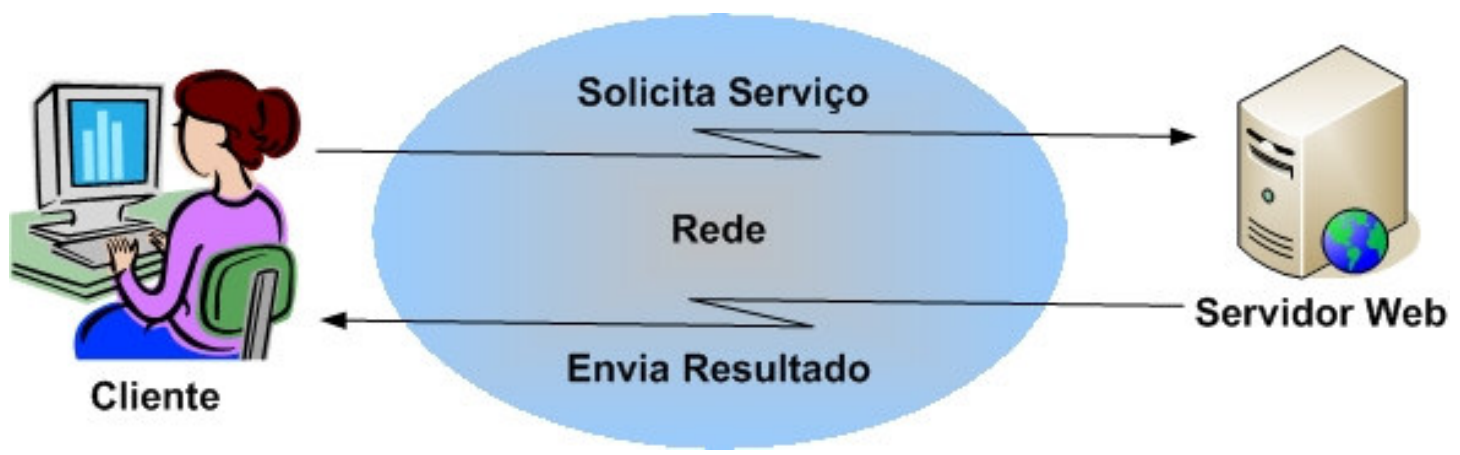

FIGURA 2.5 - Diagrama representativo Cliente-Servidor

O software a ser usado neste trabalho para servidor Web é o Apache, criado em 1995 por Rob McCool ${ }^{(35)}$. O Apache é o software para servidor Web muito utilizado e tem como uma das principais vantagens a isenção de custos, pois é disponibilizado gratuitamente. Outras vantagens podem ser consideradas como as flexibilidades, pois existem distribuições tanto para o Linux como para o Windows, o desempenho, a segurança e também por suportar a linguagem de programação e o banco de dados para o desenvolvimento deste projeto.

\subsubsection{Banco de Dados}

Um banco de dados, ou base de dados, são conjuntos de "dados" devidamente relacionados. Por "dados" podemos compreender como "fatos conhecidos" que podem ser armazenados e que possuem um significado implícito. Um banco de dados possui as seguintes propriedades ${ }^{(36)}$ :

- Um banco de dados é uma coleção lógica coerente de informações com um significado inerente, ou seja, uma disposição desordenada das informações não pode ser referenciada como um banco de dados;

- Um banco de dados é projetado, construído e "populado" com informações para um propósito específico, possuindo um conjunto pré-definido de usuários e aplicações;

- Um banco de dados representa algum aspecto do mundo real, o qual é chamado de "mini-mundo"; qualquer alteração efetuada no mini-mundo é automaticamente refletida no banco de dados. 


\subsubsection{Sistema Gerenciador de Banco de Dados}

Um banco de dados pode ser criado e mantido por um conjunto de aplicações desenvolvidas especialmente para esta tarefa ou por um Sistema Gerenciador de Banco de Dados (SGBD). Um SGBD permite aos usuários criarem e manipularem bancos de dados de propósito geral.

Um SGBD oferece aos seus usuários acesso a dados e os ajuda a transformar estes dados em informações. Esses sistemas permitem aos usuários criar, atualizar e extrair informações de seus bancos de dados. Comparados a um sistema de ficheiro manual, as principais e maiores diferenças para um banco de dados computadorizado são a velocidade, a precisão e a acessibilidade.

Existem dois principais tipos de bancos de dados: os Relacionais e os Orientados a Objeto.

Os Bancos de Dados Relacionais ${ }^{(36)}$ são de longe os tipos mais populares disponíveis no mercado. Um banco de dados relacional permite a definição de estrutura de dados, armazenamento, operações de recuperação de dados e criação de restrições de integridade. Em um banco de dados dessa natureza, os dados e as relações entre eles estão organizados em tabelas, formalmente chamadas de relações. Alguns campos podem ser designados como chaves, o que significa dizer que a procura por um determinado tipo de informação pode ser acelerada utilizando as indexações criadas com as chaves. Para o desenvolvimento deste projeto será utilizado o banco de dados relacional.

Os Bancos de Dados Orientados a Objeto ${ }^{(37)}$ seguem um padrão de definição baseado no paradigma de programação orientado a objetos. Na prática, poucos sistemas utilizam esse tipo de abordagem, visto que a simplicidade e o sucesso dos bancos de dados relacionais não permitem que esse tipo de sistema avance no mercado. Num banco de dados orientado a objetos puro, as informações são armazenados como objetos onde só podem ser manipulados pelos métodos definidos pela classe que estes objetos pertencem. Os objetos são organizados numa hierarquia de tipos, e subtipos que recebem suas 
características e podem conter referências para outros objetos, e as aplicações podem conseqüentemente acessar os dados requeridos usando um estilo de navegação de programação. 


\section{METODOLOGIA}

Este capítulo descreve os procedimentos para desenvolver o IntDosWeb, sistema para ser aplicado no programa de monitoração interna do IPEN, em ambiente Web.

As responsabilidades das áreas são:

- O Grupo de Cálculo de Dose (GCD) é responsável pelo cálculo da dose e é o elo entre os laboratórios e os supervisores;

- O Laboratório de Monitoração In Vivo (LMIV) é responsável pela monitoração individual do trabalhador por meio da medida do corpo inteiro;

- Laboratório de Monitoração In Vitro é responsável pela monitoração individual do trabalhador por meio da análise das excretas;

- Supervisor de Radioproteção ou Supervisor é encarregado de estabelecer uma monitoração rotineira dos trabalhadores, uma monitoração relacionada a tarefa ou uma monitoração especial.

\subsection{Modelo de Desenvolvimento}

Inicialmente a idéia era adotar o modelo em cascata apresentado no Capítulo 2 item 2.5.1.1, porém, após estudá-lo, percebeu-se que o modelo protótipo seria o mais indicado, por ter uma facilidade para determinar requisitos iniciais e garantia para atingir as necessidades do programa de monitoração interna do IPEN. 


\subsection{Levantamento de Requisitos}

\subsubsection{Requisitos Funcionais}

Os principais pontos relacionados aos requisitos funcionais foram identificados como:

- Uniformizar as informações entre o Grupo de Cálculo de Dose, o Laboratório de Monitoração In Vivo, o Laboratório de Monitoração In Vitro e o Supervisores. Estas informações se fazem necessárias, pois cada uma das áreas envolvidas mantém uma base de dados independente;

- Racionalizar e agilizar, por meio da automação do fluxo de informações, o processo de monitoração individual interna.

\subsubsection{Requisitos não Funcionais}

As importâncias dos requisitos não funcionais são descritas abaixo:

- Segurança dos dados transmitidos: cada informação que navega na web precisa conter componentes de segurança, a criptografia computacional como é conhecida. Tal componente protege o sistema quando existe a ameaça de perda de confiabilidade e integridade, sendo utilizada para garantir:

- Confidencialidade, somente os usuários autorizados devem ter acesso à informação;

- Integridade, garantir que a informação correta, original, não seja alterada, nem intencionalmente, nem acidentalmente;

- Autenticação do usuário, verificar se o usuário que está se comunicando é de fato o usuário que possui acesso ao sistema;

- Disponibilidade, garantir que o serviço/recurso esteja sempre acessível;

- Extensiabilidade, adicionar ou modificar novas funcionalidades sem impactar funcionalidades existentes; 
- Manutenciabilidade, oferecer backups e manutenção do banco de dados.

- Oferecer ajuda aos usuários, incluindo tutoriais e dúvidas mais freqüentes (FAQ);

\subsection{Diagrama de Fluxo de Dados}

O modelo de fluxo de informação anterior à proposta do IntDosWeb, é apresentado na FIG. 3.1. Observa-se que o Supervisor entra em contato diretamente com as áreas do programa de monitoração interna, onde em alguns casos as informações podem vir desencontradas, faltando dados ou com erro nos dados pessoais do trabalhador, acarretando assim problemas aos laboratórios e o Grupo de Cálculo de Dose. Este modelo inviabiliza o pronto atendimento para efetuar a monitoração, quer seja in vivo ou in vitro e o cálculo da dose.

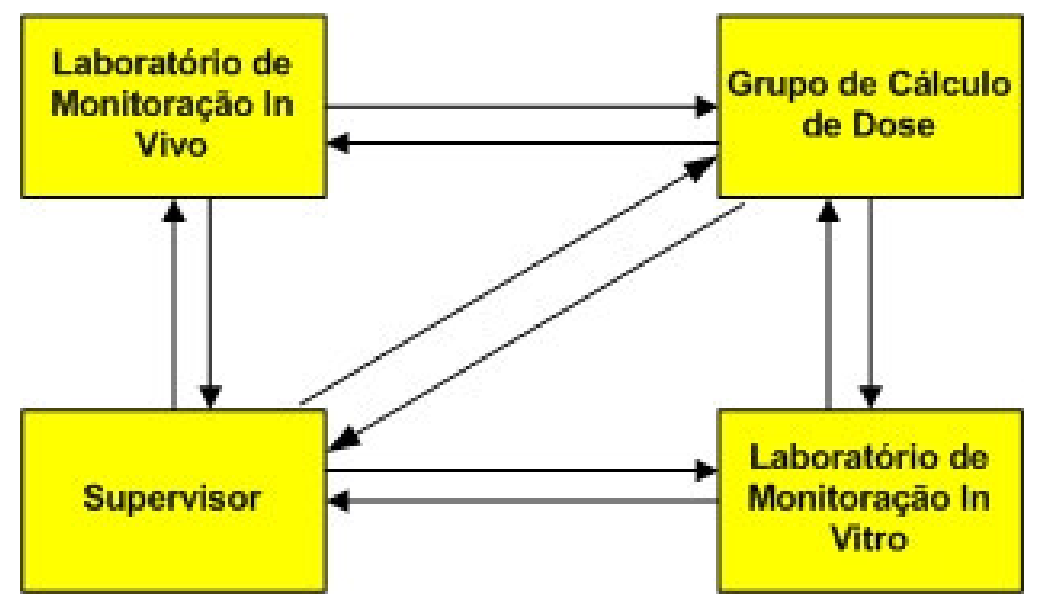

FIGURA 3.1 - Modelo atual do fluxo de informações

Na FIG. 3.2 é apresentado o modelo de fluxo de informações proposto com o desenvolvimento do IntDosWeb que tem como objetivo conduzir uma padronização do atendimento prestado pelo programa de monitoração interna do IPEN. 


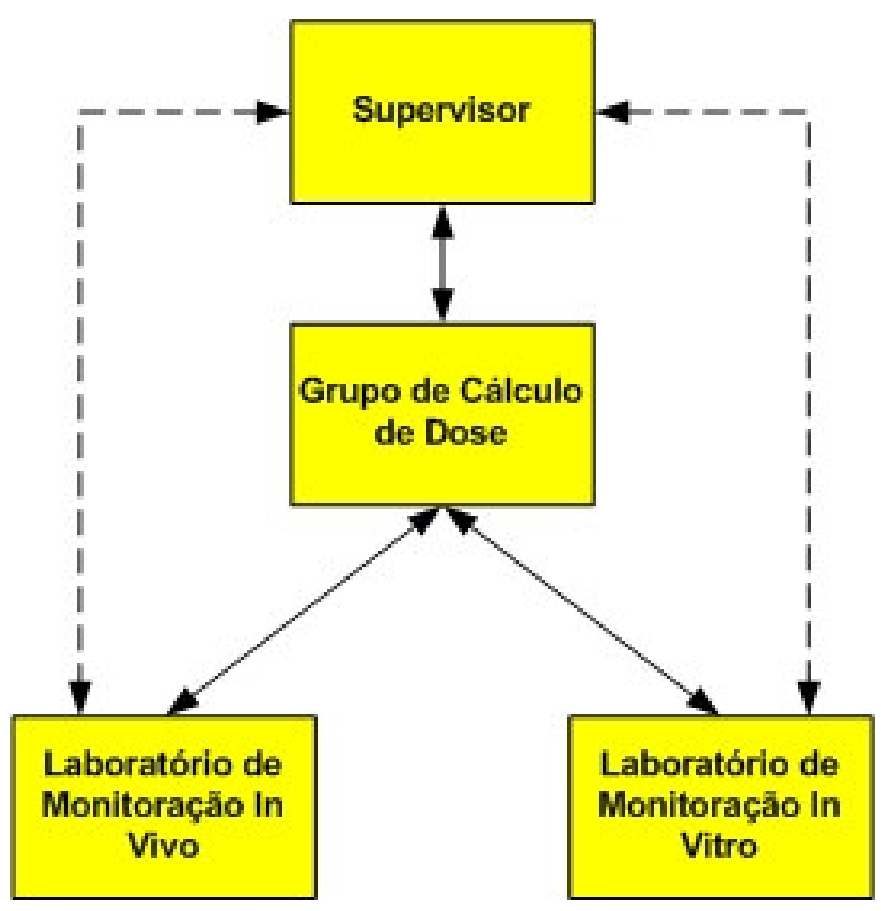

FIGURA 3.2 - Modelo do fluxo de informações proposto a partir do IntDosWeb

As linhas pontilhadas representam as situações em que o Supervisor de radioproteção tem acesso direto aos laboratórios de medidas in vivo e in vitro para resolver necessidades operacionais, entretanto o fluxo de informações relativas ao programa de monitoração interna sempre deve chegar ao Grupo de Cálculo de Dose, representadas pelas linhas contínuas.

Para entender melhor o fluxo das informações entre as áreas envolvidas a FIG. 3.3 descreve o processo das informações. 


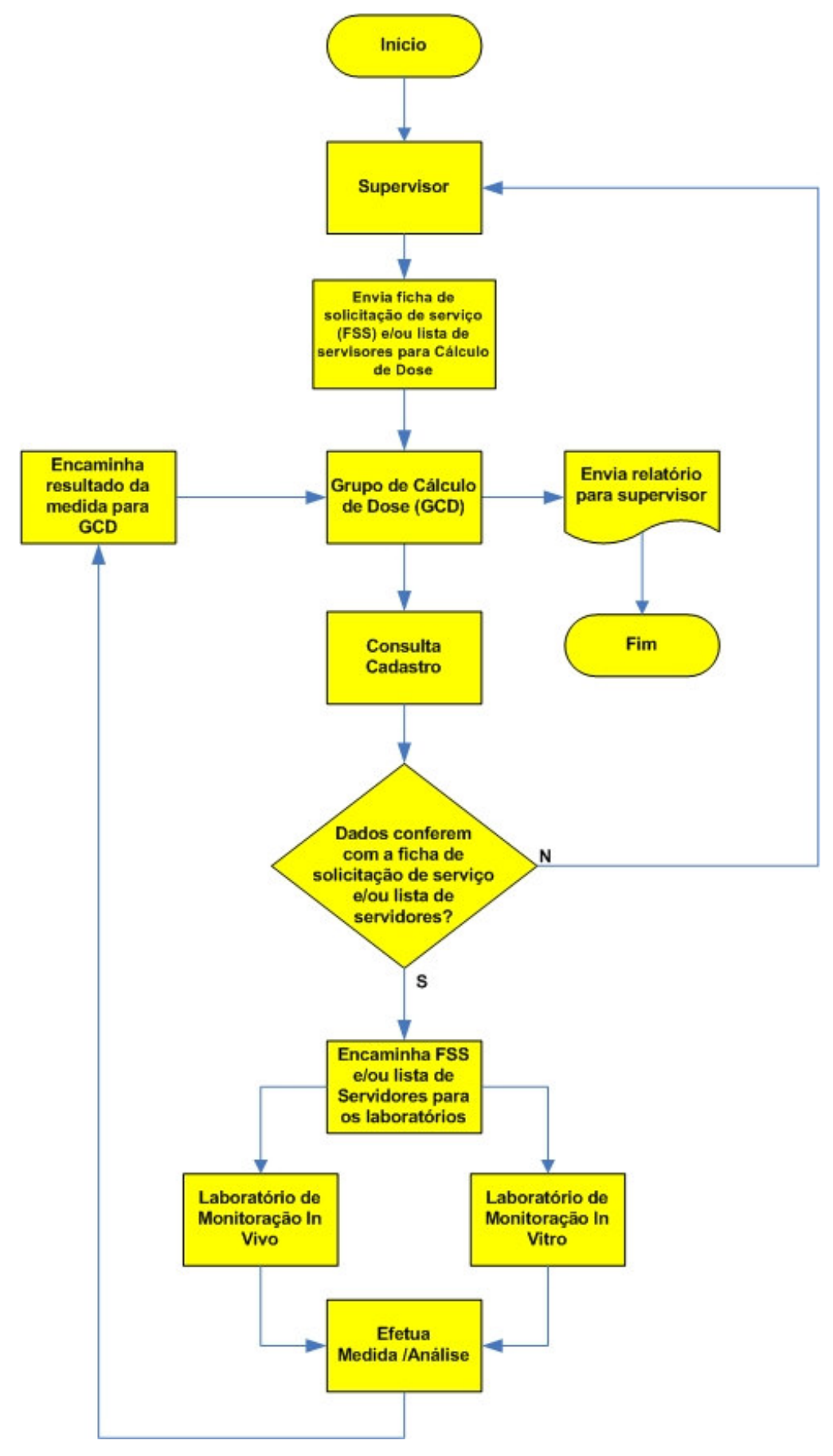

FIGURA 3.3 - Modelo complexo do fluxo de informações da monitoração individual interna

O Supervisor de Radioproteção da instalação envia a Ficha de Solicitação de Serviços (FSS), e/ou lista de servidores para o GCD que verifica as informações dos dados pessoais e de trabalho do trabalhador em seu banco de 
dados. Sendo os dados cadastrais verdadeiros, o GCD envia a solicitação para o laboratório in vivo ou in vitro de acordo com o radionuclídeo a ser monitorado. Os laboratórios efetuam a monitoração e encaminham os resultados das medidas in vivo das análises in vitro para o GCD que efetua o cálculo da dose, emite o relatório e encaminha para o Supervisor de Radioproteção.

\subsection{Projeto}

A arquitetura básica do IntDosWeb é em três camadas: cliente e servidor. A navegação do usuário cliente no navegador (clicando em links, acessando endereços específicos) gera uma demanda por conteúdo sendo transformada em uma requisição HTTP. O servidor acessa o conteúdo na forma de documentos HTML e mídias que por sua vez são transferidos pela rede e apresentados no navegador. As novas interações de navegação do usuário geram novas demandas e o ciclo repete-se de forma interativa.

\subsubsection{Modelagem do Banco de Dados}

O sistema está estruturado em tabelas que associam-se entre si por meio das regras de relacionamentos. Estas regras consistem em associar um atributo de uma tabela com um conjunto de registros de outra tabela, por meio da inclusão do campo chave da tabela.

O sistema está estruturado para armazenar uma coleção de dados que estão classificadas da seguinte maneira:

- Dados do Usuário, a modelagem do banco de dados para usuário está apresentada na FIG. 3.4;

- Dados do Trabalhador, a modelagem do banco de dados para trabalhador está apresentada na FIG. 3.5;

- Dados da Monitoração In Vivo e In Vitro e Cálculo da Dose, a modelagem do banco de dados para monitoração in vivo, in vitro e cálculo da dose está apresentada na FIG. 3.6. 


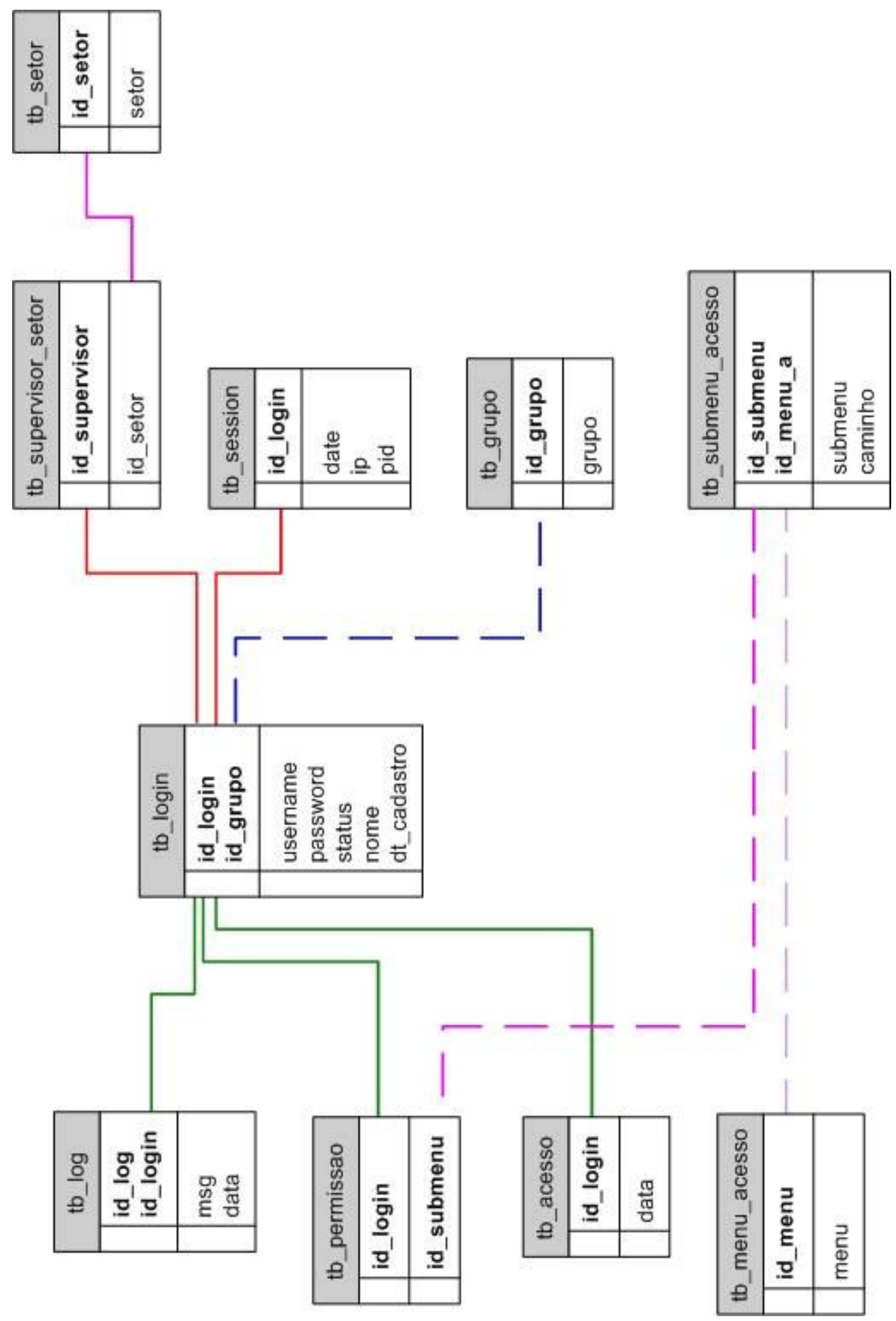

FIGURA 3.4 - Modelagem do banco de dados - Usuário 


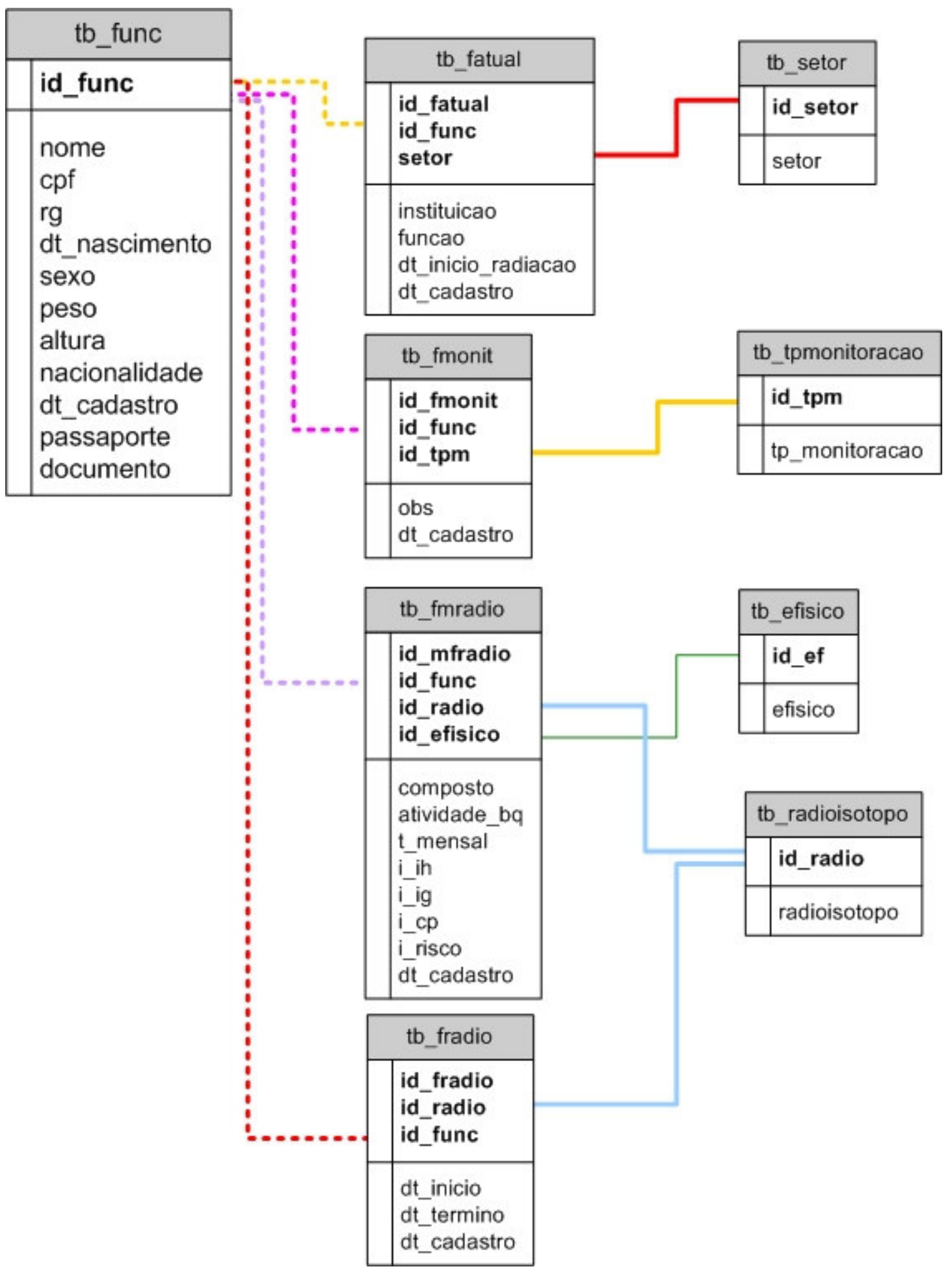

FIGURA 3.5 - Modelagem do banco de dados - Trabalhador 

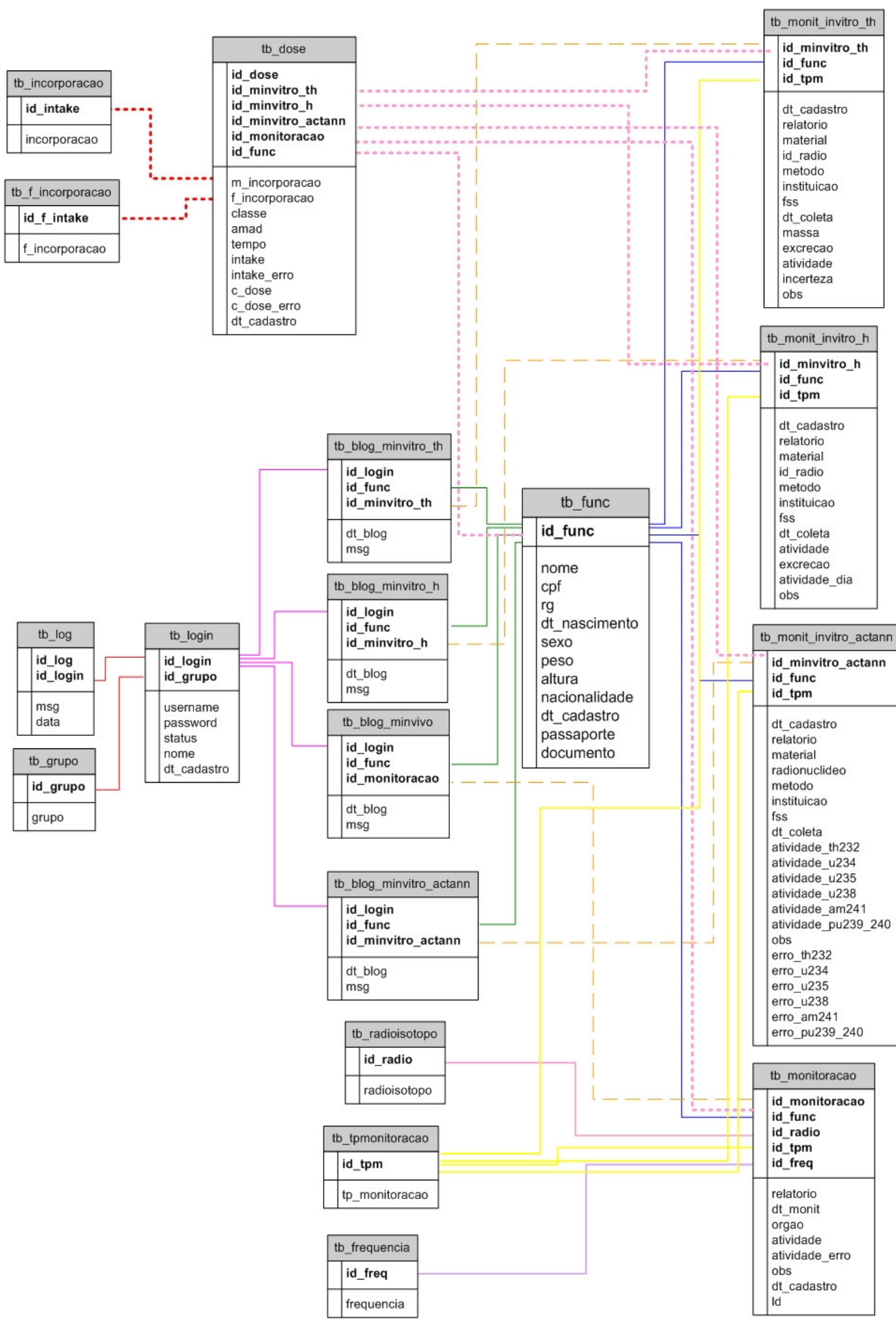

FIGURA 3.6 - Modelagem do banco de dados - Monitoração In Vivo, In Vitro e Cálculo da Dose 


\subsubsection{Modelagem do Sistema}

A FIG. 3.7 apresenta o módulo de diagrama de classe do sistema que implementa os requisitos de segurança no controle de acesso ao sistema IntDosWeb. Este controle é feito por meio do gerenciamento de sessão e login.

A classe interface é quem faz o controle do menu de acesso de acordo com as funções de cada usuário do sistema IntDosWeb. O menu de acesso foi estruturado em seis funções exclusivas de forma a facilitar a "navegação" do usuário.

A classe de sessão implementa a autenticação do usuário de acesso e o controle da sessão. A autenticação é executada a cada acesso ao sistema por meio do login e senha informada ao servidor uma única vez.

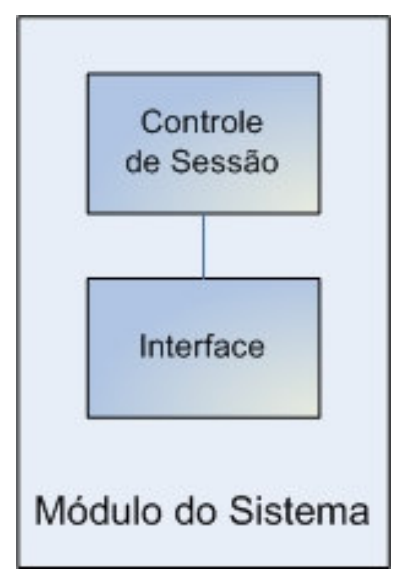

FIGURA 3.7 - Diagrama de classe do sistema

Inicialmente foram efetuadas entrevistas para verificar as necessidades dos usuários do Grupo de Cálculo de Dose, Laboratório de Monitoração In Vivo e Laboratório de Monitoração In Vitro. Esta entrevista serviu para elaboração do documento de levantamento de requisitos que formalizou o objetivo do sistema IntDosWeb e que também contribuiu para estabelecer os módulos e o estudo dos casos de uso referentes a cada uma das áreas. 
O diagrama de caso de uso para o administrador do sistema é apresentado na FIG. 3.8. O caso de uso do administrador consiste em: Inserir, Alterar e Excluir o Estado Físico, Inserir, Alterar e Excluir a Forma de Incorporação, Inserir, Alterar e Excluir a Freqüência, Inserir, Alterar e Excluir o Modo de Incorporação, Inserir, Alterar e Excluir o Radioisótopo, Inserir, Alterar e Excluir o Setor, Inserir, Alterar e Excluir o Tipo de Monitoração, Inserir, Alterar e Excluir Relação Supervisor x Setor e Inserir, Alterar e Excluir Usuário.

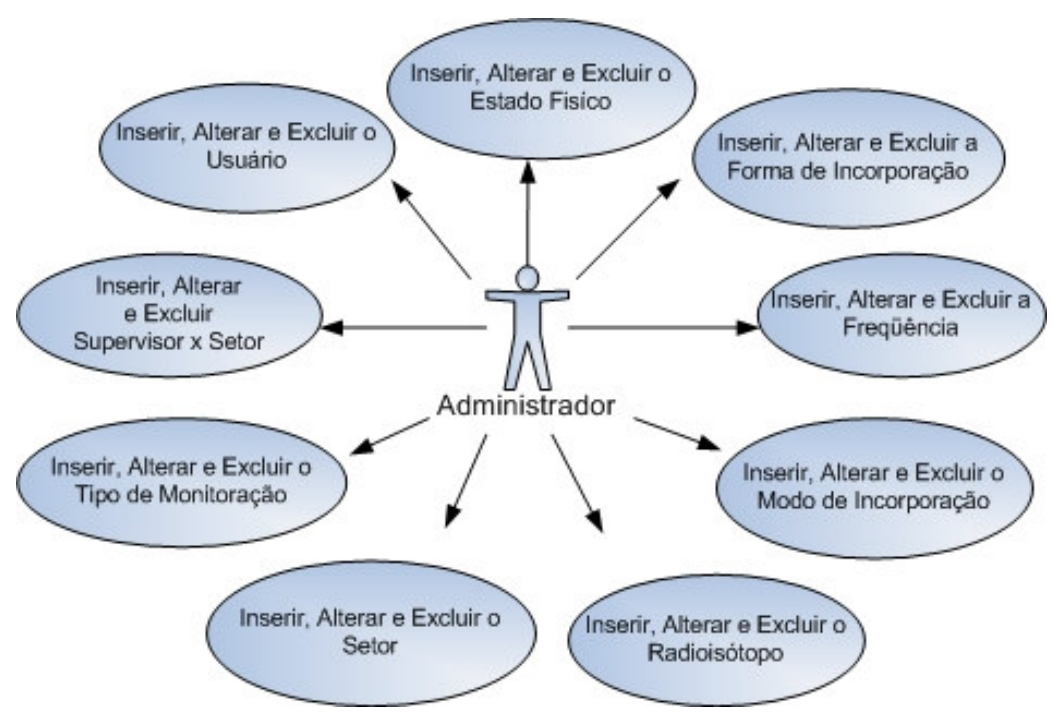

FIGURA 3.8 - Diagrama de caso de uso para o Administrador

O diagrama de caso de uso para o Grupo de Cálculo de Dose é apresentado na FIG. 3.9, O caso de uso do GCD consiste em: Cadastrar Trabalhador, Inserir Medidas In Vivo, Inserir Medidas In vitro, Inserir Resultado do Cálculo da Dose, Gerar Relatório de Dose, Alterar Resultado do Cálculo da Dose, Alterar Medidas In Vivo, Alterar Medidas In Vitro, Alterar Trabalhador, Imprimir Histórico de Dose, Imprimir Histórico de Monitoração In Vivo e In Vitro e Imprimir Ficha do Trabalhador. 


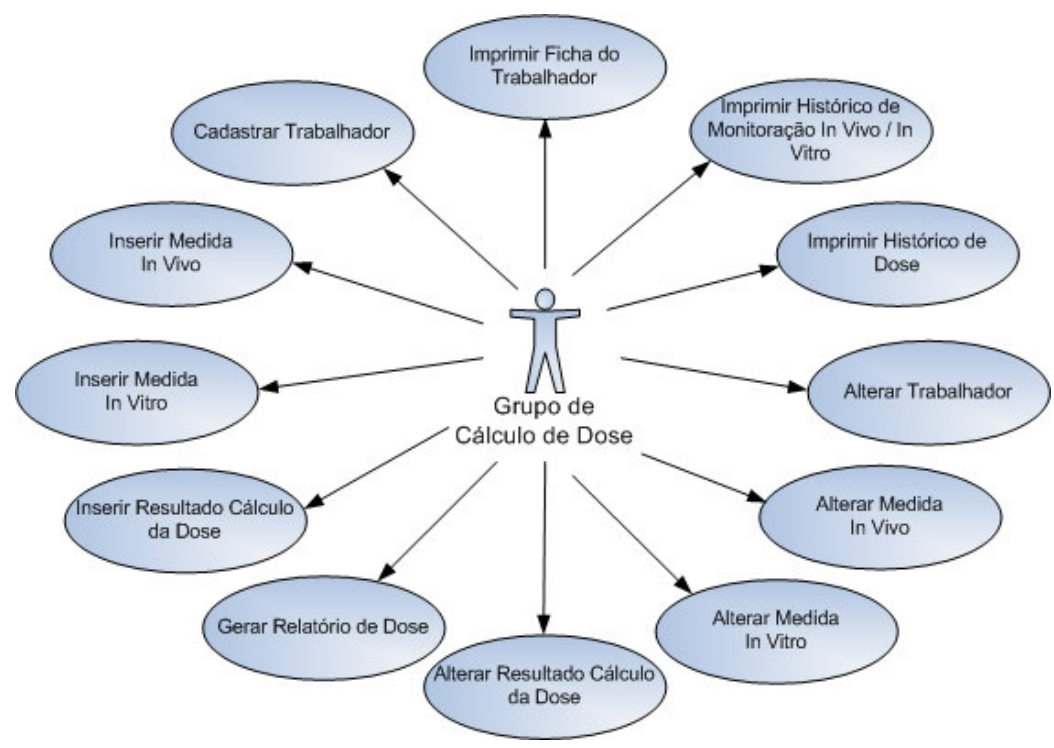

FIGURA 3.9 - Diagrama de caso de uso para o Grupo de Cálculo de Dose

O diagrama de caso de uso para o Laboratório de Monitoração In Vivo é apresentado na FIG. 3.10. O caso de uso do LMIV consiste em: Cadastrar Trabalhador, Inserir Medidas In Vivo, Alterar Trabalhador, Alterar Medidas In Vivo e Imprimir Ficha do Trabalhador.

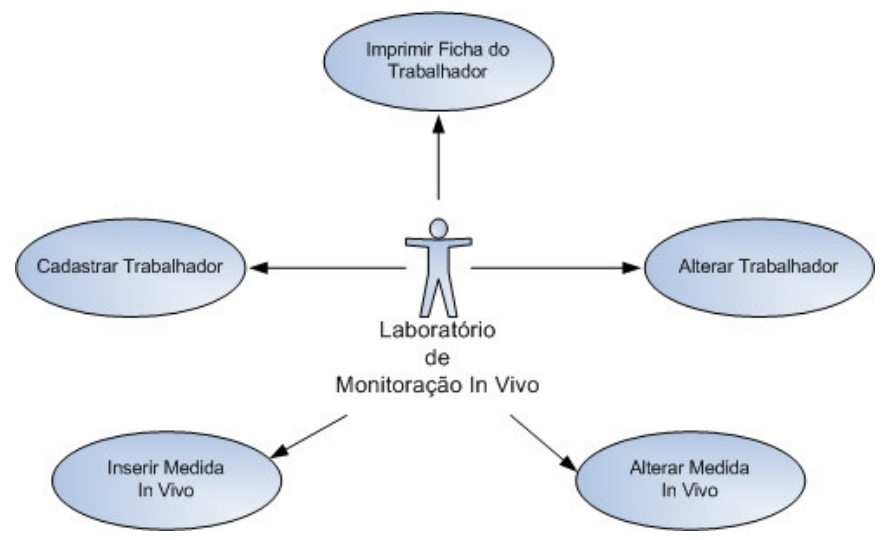

FIGURA 3.10 - Diagrama de caso de uso para o Laboratório de Monitoração In Vivo

O diagrama de caso de uso para o Laboratório de Monitoração In Vitro é apresentado na FIG. 3.11. O caso de uso do Laboratório de Monitoração In Vitro 
consiste em: Cadastrar Trabalhador, Inserir Medidas In Vitro, Alterar Trabalhador, Alterar Medidas In Vitro e Imprimir Ficha do Trabalhador.

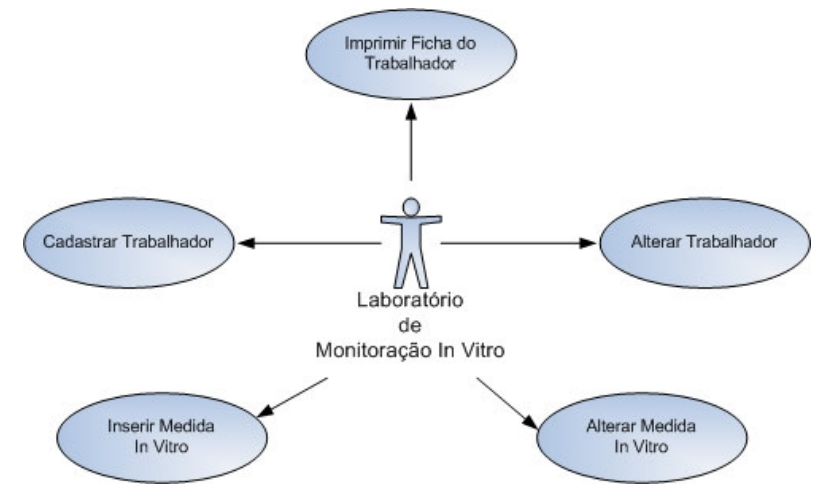

FIGURA 3.11 - Diagrama de caso de uso para o Laboratório de Monitoração In Vitro

O diagrama de caso de uso para o Supervisor de Radioproteção é apresentado na FIG. 3.12. O caso de uso do Supervisor consiste em: Cadastrar Trabalhador, Alterar Trabalhador, Imprimir Ficha do Trabalhador e Visualizar Relatório de Dose.

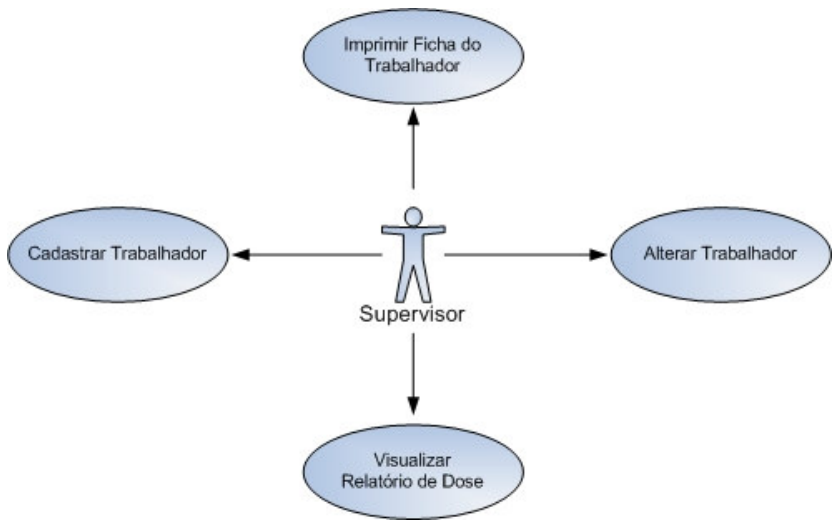

FIGURA 3.12 - Diagrama de caso de uso para o Supervisor 
O diagrama de caso de uso para o Trabalhador é apresentado na FIG. 3.13. O caso de uso do trabalhador consiste em: Visualizar Ficha de Cadastro.

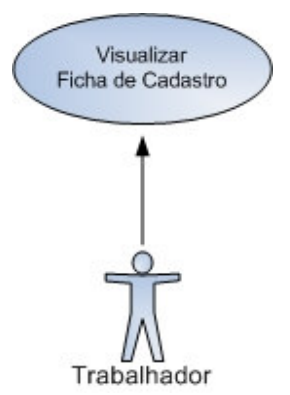

FIGURA 3.13 - Diagrama de caso de uso para o Trabalhador

\subsubsection{Dados do Hardware}

Por se tratar de um trabalho acadêmico, foi utilizado em sua implementação um computador do tipo PC mantido dentro do ambiente de trabalho do Grupo de Cálculo de Dose, entretanto, em condições ideais deveria ser utilizado um equipamento servidor em um Centro de Processamento de Dados (CPD).

\subsubsection{Dados do Software}

As escolhas dos softwares para o desenvolvimento do IntDosWeb foi baseado no uso de software livre, onde alguns aspectos foram observados:

- Licença: Gratuita;

- Usabilidade: Interface gráfica de fácil entendimento;

- Performance: Bom desempenho das ferramentas de uso;

- Suporte: Manual de uso, correção de falhas e suporte no Brasil.

Para desenvolver este trabalho os seguintes softwares foram escolhidos: 


\section{- Linguagem de Programação:}

A linguagem de programação $\mathrm{PHP}^{(38,39)}$ versão 5 , pode ser executada por diferentes servidores para os sistemas operacionais Unix, Linux ou Windows. O que diferencia o PHP das outras linguagens é o HTML, pois o código PHP fica embutido no próprio HTML.

O PHP é uma linguagem de programação que permite criar sistemas em ambiente Web com páginas dinâmicas, possibilitando interação com o usuário por meio dos formulários, URL e links. O PHP é executado no Servidor Web, quando há solicitação do cliente (usuário), e é enviado para o cliente apenas o HTML, ou seja, o código fonte do PHP não é exposto ao cliente. Isto é muito útil quando o programa está lidando com senhas e informações confidenciais.

\section{- Banco de Dados:}

O banco de dados escolhido para implementar o IntDosWeb foi o PostgreSQL ${ }^{(40)}$ versão 8.2. Trata-se de um banco de dados desenvolvido como projeto de software livre, compatível com a linguagem de programação escolhida.

O PostgreSQL é um software de livre distribuição e, em termos de recursos, pode ser comparado aos melhores bancos de dados comerciais existentes, além de exigir baixos recursos de memória e processamento e integrar-se ao Servidor Web Apache.

O PostgreSQL pode trazer muitos benefícios para o IPEN. O primeiro deles, sem dúvida, é uma economia tangível em licença de software. Outro ponto importante é a simplificação do processo de gerenciamento de licenças de software, o que não é necessário para um software livre. Além disto, a substituição também causa benefícios como o aumento da estabilidade e do desempenho do sistema. Uma das características mais destacadas do PostgreSQL é a sua capacidade de lidar com um grande volume de dados. Existem aplicações em produção com tabelas possuindo mais de 100 milhões de registros. 
- Ferramenta de Administração do PostgreSQL:

O phpPgAdmin ${ }^{(41)}$ versão 4.1 é uma ferramenta de sistema de gerenciamento de banco de dados escolhida para a administração do PostgreSQL. Trata-se de uma ferramenta com interface web muito simples e ajuda nas tarefas rotineiras para a administração de um banco de dados. Por meio deste software o administrador pode criar banco de dados, novos usuário de acesso ao PostgreSQL e tabelas.

\section{- Servidor Web:}

O Servidor Web Apache ${ }^{(35)}$ versão 2.2.4 é definido como servidor de páginas para internet, mas pode ser usado como servidor web restrito na Intranet.

Para garantir segurança nas transações HTTP, o servidor dispõe de um módulo chamado mod_ssl, o qual adiciona a capacidade do servidor atender requisições utilizando o protocolo HTTPS. Este protocolo utiliza uma camada SSL para criptografar todos os dados transferidos entre o cliente e o servidor, provendo maior grau de segurança, confidencialidade e confiabilidade dos dados. 


\section{SISTEMA IntDosWeb}

A FIG. 4.1 ilustra o IntDosWeb, Dosimetria Interna na Web, que é um sistema baseado na troca de informações por meio da Intranet, na qual todos os dados referente aos trabalhadores que manuseiam materiais radioativos na forma não selada são registrados em um banco de dados durante cada etapa do programa de monitoração interna do IPEN. Neste capítulo será destacada as principais funcionalidades do sistema IntDosWeb.

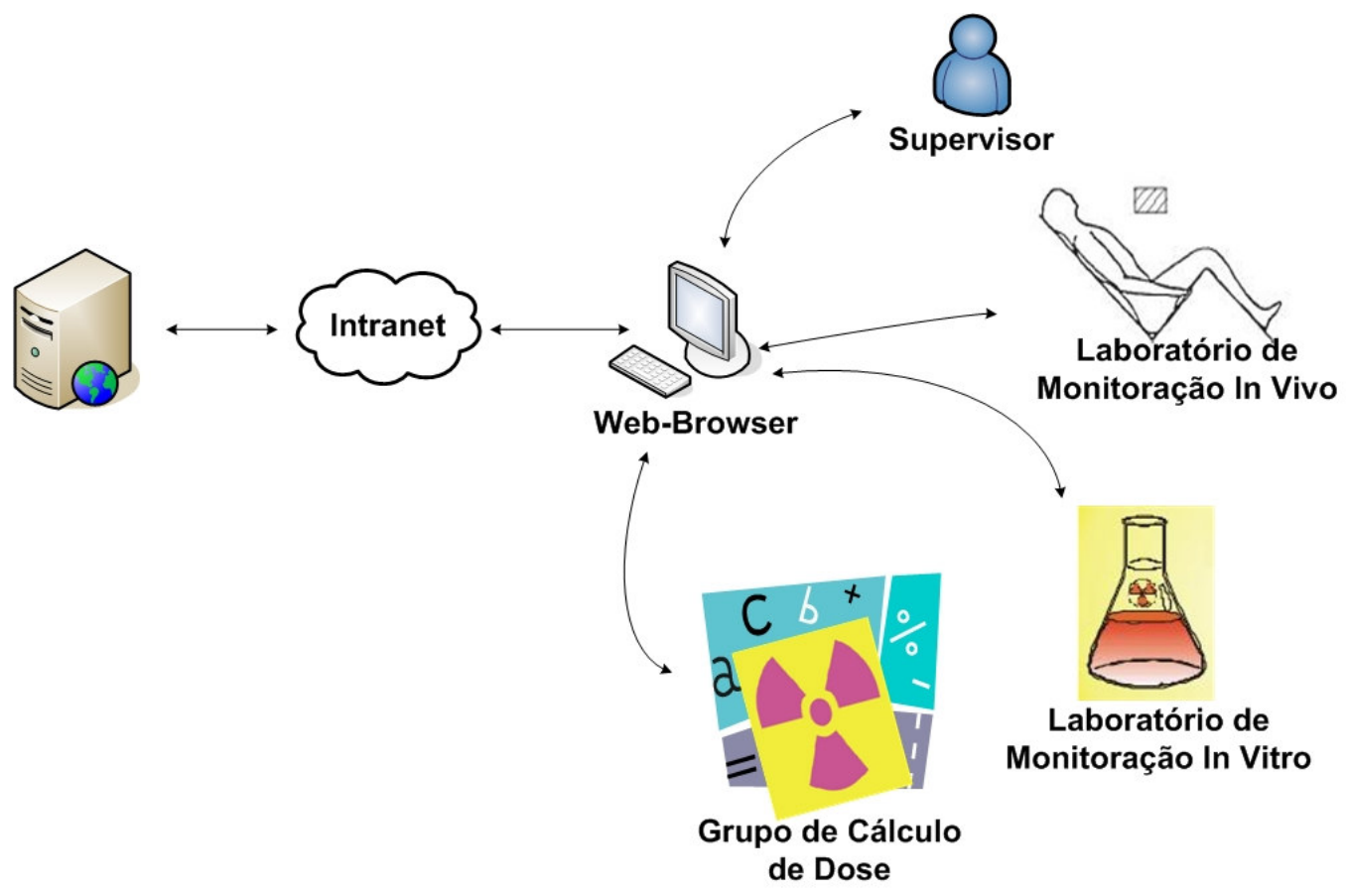

FIGURA 4.1 - Representação gráfica do IntDosWeb baseado na troca de informações utilizando Intranet por meio de um único banco de dados

\subsection{Níveis de Acesso}

Para atender as necessidades do sistema foram definidos níveis de acessos a funções exclusivas de acordo com o perfil dos usuários do IntDosWeb. A FIG. 4.2 e FIG. 4.3 apresenta o fluxograma de acesso ao sistema. 


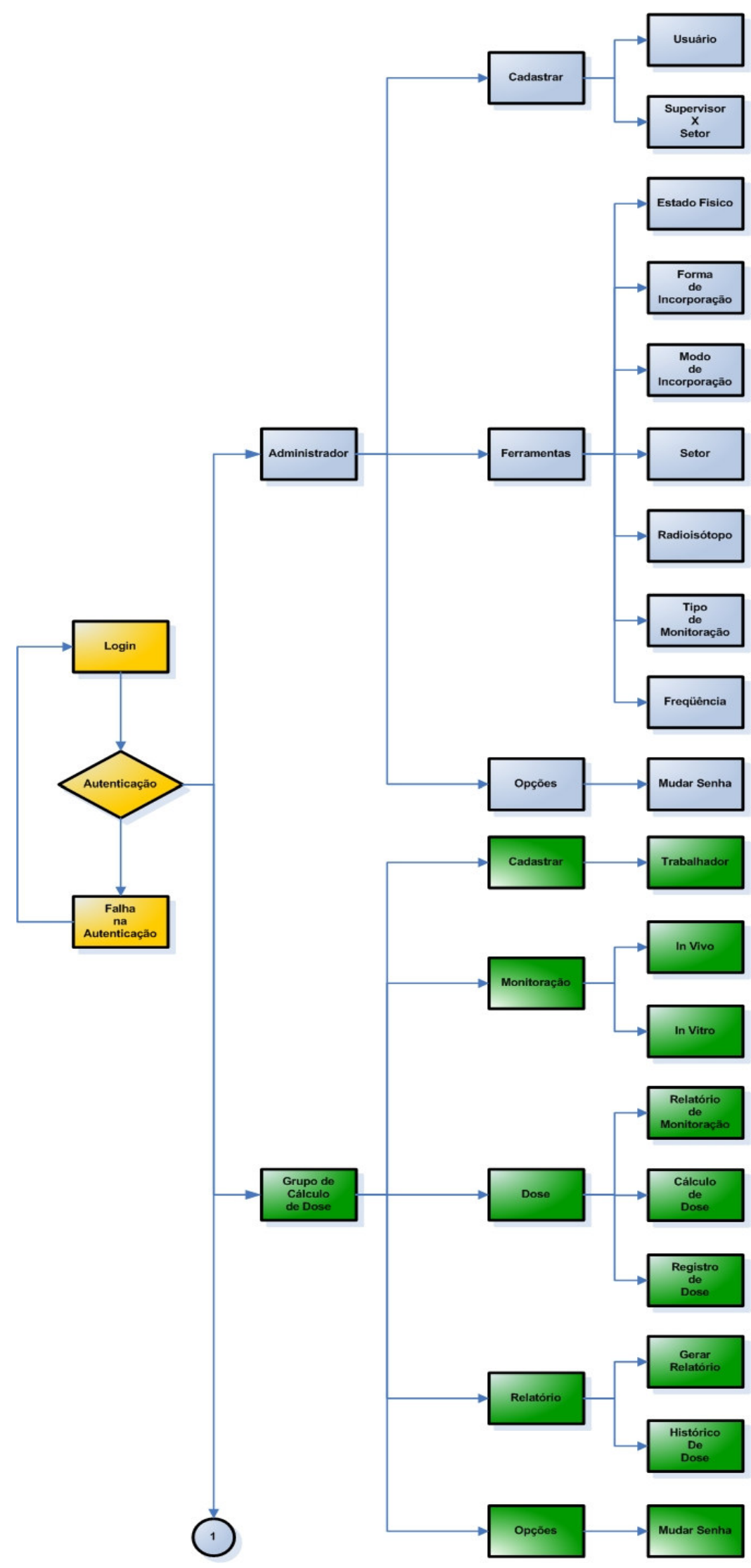

FIGURA 4.2 - Fluxograma de acesso ao sistema IntDosWeb 


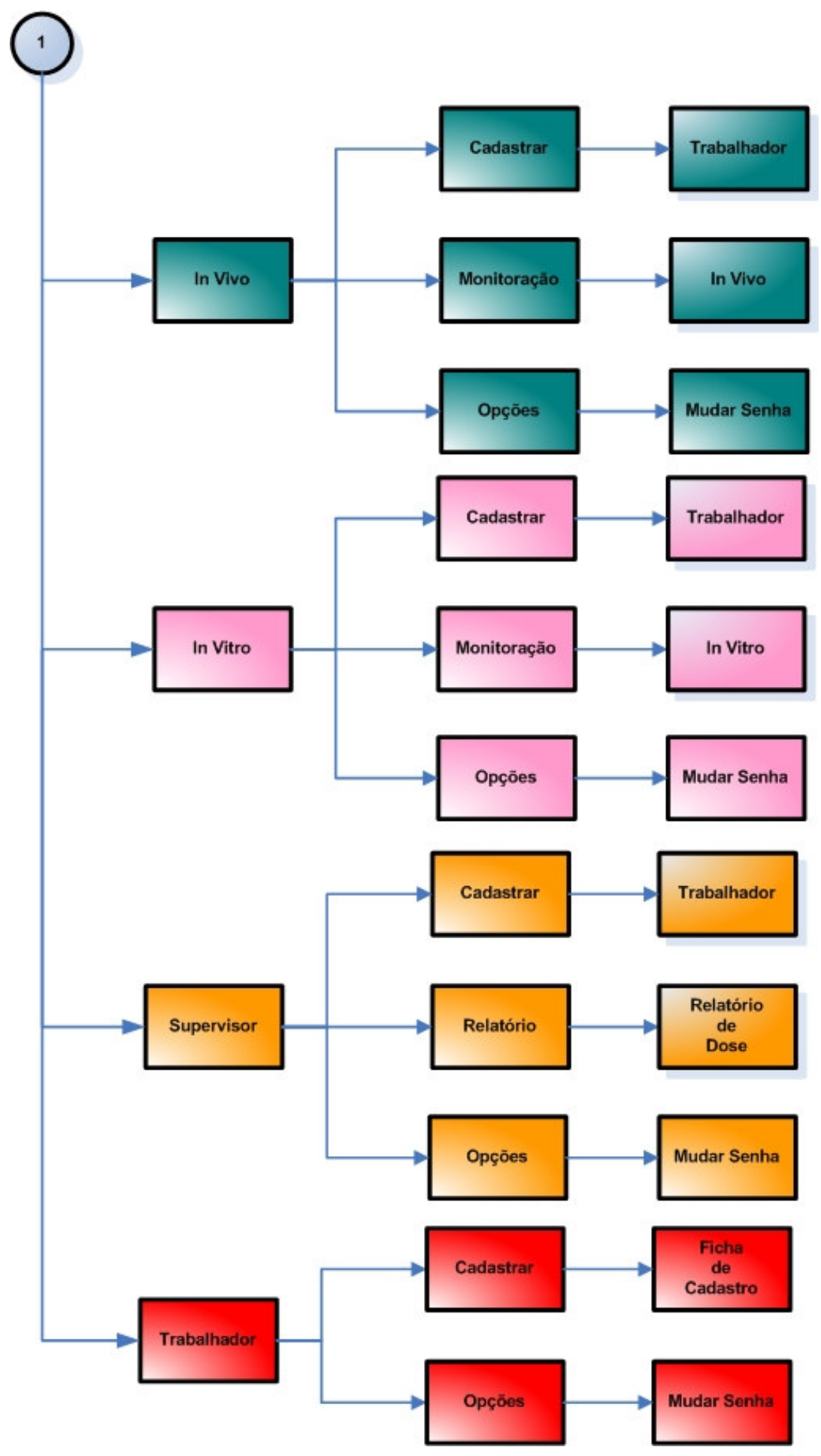

FIGURA 4.3 - Fluxograma de acesso ao sistema IntDosWeb - continuação 
O acesso é definido em seis níveis:

- Administrador: O Administrador gerencia o sistema e o banco de dados. Ele tem acesso total ao banco de dados e é responsável pela criação e administração de usuários e ferramentas do IntDosWeb;

- Grupo de Cálculo de Dose: O Grupo de Cálculo de Dose é o conjunto de usuários que efetuam o cálculo da dose a partir dos resultados das medidas in vivo e in vitro. Também elaboram os relatórios e históricos de dose.

- Laboratório de Monitoração In Vivo: O Laboratório de Monitoração In Vivo é responsável pela alimentação dos dados da monitoração. Tais dados como já foi mencionado anteriormente, são obtidos por meio da medida do corpo inteiro ou de partes do corpo;

- Laboratório de Monitoração In Vitro: O Laboratório de Monitoração In Vitro é responsável pela alimentação dos dados da monitoração obtidos por meio da análise das excretas;

- Supervisor: O Supervisor é o usuário responsável pelos trabalhadores da instalação de sua respectiva área de atuação. Ele também é responsável pela manutenção e atualização das informações relativas ao trabalhador e terá acesso aos relatórios de dose dos trabalhadores;

- Trabalhador: O Trabalhador é quem possui o acesso com maior restrição, uma vez que só tem permissão para visualizar seus respectivos dados de cadastro.

O aumento das redes abertas fez com que surgissem vários problemas de segurança, como o roubo de senhas, onde uma pessoa se faz passar por outra para obter acesso privilegiado, portanto surgiu a necessidade de uma autenticação, que consistisse na verificação da identidade do usuário do sistema. A autenticação é o modo mais utilizado para fornecer uma identidade, no qual se destaca o uso de segredo, como chave de criptografia.

A Criptografia (do Grego kryptós, "escondido", e gráphein, "escrever") é geralmente entendida como sendo o estudo dos princípios e das técnicas pelas quais a informação pode ser transformada da sua forma original para outra ilegível, a menos que seja conhecida uma "chave secreta", o que a torna difícil de 
ser lida por pessoas não autorizadas. Assim sendo, só o receptor da mensagem pode ler a informação com facilidade ${ }^{(42)}$.

O IntDosWeb no momento que está criando um usuário de acesso, executa uma criptografia da senha (password) e armazena no banco de dados. Para o usuário, a senha sempre será mesma, porém toda vez que a senha for informada, o sistema, executará a criptografia e irá compará-la com a senha armazenada anteriormente no banco de dados.

A desvantagem deste tipo de autenticação é o esquecimento da senha ou do nome do usuário, conhecido também como username ou login. Neste caso o administrador deverá efetuar uma pesquisa de usuários por meio do nome e deverá gerar uma nova senha, pois não é possível decifrar a criptografia.

\subsubsection{Administrador}

O menu principal para o perfil Administrador é apresentado na FIG. 4.4. Observa-se na primeira linha deste menu as opções: "Cadastrar", "Ferramentas" e "Opções". Posteriormente, quando cada uma dessas opções são acessadas elas vão conduzir a novos sub-menus para a inserção de informações relativa aos usuários e ao programa dosimetria interna.

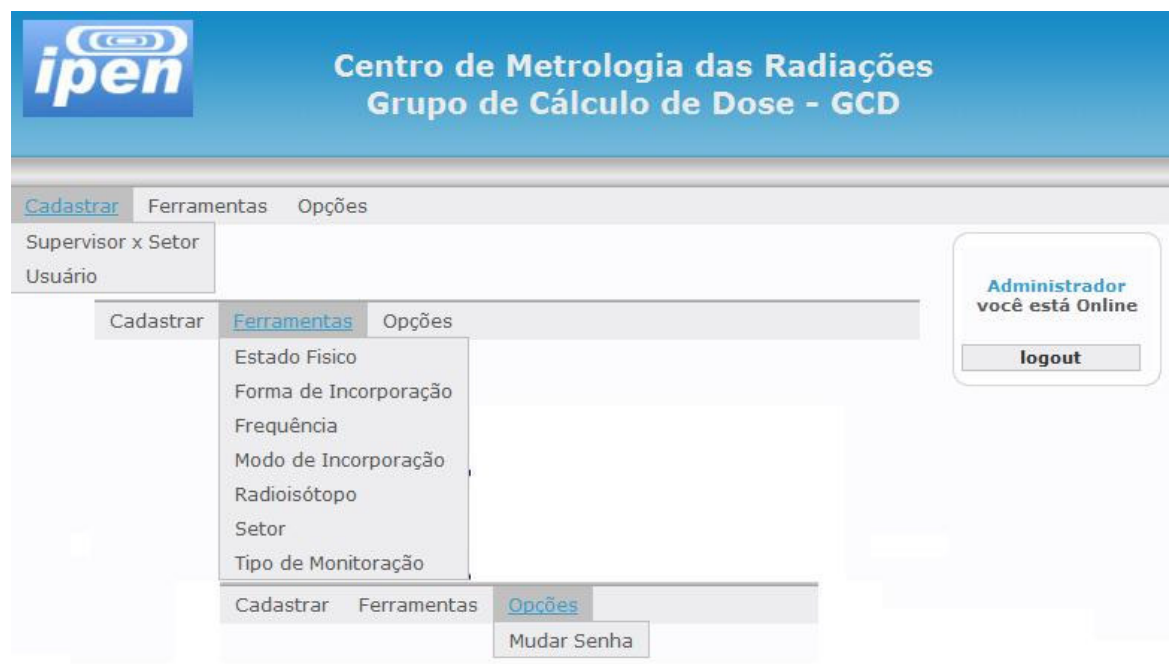

FIGURA 4.4 - Representação gráfica do menu de acesso ao perfil Administrador 
A seguir são descritas as funcionalidades de cada um destes submenus.

\section{- Menu Cadastrar}

O menu Cadastrar é utilizado para incluir novos usuários e relacionar as atividades do supervisor com o setor.

Sub Menu Usuário - Como foi mencionado anteriormente, o administrador do sistema é único capaz de criar usuários para acessar o IntDosWeb. Esta opção tem por objetivo fornecer todo controle dos usuários que utilizam o sistema.

Sub Menu Supervisor x Setor - Sabe-se que no IPEN existem supervisores que são responsáveis por mais de um setor e também setores que tem mais de um supervisor. Portanto foi necessário criar um formulário para efetuar a relação entre supervisor e o setor por esta razão.

\section{- Menu Ferramentas}

As opções no sub menu para "Estado Físico", "Forma de Incorporação", "Modo de Incorporação", "Setor", "Radioisótopo", "Tipo de Monitoração" e "Freqüência", são para criar parâmetros que serão utilizados no IntDosWeb. Esses parâmetros são armazenados no banco de dados. É possível com cada uma dessas opções incluir, alterar e excluir.

Para efetuar as opções alterar ou excluir deve-se prestar muita atenção, pois são parâmetros utilizados praticamente em todos os formulários do sistema, uma alteração ou exclusão implicará na alteração de todos os dados comuns relacionados no banco de dados. 
- Menu Opções

Sub Menu Mudar Senha - é utilizado para a mudança de senha pessoal e recomenda-se que seja mantida em sigilo. O usuário poderá trocar sua senha por meio do próprio IntDosWeb caso seja necessário.

\subsubsection{Grupo de Cálculo de Dose}

O menu principal para o perfil Grupo de Cálculo de Dose apresenta as seguintes opções: "Cadastrar", "Monitoração", "Dose", "Opções" e "Relatório". A FIG. 4.5 apresenta a página inicial com menu e sub menu para o perfil Grupo de Cálculo de Dose.

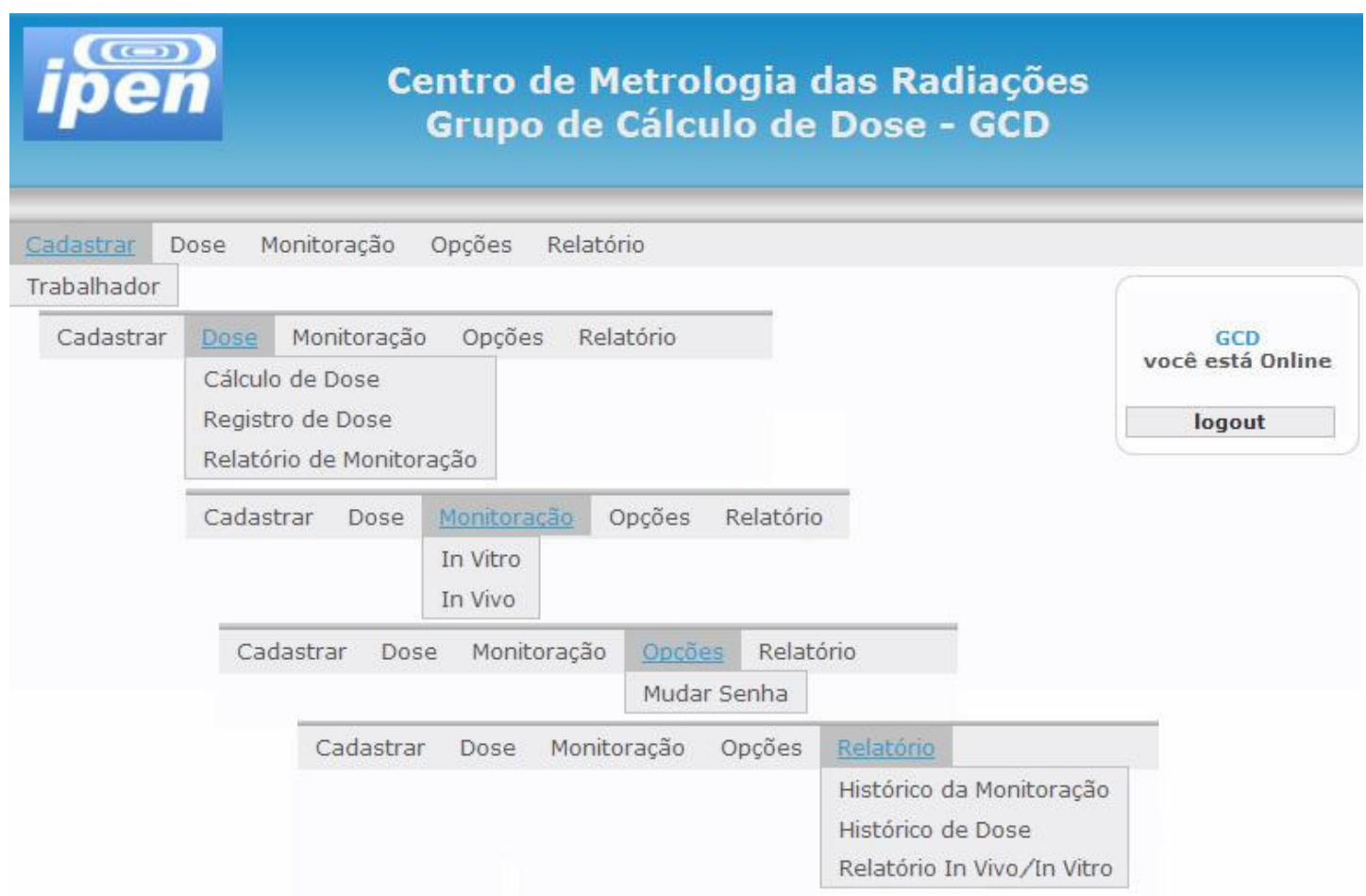

FIGURA 4.5 - Representação gráfica do menu de acesso ao perfil Grupo de Cálculo de Dose 
- Menu Cadastrar

Sub Menu Trabalhador - eventualmente o Grupo de Cálculo de Dose poderá registrar os dados do trabalhador. Essa função é exclusiva do Supervisor responsável pelo Trabalhador.

- Menu Monitoração

Sub Menu In Vivo - eventualmente o Grupo de Cálculo de Dose poderá inserir dados da monitoração In Vivo, fornecido pelo Laboratório de Monitoração In Vivo e também poderá efetuar pesquisas e alteração de dados da monitoração.

Sub Menu In Vitro - eventualmente o Grupo de Cálculo de Dose poderá inserir dados da monitoração In Vitro, fornecido pelo Laboratório de Monitoração In Vitro e também poderá efetuar pesquisas e alteração de dados da monitoração.

Sabe-se que qualquer alteração efetuada é registrada no banco de dados indicando a data e o usuário.

- Menu Dose

Sub Menu Relatório de Monitoração - esta opção permite ao grupo de cálculo de dose pesquisar, por período, as monitorações inseridas no banco de dados para os quais o cálculo de dose ainda não tenha sido efetuado. Permite também salvar a pesquisa em planilha Excel.

Sub Menu Cálculo de Dose - a avaliação da incorporação e da dose efetiva comprometida é efetuada utilizando um programa auxiliar denominado Activity Internal Dose Estimation ${ }^{(43)}$, (AIDE). Este programa foi desenvolvido pelo Dr. Luiz Bertelli, por solicitação de um programa de treinamento da Acordo Regional de Cooperação para a Promoção da Ciência e Tecnologia Nucleares na America Latina e Caribe, (ARCAL) para ser utilizado na harmonização das avaliações das doses para os países membros da América Latina. 
Sub Menu Registro de Dose - aqui é onde o Grupo de Cálculo de Dose poderá pesquisar e quando necessário alterar registro de dose inserido no IntDosWeb.

- Menu Relatório

Sub Menu Histórico de Dose - apresenta o histórico dos resultados das doses dos trabalhadores calculadas pelo Grupo de Cálculo de Dose.

Sub Menu Histórico de Monitoração - apresenta o histórico das medidas e análises das monitorações dos trabalhadores efetuados pelos Laboratórios de Monitoração In Vivo e In Vitro.

Sub Menu Relatório In Vivo / In Vitro - onde se realiza os relatórios da dose efetiva comprometida dos trabalhadores por meio da monitoração in vivo e in vitro.

- Menu Opções

Sub Menu Mudar Senha - O usuário do cálculo de dose poderá trocar sua senha no próprio IntDosWeb caso seja necessário.

\subsubsection{Laboratório de Monitoração In Vivo}

O menu principal para o perfil Laboratório de Monitoração In Vivo encontra-se as seguintes opções: "Cadastrar", "Monitoração" e "Opções". A FIG. 4.6 apresenta a página inicial com menu e sub menu para o perfil Laboratório de Monitoração In Vivo. 


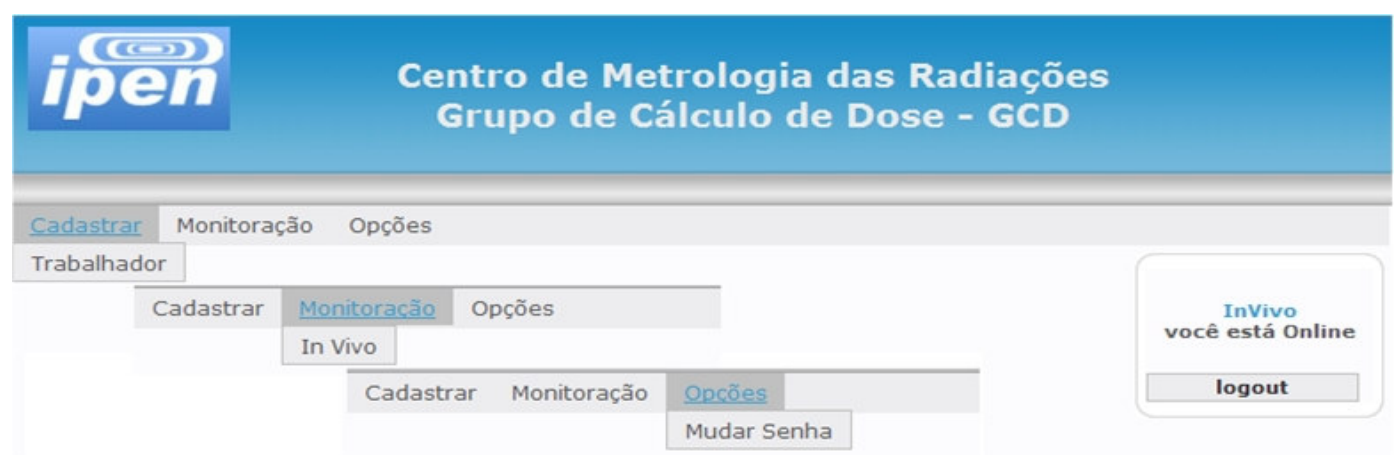

FIGURA 4.6 - Representação gráfica do menu de acesso ao perfil Laboratório de Monitoração In Vivo

- Menu Cadastrar

Sub Menu Trabalhador - eventualmente o Laboratório de Monitoração In Vivo poderá registrar os dados do trabalhador. Como mencionado anteriormente essa função é exclusiva do Supervisor responsável pelo Trabalhador.

- Menu Monitoração

Sub Menu In Vivo - Esta opção permite inserir os dados da monitoração in vivo obtidos por meio da medida do corpo inteiro, além de pesquisar e alterar os dados quando estritamente necessário.

- Menu Opções

Sub Menu Mudar Senha - a senha é de uso pessoal e recomenda-se que seja mantida em sigilo. O usuário poderá trocar sua senha por meio do próprio IntDosWeb caso seja necessário.

\subsubsection{Laboratório de Monitoração In Vitro}

O menu principal para o perfil Laboratório de Monitoração In Vitro apresenta as seguintes opções: "Cadastrar", "Monitoração" e "Opções". 
A FIG. 4.7 apresenta a página inicial com menu e sub menu para o perfil Laboratório de Monitoração In Vitro.

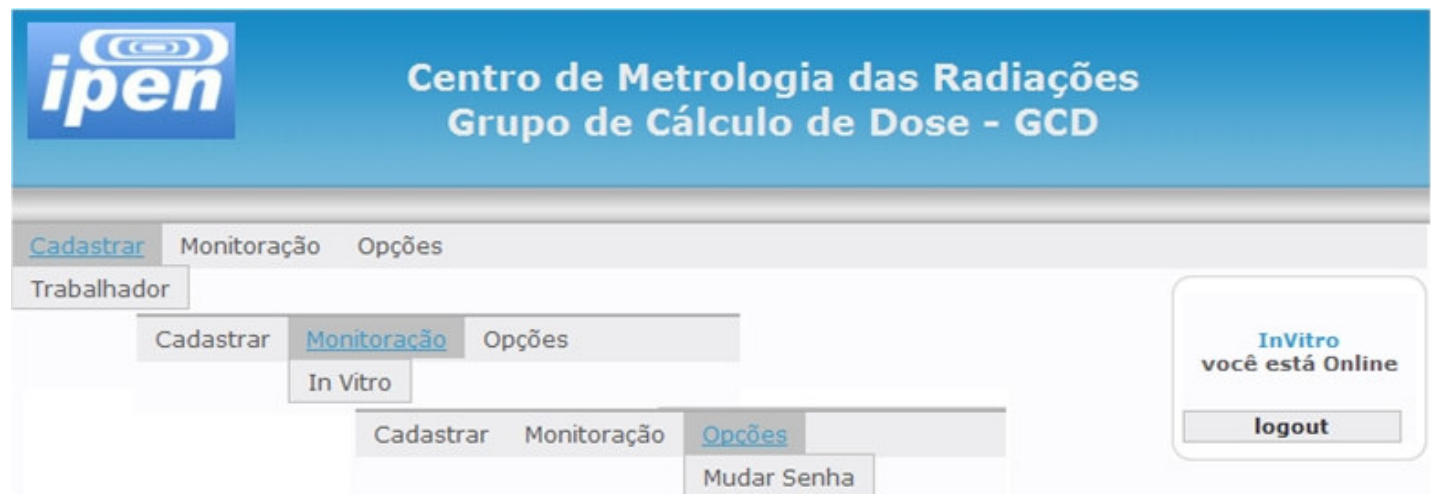

FIGURA 4.7 - Representação gráfica do menu de acesso ao perfil Laboratório de Monitoração In Vitro

- Menu Cadastrar

Sub Menu Trabalhador - o Laboratório de Monitoração In Vitro também tem permissão para registrar os dados do trabalhador em caso da impossibilidade do supervisor efetuá-la.

- Menu Monitoração

Sub Menu In Vitro - A pessoa cadastrada para esta tarefa pode inserir os dados da monitoração in vitro obtidos por meio da análise das excretas, além de pesquisar e alterar os dados quando estritamente necessário.

- Menu Opções

Sub Menu Mudar Senha - o usuário poderá trocar sua senha por meio do próprio IntDosWeb em caso de necessidade. 


\subsubsection{Supervisor}

O menu principal para o perfil Supervisor apresenta as seguintes opções: "Cadastrar", "Relatório" e "Opções". A FIG. 4.8 apresenta a página inicial com menu e sub menu para o perfil Supervisor.

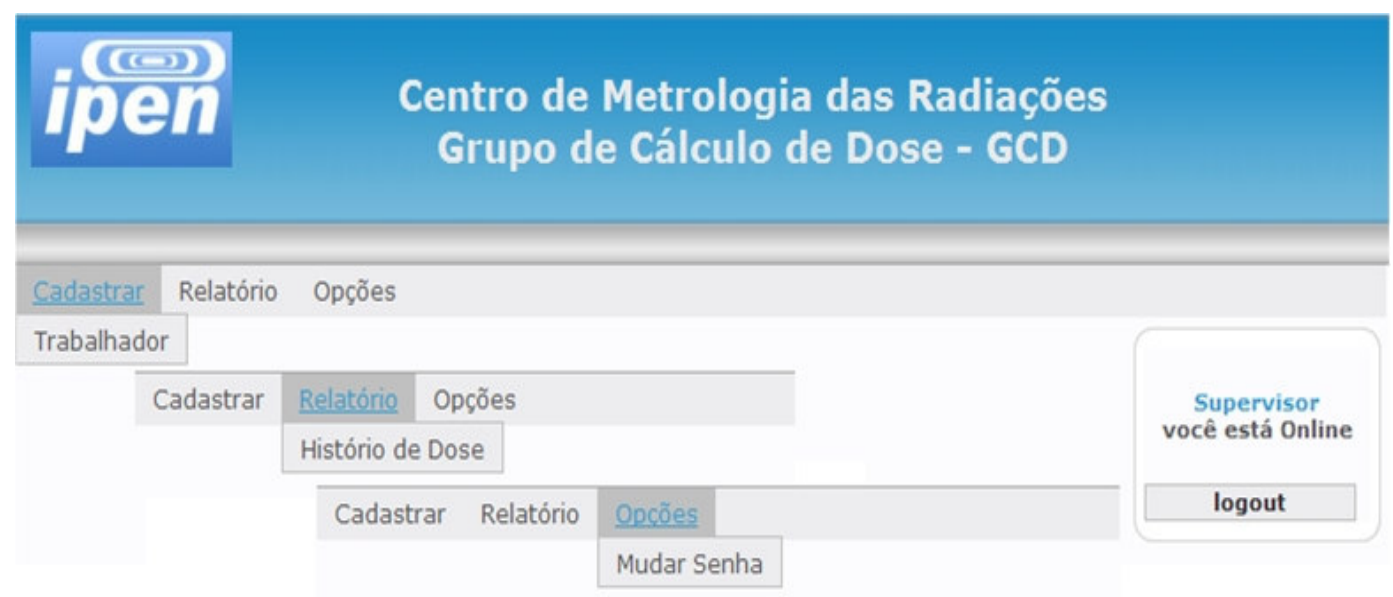

FIGURA 4.8 - Representação gráfica do menu de acesso ao perfil Supervisor

- Menu Cadastrar

Sub Menu Trabalhador - o Supervisor é responsável pelo cadastro do trabalhador da instalação sob sua área de atuação. Neste sub menu é possível efetuar pesquisas e alteração de dados.

- Menu Relatório

Sub Menu Relatório de Dose - o perfil Supervisor tem acesso somente ao relatório de dose dos trabalhadores de sua supervisão.

- Menu Opções

Sub Menu Mudar Senha - caso seja necessário o Supervisor poderá trocar sua senha por meio do próprio IntDosWeb. 


\subsubsection{Trabalhador}

O menu principal para o perfil Trabalhador apresenta as seguintes opções: "Cadastrar" e "Opções". A FIG. 4.9 apresenta a página inicial com menu e sub menu para o perfil Trabalhador.

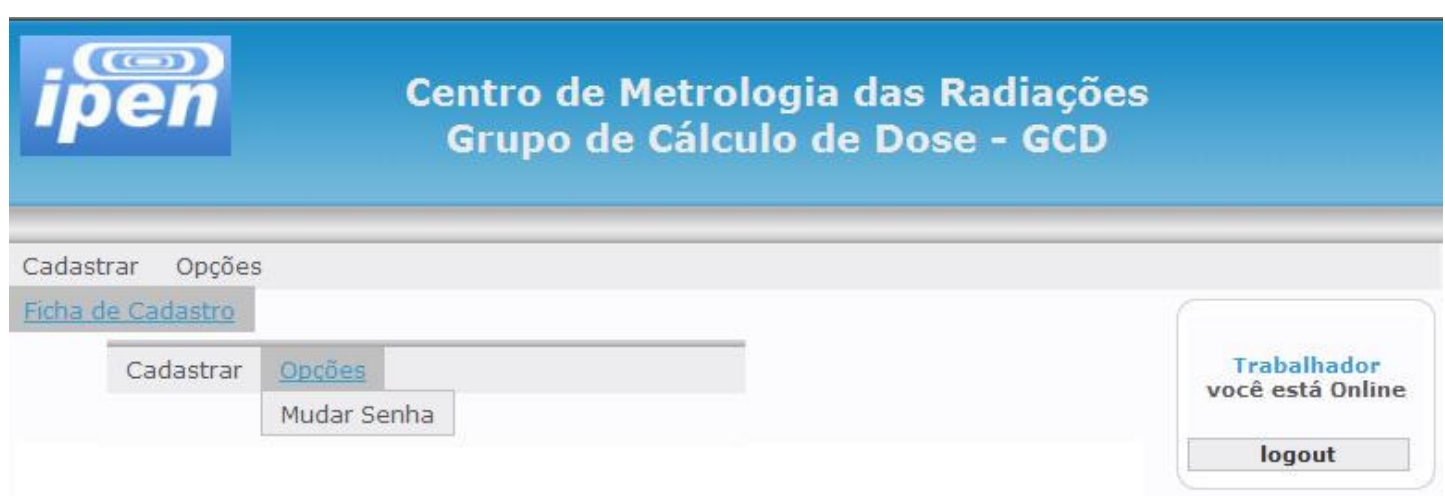

FIGURA 4.9 - Representação gráfica do menu de acesso ao perfil Trabalhador

- Cadastrar

Sub Menu Ficha de Cadastro - o perfil Trabalhador permite apenas acesso a visualização dos dados cadastrais.

- Menu Opções

Sub Menu Mudar Senha - este sub menu permite ao Trabalhador alterar a sua senha caso seja necessário. 


\subsection{Funcionalidade do IntDosWeb}

\subsubsection{Cadastro de Usuários do Sistema}

O Administrador do sistema é quem efetua a inclusão de novos usuários no IntDosWeb, porém quem solicita a inclusão são as áreas envolvidas no programa de monitoração interna. O cadastro é feito a partir do formulário, conforme apresentado na FIG. 4.10 onde todos os campos precisam ser preenchidos.

A distinção dos tipos de usuários é feito por meio do campo Grupo com as seguintes opções: "Administrador", "GCD", "In Vivo", "In Vitro", "Supervisor" e "Trabalhador".

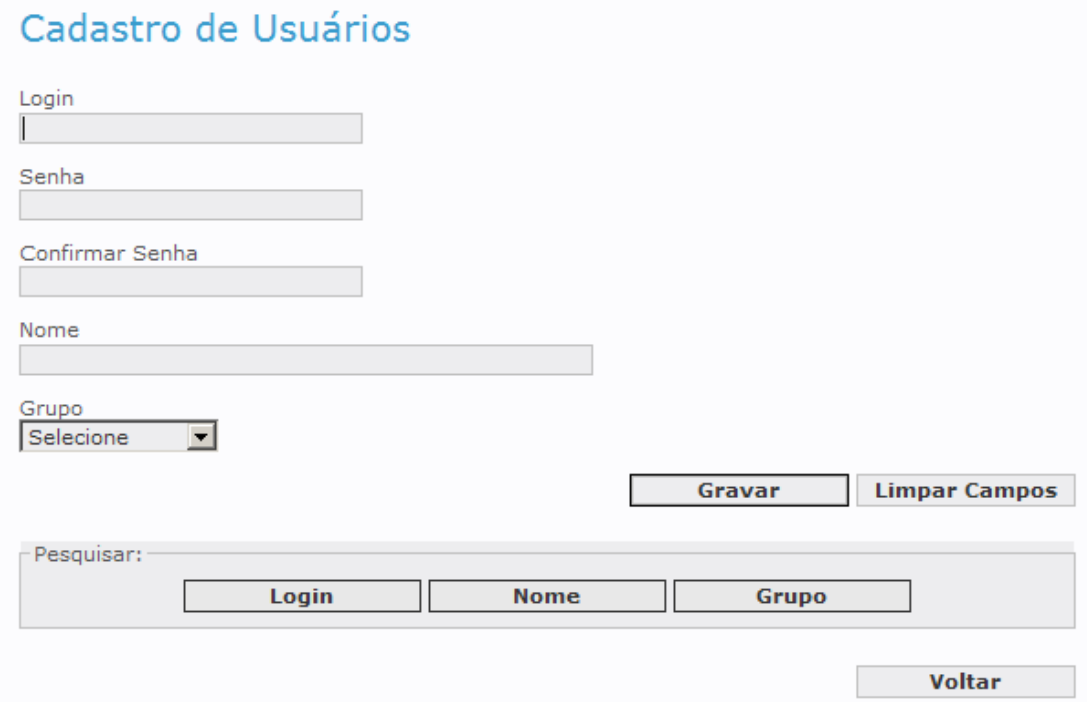

FIGURA 4.10 - Formulário de cadastro de usuários

\subsubsection{Relação Supervisor $x$ Setor}

A FIG. 4.11 apresenta o formulário relação Supervisor e Setor. Este formulário foi criado para atender o fato de existirem supervisores que atuam em mais de um setor e setores que possuem mais de um supervisor. 
Os combos da FIG. 4.11 são "populados" pelo próprio sistema por meio do banco de dados. O sistema também verifica a duplicidade das relações, ou seja, as relações existentes são informadas com uma mensagem de alerta.

\section{Supervisor $\times$ Setor}

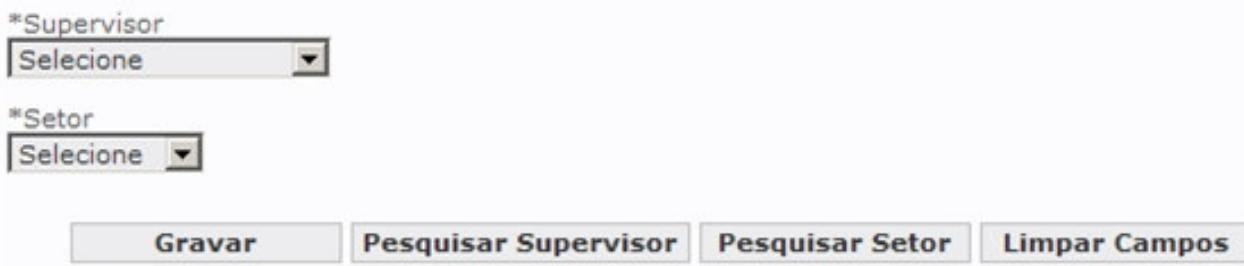

FIGURA 4.11 - Formulário de relação supervisor x setor

\subsubsection{Cadastro de Trabalhador}

O cadastro do trabalhador é destinado ao trabalhador que está ocupacionalmente exposto ao material radioativo na forma não selada. Esse cadastro será efetuado pelo s upervisor e opcionalmente pelo responsável do Grupo de Cálculo de Dose ou pelo responsável pelos Laboratórios de Monitoração In Vivo e In Vitro.

O cadastro é efetuado por meio de alguns passos que prevêem o preenchimento de dados para a identificação do trabalhador. A FIG. 4.12 apresenta o primeiro passo no cadastro de pessoal. Os campos que contém 0 caractere asterisco $\left(^{*}\right)$ são de preenchimento obrigatório. O campo "Nacionalidade" apresenta as opções "Brasileiro" e "Estrangeiro". Ao optar pela nacionalidade estrangeira os campos "CPF" e "RG" alteram-se para "Passaporte" e "Documento". Os campos que não contém o caractere asterisco $\left(^{*}\right)$ são de preenchimento opcional, como o "Documento de Identidade", "Peso" e "Altura". 


\section{Cadastro de Dados Pessoais de Trabalhadores}

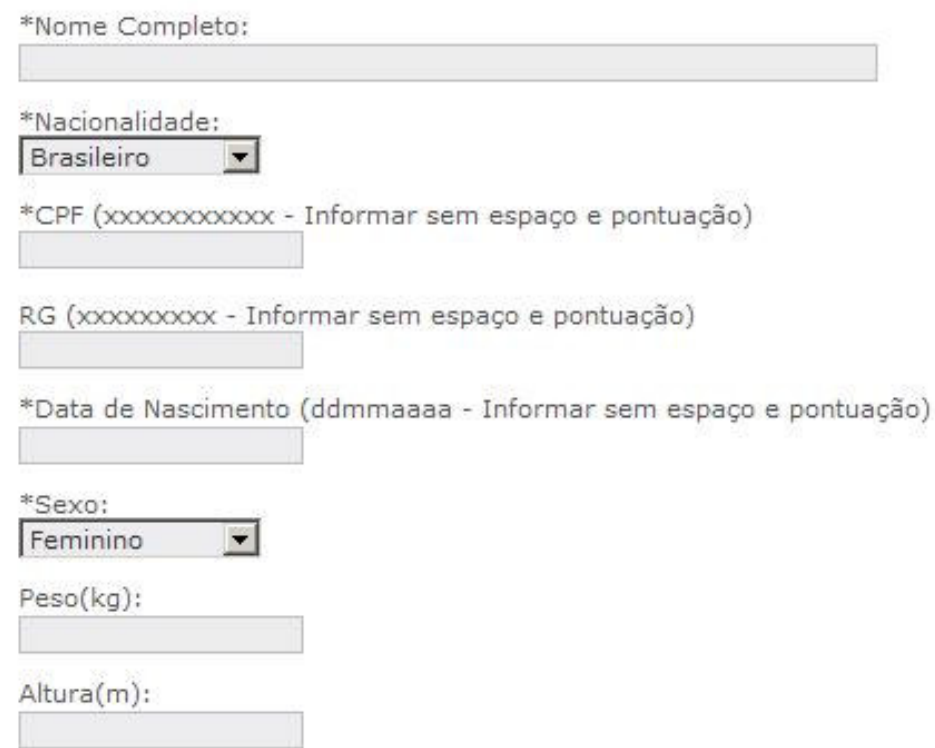

Gravar Limpar Campos

Pesquisar

Voltar

FIGURA 4.12 - Formulário de cadastro de trabalhador - primeiro passo

O segundo passo no preenchimento de cadastro é informar a instituição onde o trabalhador exercerá sua função. A FIG. 4.13 apresenta os seguintes campos "Instituição" e "Setor", todos eles são dados de preenchimento obrigatório, enquanto "Função" e "Início com a radiação" são dados de preenchimento recomendados, mas que não impedirá o cadastramento. 


\section{Cadastro de Trabalhadores Instituição onde Trabalha Atualmente}

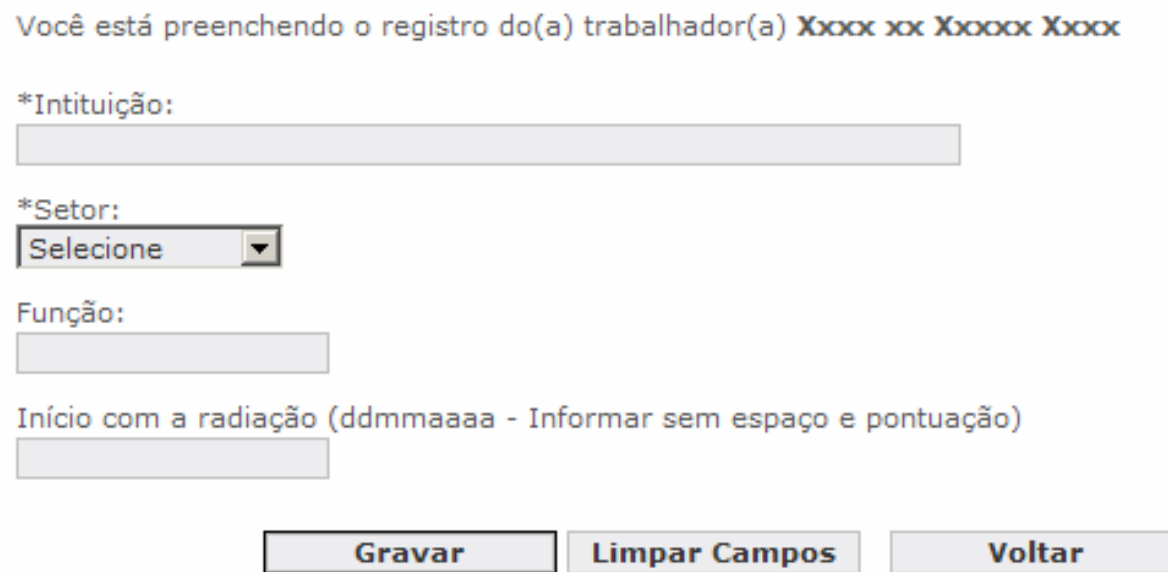

FIGURA 4.13 - Formulário de cadastro de trabalhador - segundo passo

O terceiro passo trata das informações relativas ao material radioativo que o trabalhador manuseia. A FIG. 4.14 apresenta os campos "Radioisótopo", "Estado Físico", "Composto", "Atividade (Bq)", "Manipulação \% de Tempo", "Risco" e "Modo de Incorporação". Todos os campos são de preenchimento obrigatório.

\section{Cadastro de Trabalhadores Informações Relativa com Material Radioativo}

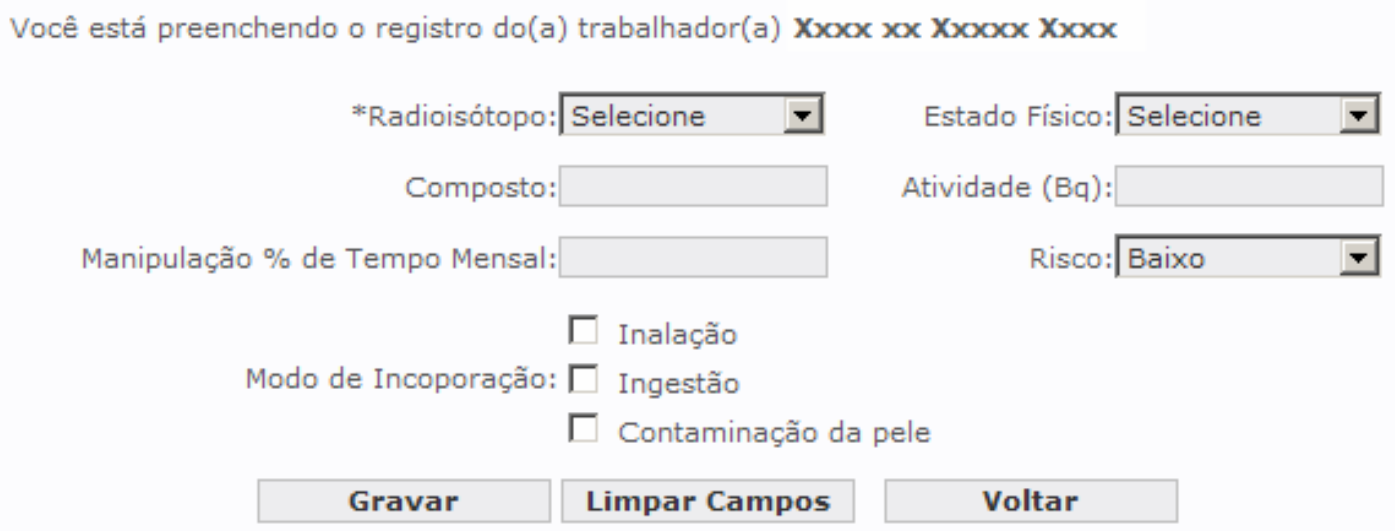

FIGURA 4.14 - Formulário de cadastro de trabalhador - terceiro passo 
No quarto passo deve-se informar os radioisótopos manuseados pelo trabalhador. A FIG. 4.15 apresenta os campos "Radioisótopo", "Início" e "Término".

\section{Cadastro de Trabalhador Radioisótopo com os Quais Trabalhou (ou Trabalha)}

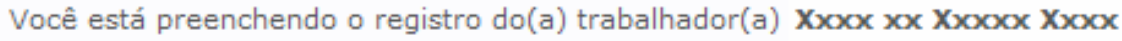

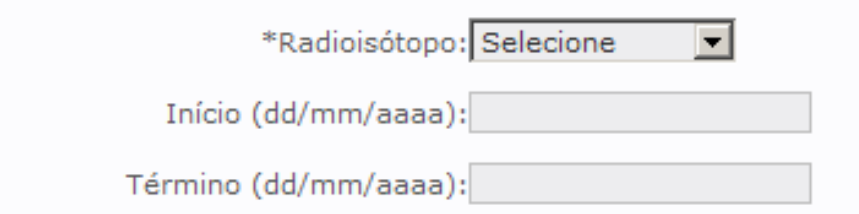

Gravar

Limpar Campos

Voltar

FIGURA 4.15 - Formulário de cadastro de trabalhador - quarto passo

Por fim, o quinto e último passo deve-se informar o tipo de monitoração adequada para o trabalhador sendo este dependente dos demais, pois o tipo de emissão do radioisótopo é que vai determinar o tipo de monitoração. A FIG. 4.16 apresenta os seguintes campos, "Monitoração" e "Observação".

\section{Cadastro de Trabalhador Tipo de Monitoração \\ Você está preenchendo o registro do(a) trabalhador(a) Xxxox xx Xxxxx Xxxx \\ *Monitoração: Selecione $\quad$

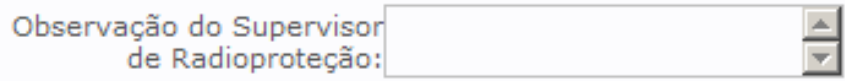

Gravar Limpar Campos Voltar

FIGURA 4.16 - Formulário de cadastro de trabalhador - quinto passo 


\subsubsection{Monitoração In Vivo}

Este módulo do IntDosWeb possui três formulários. Para efetuar a inserção da monitoração é preciso saber se o trabalhador está cadastrado na base de dados. Neste caso ao optar pelo menu Monitoração e Sub Menu In Vivo da FIG. 4.6 o primeiro formulário que o usuário irá visualizar é o Formulário de Pesquisa, apresentado na FIG. 4.17. Este formulário vem apenas com o campo para inserir o nome do trabalhador a ser pesquisado.

\section{Monitoração In Vivo}

Pesquisar trabalhadores

Nome:

I

Pesquisar

Yoltar

FIGURA 4.17 - Formulário de monitoração in vivo - pesquisa de trabalhador

Após acionar o botão "Pesquisar", um segundo formulário, Pesquisa de Trabalhadores será exibido conforme apresentado na TAB. 4.1. Neste formulário visualiza-se uma tabela com duas colunas sendo que a primeira contém um link com o nome do trabalhador e a segunda contém um link com seu Histórico. Ao clicar no link com o nome do trabalhador um terceiro formulário, Monitoração In Vivo, é visualizado, conforme apresentado na FIG. 4.18. 
TABELA 4.1 - Formulário de monitoração in vivo - resultado da pesquisa de trabalhador

\section{Pesquisa de Trabalhadores \\ Monitoração In Vivo \\ 2 registro(s) encontrado(s)}

\begin{tabular}{|l|l|}
\hline \multicolumn{2}{|c|}{ Nome } \\
\hline$X x x x x x x X x x y x X X x x x$ & Histórico \\
\hline Yyyyyy Yyyyyy & Histórico \\
\hline
\end{tabular}

Pode-se observar na parte superior do formulário, na FIG. 4.18, os dados pessoais do trabalhador como "Nome", "CPF", "Instituição", "Setor", "Função", "Início com a radiação" e seu(s) respectivo(s) supervisor(ers). Abaixo destas informações vem os campos para inserir os dados na monitoração in vivo, são eles, "Tipo de Monitoração", "Identificação do Relatório", "Data da Monitoração", "Freqüência", "Radionuclídeo", "Órgão”, “Atividade (Bq)", “LD” e "Observação".

Essas informações são obtidas por meio da monitoração do corpo inteiro efetuado pelo Laboratório de Monitoração In Vivo.

Vale ressaltar que somente os usuários do Laboratório de Monitoração In Vivo e usuários do Grupo de Cálculo de Dose têm acesso a estes formulários, conforme descrito nos itens 4.1.2 e 4.1.3.

Ao clicar no link "Histórico" da segunda coluna pode-se observar os resultados da monitoração. 


\section{Monitoração In Vivo}

Trabalhador: Xxxx xx Xxxxx Xxxx

CPF: $x x x \cdot x \times x \cdot x x x-x x$

Data de Nascimento: $x x x x-x x-x x$

Instiuição: $x \times x X$

Setor: $X X X X$

Função: $x x x x x x x x$

Início com a radiação: $x X / X x / X x X X$

Supervisor(es): $x \times x x x x x x$

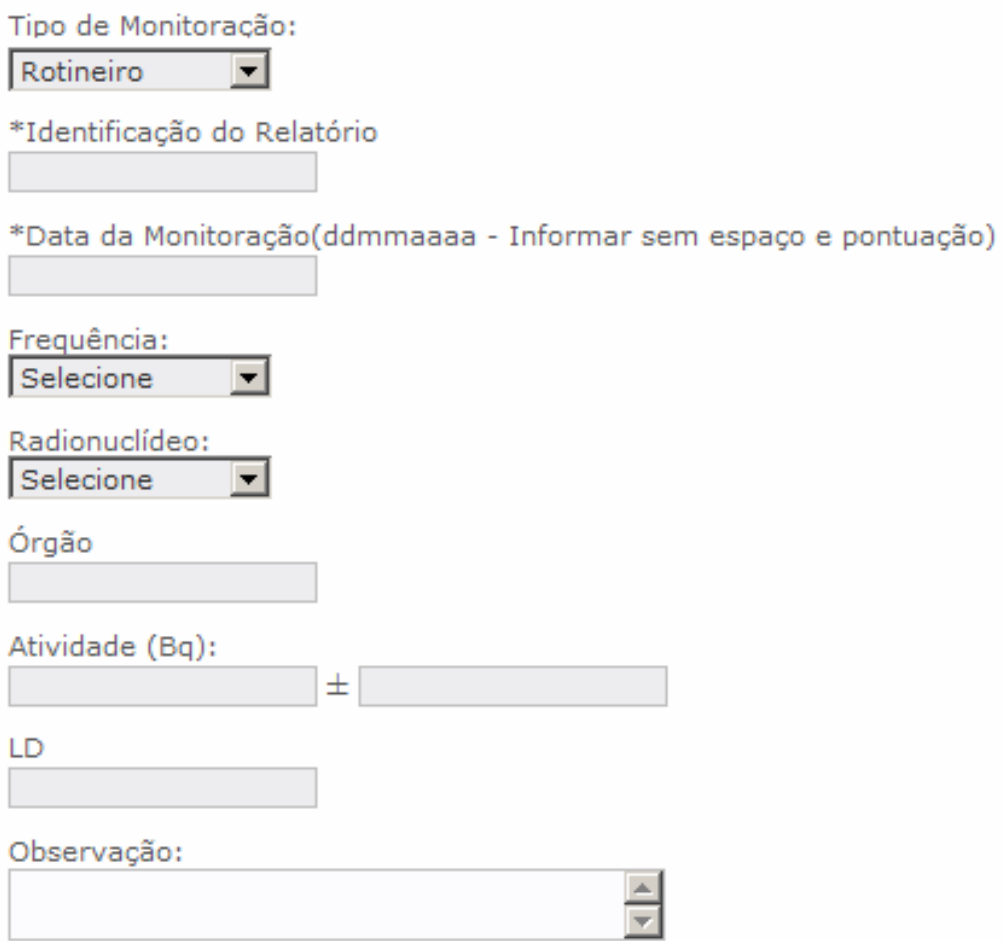

\begin{tabular}{l|l|l|}
\hline Gravar & Limpar Campos \\
\hline
\end{tabular}

FIGURA 4.18 - Formulário de monitoração in vivo - inserção dos dados da monitoração 


\subsubsection{Monitoração In Vitro}

O módulo da monitoração in vitro no IntDosWeb possui cinco formulários. Tal como feito na monitoração in vivo, começamos com o formulário de pesquisa apresentado na FIG. 4.19, pois antes de inserir os dados da monitoração in vitro deve-se verificar a existência do trabalhador na base de dados.

\section{Monitoração In Vitro}

Pesquisar trabalhadores Nome:

I

Pesquisar

FIGURA 4.19 - Formulário de monitoração in vitro - pesquisa de trabalhador

A FIG. 4.19 apresenta o formulário para efetuar a pesquisa do trabalhador por meio do nome. Ao efetuar esta pesquisa será visualizada a TAB. 4.2. Aqui, visualiza-se uma tabela com cinco colunas, sendo que a primeira coluna contém um link com o nome do trabalhador, as três colunas seguintes o método de análise Tório, Trítio e por Actinídeos, e a quinta coluna contém um link com o Histórico da monitoração para o trabalhador daquela linha. Vamos destacar nesse item a segunda, terceira e quarta coluna.

Após clicar no link "Tório" o usuário irá visualizar o formulário apresentado na FIG. 4.20. 
TABELA 4.2 - Formulário de monitoração in vitro - resultado da pesquisa de trabalhador

\section{Pesquisa de Trabalhadores Monitoração In Vitro}

2 registro(s) encontrado(s)

\begin{tabular}{|c|c|c|c|c|}
\hline Nome & & Etodo d & lise & \\
\hline 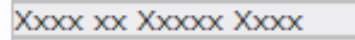 & Tório & Trítio & ACTAAN & Histórico \\
\hline Yyyyyy Yyyyyy & Tório & Trítio & ACTAAN & Histórico \\
\hline
\end{tabular}

Pode-se observar na parte superior do formulário na FIG. 4.20 os dados pessoais do trabalhador como "Nome", "CPF", "Instituição", "Setor", "Função", "Início com a radiação" e seu(s) respectivo(s) supervisor(ers). Abaixo destas informações vêm os campos para inserir os dados na monitoração in vitro por meio do método de análise para o Tório. Esses campos são "Tipo de Monitoração", "Identificação do Relatório", "Material Analisado", "Radionuclídeo", "Método", "Instituição", "FSS (Ficha de Solicitação de Serviço)", "Data da Coleta", "Massa de Th-232 ng/L", "Excreção diária micrograma/dia", "Atividade (Bq/dia)", "Incerteza (Bq/dia)" e "Observação". 


\section{Monitoração In Vitro - Tório}

Trabalhador: Xxox $\times x \times x \times x \times$ Xxox

CPF: $X X X, X X X . X X X-X X$

Data de Nascimento: $X X X X-X X-X X$

Instiuição: $x \times x \times$

Setor: $x \times x x$

Função: $x x x x x x x x$

Início com a radiação: $X X / X X / X X X X$

Supervisor(es): $x x x x x x x x$

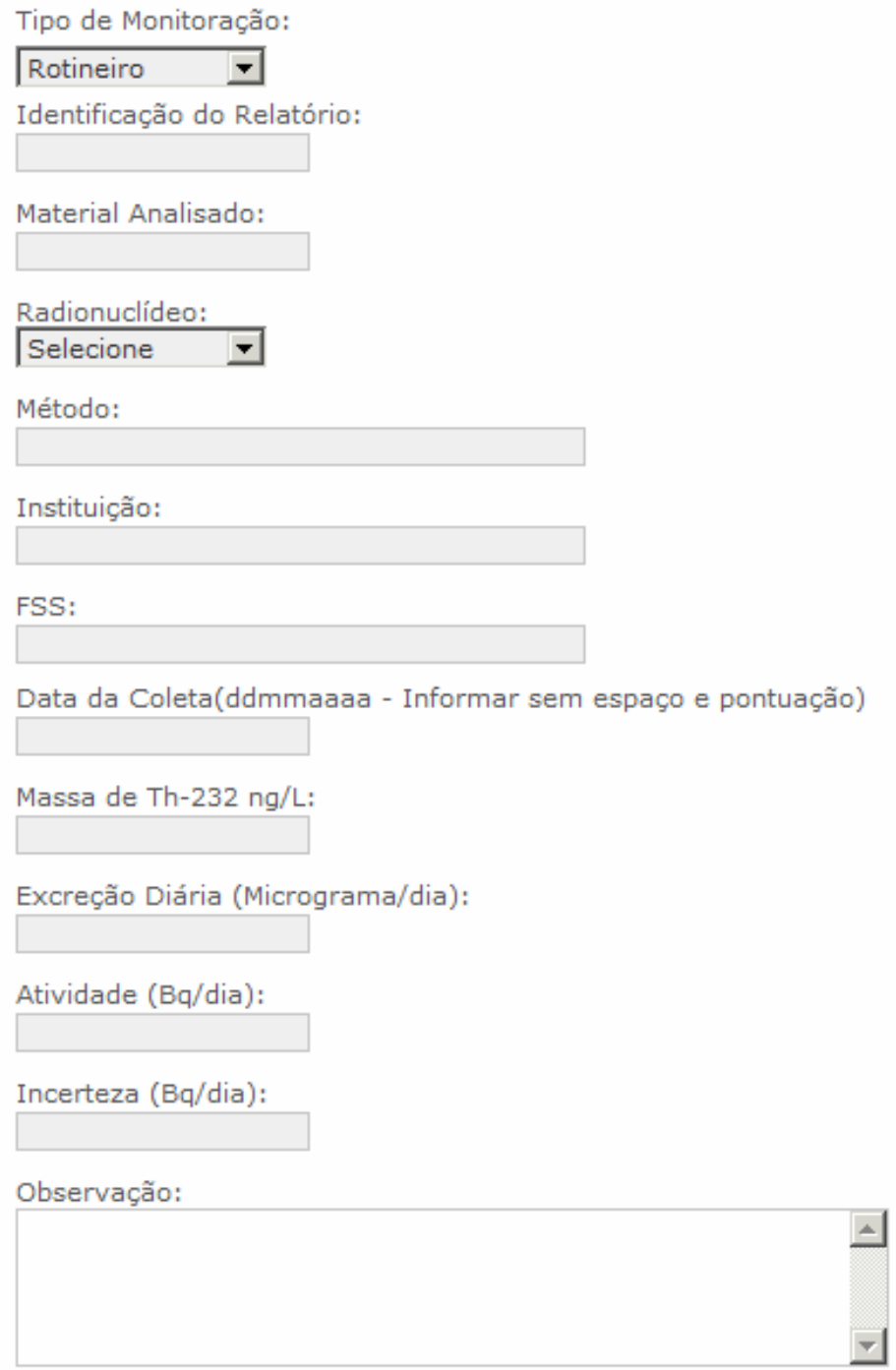

\begin{tabular}{|l|l|l|}
\hline Gravar & Limpar Campos \\
\hline
\end{tabular}

FIGURA 4.20 - Formulário de monitoração in vitro - inserção dos dados da monitoração in vitro para o método de análise tório 
A FIG. 4.21 apresenta o formulário para análise do Trítio. Pode-se observar na parte superior do formulário os dados pessoais do trabalhador sendo eles "Nome", "CPF", "Instituição", "Setor", "Função", "Início com a radiação" e seu(s) respectivo(s) supervisor(ers). Abaixo destas informações vêm os campos para inserir os dados na monitoração in vitro por meio do método de análise para o Trítio que são: "Tipo de Monitoração", "Identificação do Relatório", "Material Analisado", "Radionuclídeo", "Método", "Instituição", "FSS (Ficha de Solicitação de Serviço)", "Data da Coleta", "Excreção diária micrograma/dia", "Atividade (Bq/dia)", "Incerteza (Bq/dia)" e "Observação".

Na FIG. 4.22 o formulário apresenta os dados a serem inseridos para análise dos Actinídeos. Observa-se na parte superior do formulário os mesmo dados pessoais do trabalhador, como feito para análise do Tório e do Trítio. Abaixo destas informações vêm os campos para inserir os dados na monitoração in vitro por meio do método de análise dos actinídeos, ou seja, "Tipo de Monitoração", "Identificação do Relatório", "Material Analisado", "Radionuclídeos Quantificados", "Método", "Instituição", "FSS (Ficha de Solicitação de Serviço)", "Data da Coleta", "Atividade em Bq/L Th-232", "Atividade em Bq/L U-234", "Atividade em Bq/L U-235", "Atividade em Bq/L U-238", "Atividade em Bq/L Am241", "Atividade em Bq/L Pu-239/240" e "Observação".

Essas informações são obtidas por meio da monitoração de análise das excretas efetuadas pelo Laboratório de Monitoração In vitro.

Vale ressaltar que somente os usuários do Laboratório de Monitoração In vitro e usuários do Grupo de Cálculo de Dose tem acesso a estes formulários, conforme descrito nos itens 4.1 .2 e 4.1.4. 


\section{Monitoração In Vitro - Trítio}

Trabalhador: Xxxx xx Xxoxx Xxxx

CPF: $x x x \cdot x x x \cdot x x x-x x$

Data de Nascimento: $x x x x-x x-x x$

Instiuição: $x \times x x$

Setor: $x \times x x$

Função: $x \times x \times x X X X$

Início com a radiação: $x \times / x \times / x x x x$

Supervisor(es): $x x x x x x x x$

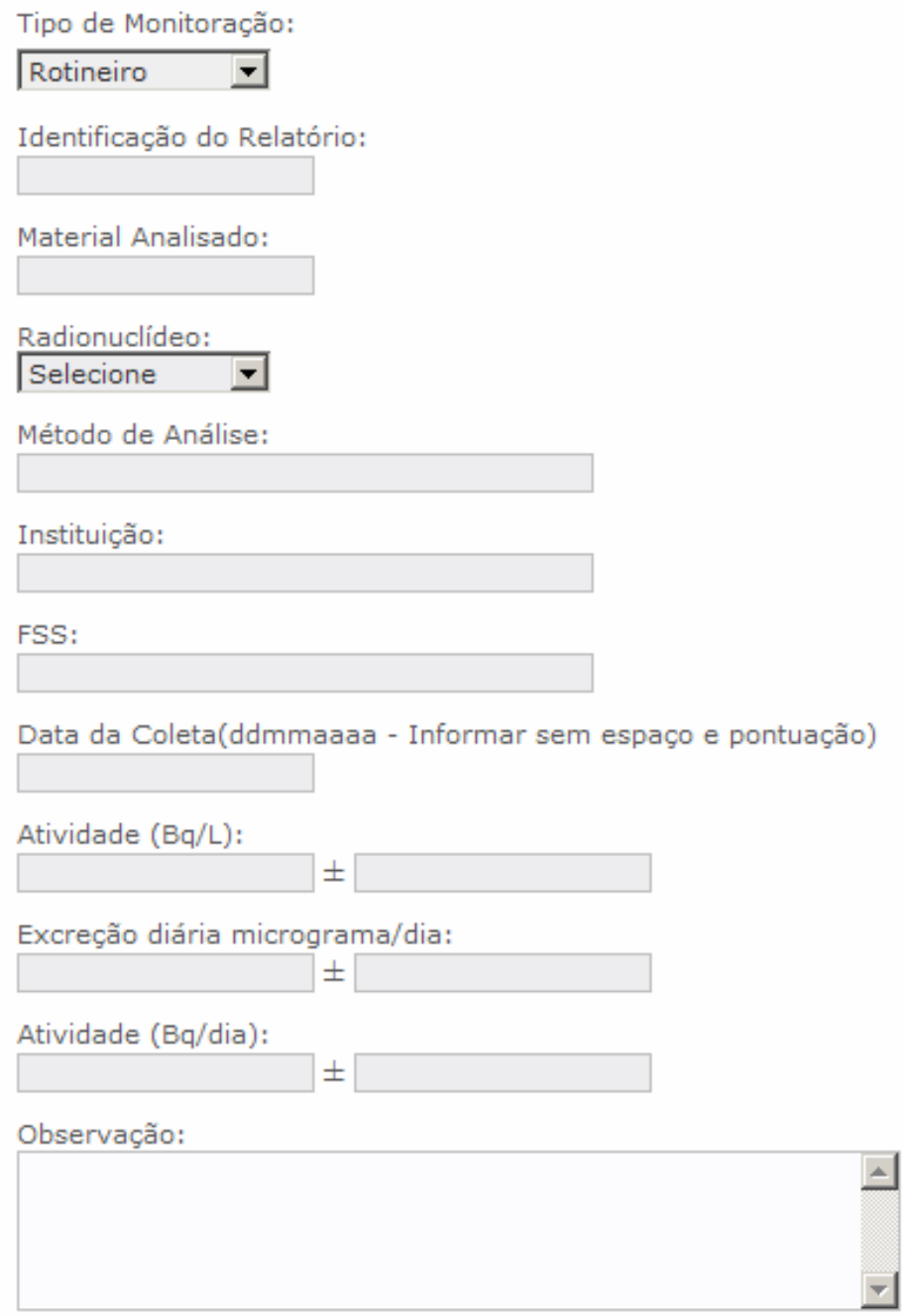

Tipo de Monitoração:

Identificação do Relatório:

Material Analisado:

Radionuclídeo:

Selecione

Método de Análise:

Instituição:

FSS:

Data da Coleta(ddmmaaaa - Informar sem espaço e pontuação)

Atividade $(\mathrm{Bq} / \mathrm{L})$

Excreção diária micrograma/dia:

Atividade (Bq/dia):

Observação:

$\Delta$

\begin{tabular}{l|l|l} 
Gravar & Limpar Campos \\
\hline
\end{tabular}

FIGURA 4.21 - Formulário de monitoração in vitro - inserção dos dados da monitoração in vitro para o método de análise trítio 


\section{Monitoração In Vitro - ACTAAN}

\section{Trabalhador: Xxxx $\mathbf{x x}$ Xxxxx Xxxx}

CPF: $X X X . X X X . X X X-X X$

Data de Nascimento: $x x x x-x x-x x$

Instiuição: $x \times x x$

Setor: $x x x x$

Função: $x x x x x x x x$

Início com a radiação: $x \times / x x / x \times x x$

Supervisor(es): $x x x x x x x x$

Tipo de Monitoração:

Rotineiro $\quad \mathbf{}$

Identificação do Relatório:

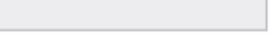

Material Analisado:

Radionuclídeos Quantificados:



Método de Análise:

Instituição:

FSS:

Data da Coleta(ddmmaaaa - Informar sem espaço e pontuação)

Atividade em Bq/L Th-232:

$\pm$

Atividade em Bq/L U-234:

$\pm$

Atividade em Bq/L U-235:

\begin{tabular}{l} 
Atividade em Bq/LU-235: \\
\hline
\end{tabular}

Atividade em Bq/L U-238:

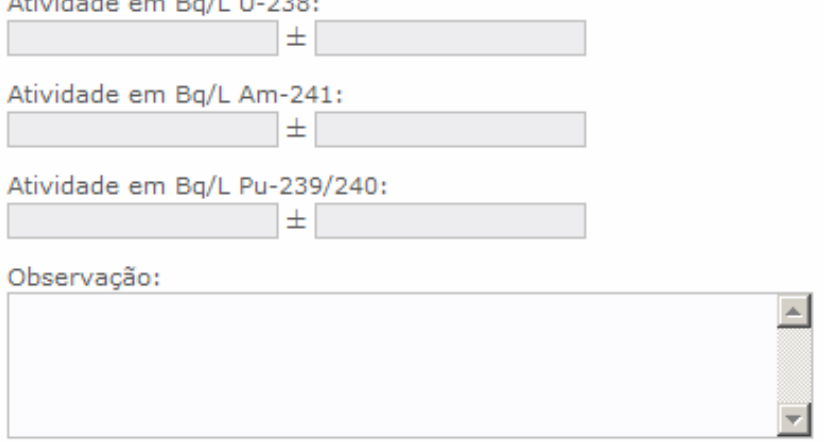

Gravar

Voltar

FIGURA 4.22 - Formulário de monitoração in vitro - inserção dos dados da monitoração in vitro para o método actinídeos 


\subsubsection{Cálculo da Dose}

Presentemente, o Grupo de Cálculo de Dose recebe os relatórios de medida dos Laboratórios de Monitoração In Vivo e In Vitro, respectivamente em planilha Excel e em documento editado no Word. Pretende-se com a implementação do IntDosWeb que o fluxo das informações passe a ser efetuada eletronicamente, e os laboratórios registrem os dados conforme mencionado nos itens 4.2 .4 e 4.2 .5 .

No IntDosWeb o cálculo de dose é efetuado em três etapas. A primeira etapa é verificar para qual monitoração existente na base de dados ainda não foi efetuada a avaliação da dose. Para tanto, foi criado um formulário para efetuar uma pesquisa por período, o que é apresentado na FIG. 4.23.

\section{Pesquisa de Monitoração para Cálculo da Dose}

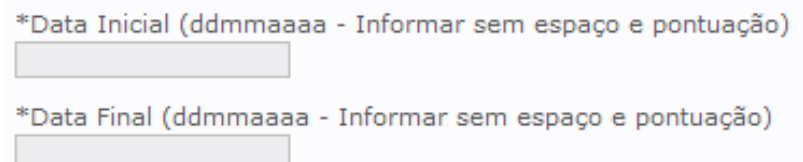

Pesquisar Limpar Campos

FIGURA 4.23 - Formulário de pesquisa de monitoração para cálculo da dose

O formulário da FIG. 4.23 contém dois campos, que são: "Data Inicial" e "Data Final". Esses campos são de preenchimento obrigatório e caso o usuário não preencha corretamente estes campos, o IntDosWeb emitirá uma mensagem de erro. A mensagem de erro é apresentada na FIG. 4.24. 


\section{Atenção}

$\therefore$ Favor, informar a data inicial.

.: Favor, informar a data final.

Clique aqui para voltar.

FIGURA 4.24 - Mensagem de erro - pesquisa de monitoração para cálculo da dose

Após os campos preenchidos corretamente o sistema irá gerar uma tabela, TAB. 4.3, com o registro das monitorações realizadas na data informada. Esta tabela poderá ser salva em planilha Excel de acordo com a conveniência.

A TAB. 4.3 apresenta os resultados das medidas separada em blocos de acordo com o tipo de análise realizado e informa, na coluna 1 e na coluna 3 os códigos de monitoração e do trabalhador que são gerados automaticamente pelo sistema. O código do trabalhador é gerado na etapa de cadastramento do trabalhador, isto é na finalização da inserção dos dados pessoais. O código da monitoração é gerado na etapa de inserção dos dados de medidas in vivo ou in vitro.

A segunda etapa é a avaliação da dose pelo Grupo de Cálculo de Dose. A avaliação da incorporação e da dose efetiva comprometida é efetuada utilizando um programa auxiliar AIDE ${ }^{(43)}$. Este programa foi desenvolvido pelo Dr. Luiz Bertelli, por solicitação de um programa de treinamento da (ARCAL) para ser utilizado na harmonização das avaliações das doses para os paises membros da América Latina.

A terceira etapa é a de inserir os resultados do cálculo efetuado no AIDE para o IntDosWeb. Para inserir os dados, o usuário deverá clicar no Menu Dose e Sub Menu Cálculo de Dose da FIG. 4.5 para acessar o formulário da FIG. 4.25. Os campos "Código de Trabalhador", "Código da Monitoração" e "Método de Análise" da FIG. 4.25 são aqueles constantes na TAB. 4.3. Ao informar este dados, o sistema irá gerar o formulário da FIG. 4.26, onde os campos "Modo de Incorporação", "Forma de Incorporação", "Classe", "AMAD", 
"Tempo depois da incorporação", "Incorporação (Bq)" e "Cálculo da Dose (mSv)" devem ser preenchidos.

TABELA 4.3 - Resultado da pesquisa de monitoração para cálculo da dose

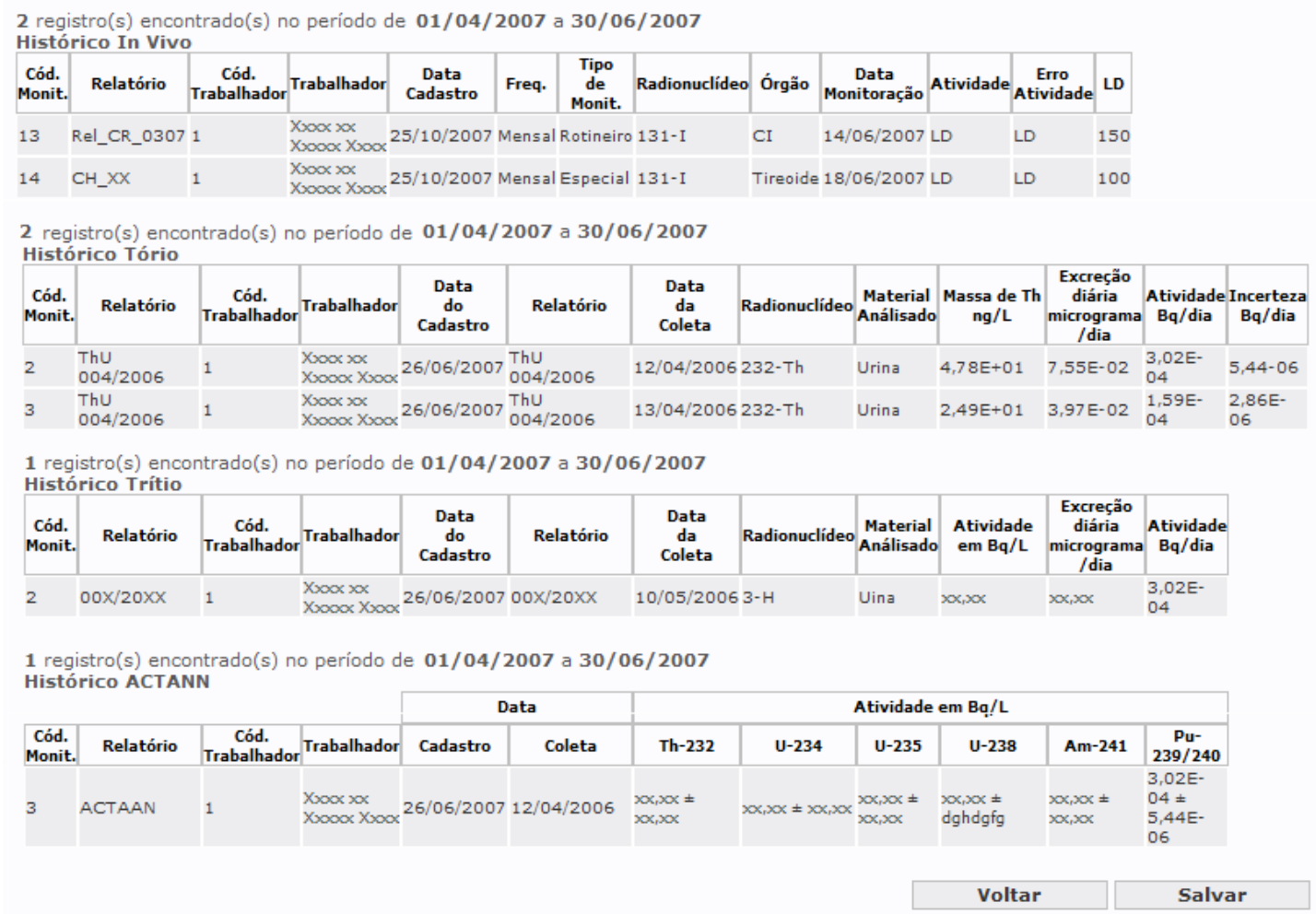

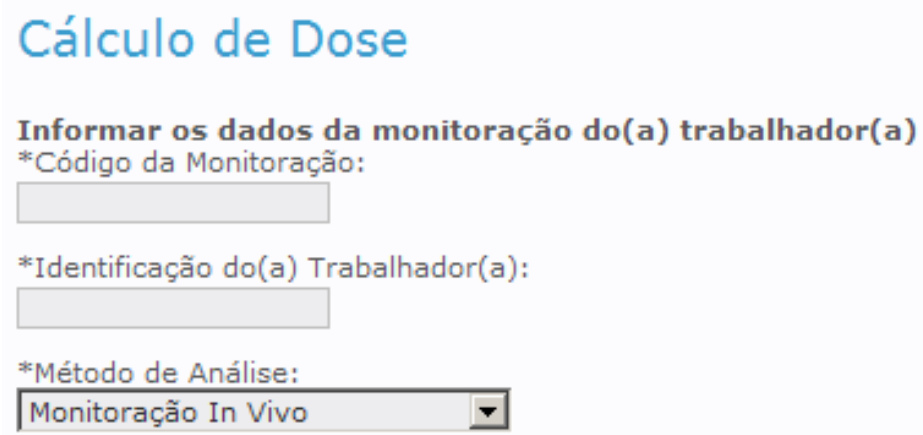

FIGURA 4.25 - Formulário para pesquisar o registro do trabalhador e monitoração 


\section{Cálculo de Dose}

\section{Trabalhador: Xxxx xx Xxxxx Xxxx}

CPF: $x x x \cdot x x x \cdot x x x-x x$

Data de Nascimento: $x x x x-x x-x x$

Instiuição: $x x x x$

Setor: $x x x x$

Função: $x x x x x x x x$

Início com a radiação: $x \times / X x / \times x \times x$

Supervisor(es): $x x x x x x x x$

Cód. da Monitoração: 13

Relatório: Rel_CR_0307

Freqüência: Mensal

Data da Monitoração: 14/06/2007

Tipo de Monitoração: Rotineiro

Radionuclídeo: 131-I

Órgão: CI

Atividade: $L D \pm L D$

LD: 150

Obs:

Modo de Incorporação:

Inalação

Forma de Incorporação:

Agudo $>$

Classe:

$\mathrm{F} \rightleftharpoons$

AMAD:

Tempo depois da incorporação:

ra

Incorporação (Bq):

$\pm \square$

Cálculo da Dose (mSv):

$\pm \square$

FIGURA 4.26 - Formulário para inserir resultado da dose 


\subsubsection{Relatórios de Dose}

O IntDosWeb dispõe de opções para gerar relatórios individuais e relatórios com resultados do cálculo de dose das monitorações in vivo e in vitro de todos os trabalhadores da instalação da área de atuação de cada supervisor.

O relatório gerado para o supervisor contém os dados dosimétricos, a incorporação e dose efetiva comprometida e os dados de identificação dos trabalhadores.

\subsubsection{Relatório In Vivo e In Vitro}

A FIG. 4.27 apresenta o formulário pra gerar os relatórios para as medidas in vivo e in vitro. Este formulário é subdivido em três funções: "Relatório Supervisor", "Relatório Individual" e "Relatórios Emitidos".

A função "Relatório Supervisor", gera um único relatório com os dados de todos os trabalhadores da instalação. Os seguintes campos devem ser preenchidos: "Setor", "Método de Análise", "Tipo de Monitoração", "Freqüência", "Data Inicial" e "Data Final".

A função "Relatório Individual" é para gerar relatórios individuais dos trabalhadores. Os seguintes campos devem ser preenchidos: "CPF", "Método de Análise", "Tipo de Monitoração", "Freqüência", "Data Inicial" e "Data Final".

A função "Relatórios Emitidos" é para pesquisar os relatórios gerados. A pesquisa poderá ser efetuada informando o código completo do relatório ou parte do mesmo. 


\section{Relatório Monitoração Interna}
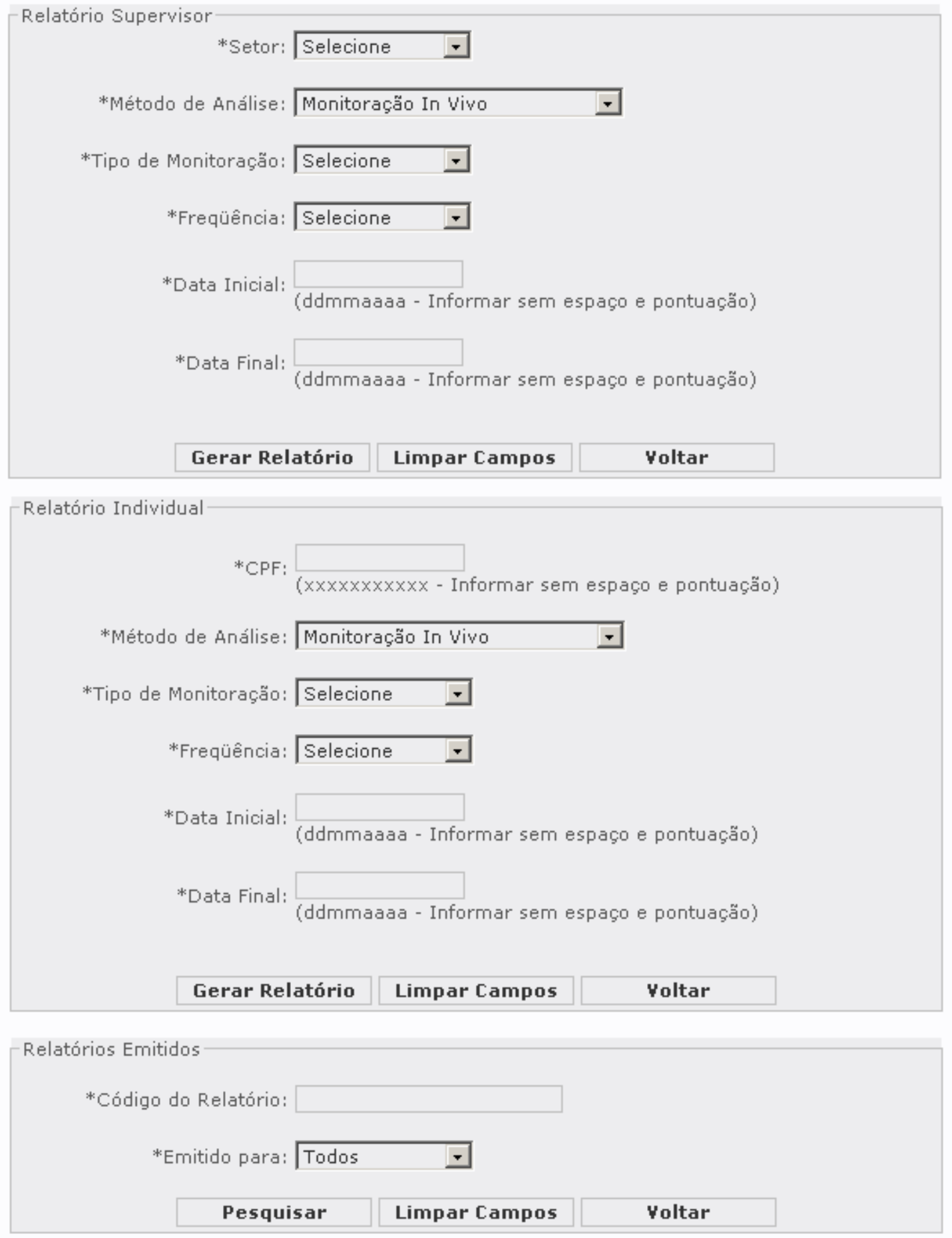

FIGURA 4.27 - Formulário para gerar o relatório do cálculo de dose da monitoração in vivo e in vitro 


\section{RESULTADOS E DISCUSSÕES}

O IntDosWeb é um sistema computadorizado para armazenamentos dos dados dos trabalhadores expostos ao material radioativo, sob a forma não selada, implementado em uma arquitetura cliente-servidor, com interface gráfica, utilizando linguagem de programação PHP, para sistemas web dinâmicos, banco de dados PostgreSQL e servidor web Apache.

\subsection{Login}

O passo inicial para realizar o acesso ao sistema é a partir de um Login e uma Senha. O usuário informará seu nome de acesso e senha, o sistema fará uma autenticação. Sendo os dados verdadeiros, o usuário será encaminhado para página inicial de acordo com o seu perfil. A FIG. 5.1 ilustra o formulário de autenticação.

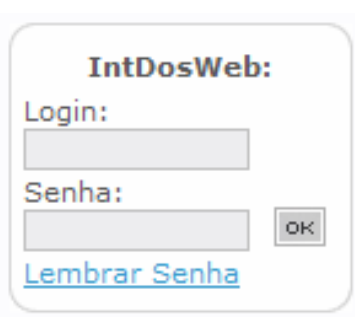

FIGURA 5.1 - Formulário de autenticação de usuários

\subsection{Cadastro}

\subsubsection{Cadastro de Usuários}

No capítulo 4, item 4.2.1, foi apresentado como efetuar o cadastro de usuários de acesso ao sistema IntDosWeb. A partir do banco de dados formado por esse cadastro, o sistema permite a consulta dos usuários que pode ser realizada por login, do nome do usuário ou por grupo de usuários 
("Administrador", "GCD”, "In Vivo", "In Vitro", "Supervisor" ou "Trabalhador"), conforme apresentado na FIG. 5.2.

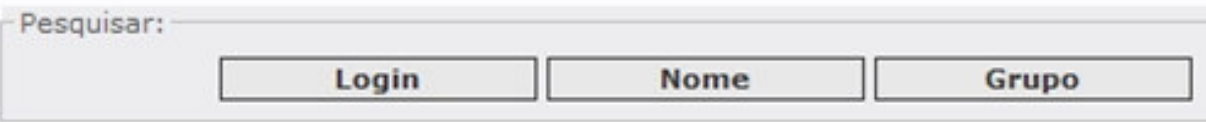

Voltar

FIGURA 5.2 - Pesquisa de usuários, parte do formulário cadastro de usuários

Após o preenchimento do campo específico e o botão de pesquisa selecionado, a TAB. 5.1 é apresentada. Convém salientar que, caso o preenchimento do campo for omitido, a tabela apresentará o total de usuários cadastrados, exceto nas pesquisas efetuadas por grupo, uma vez que há a necessidade de especificar o perfil desejado.

TABELA 5.1 - Pesquisa de usuários de acesso efetuada por nome Pesquisa de Usuários de Acesso Efetuada por Nome 6 registro(s) encontrado(s)

\begin{tabular}{|l|l|l|l|}
\hline Nome & Username & Permissão & Status \\
\hline Administrador & Administrador & Admnistrador & Ativo \\
\hline GCD & GCD & GCD & Ativo \\
\hline In Vitro & InVitro & In Vitro & Ativo \\
\hline In Vivo & InVivo & In Vivo & Ativo \\
\hline Supervisor & Supervisor & Supervisor & Ativo \\
\hline Trabalhador & Trabalhador & Trabalhador & Ativo \\
\hline
\end{tabular}

Voltar

Selecionando um usuário na tabela de pesquisa um formulário para alteração de login aparecerá conforme mostrado na FIG. 5.3. Por meio deste formulário é possível realizar a alteração de senha do Usuário, do Grupo a que este Usuário pertence e o seu status de Ativo para Inativo e vice-versa. Cabe dizer que, se o status do usuário estiver como "Inativo", o mesmo não conseguirá 
acessar o sistema. Após as alterações realizadas no referido formulário é necessário selecionar o botão "Salvar" de maneira a validar todo o processo descrito anteriormente.

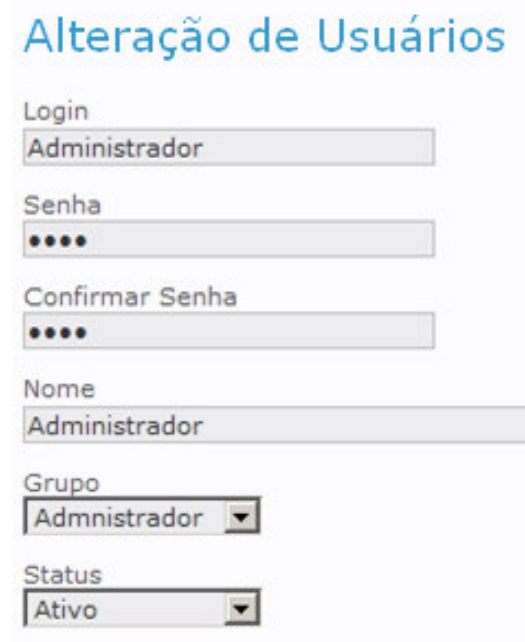

Salvar Voltar

FIGURA 5.3 - Formulário para alteração de dados do usuário

\subsubsection{Cadastro de Trabalhadores}

Quando o formulário cadastro de trabalhadores é selecionado, conforme descrito em 4.2.3 existe a possibilidade de se realizar uma pesquisa por trabalhadores por meio do campo "Nome" e botão "Pesquisar". Um exemplo do resultado desta pesquisa é apresentado na TAB. 5.2.

TABELA 5.2 - Pesquisa de trabalhadores

Pesquisa de Trabalhadores
2 registro(s) encontrado(s)
\begin{tabular}{|l|c|c|c|c|}
\hline Nome & Intituição & $\begin{array}{c}\text { Material } \\
\text { Radioativo }\end{array}$ & Radioisótopo & $\begin{array}{c}\text { Tipo } \\
\text { de } \\
\text { Monitoração }\end{array}$ \\
\hline Xxxx xx Xxxxx Xxxx & $\frac{\text { Preenchido }}{\text { Yyyyyy Yyyyyy }}$ & Preenchido & Preenchido & Preenchido Impressão \\
\hline
\end{tabular}

Voltar 
Observa-se que a pesquisa de trabalhadores apresenta seis colunas: "Nome”, "Instituição", "Material Radioativo", "Radioisótopo", "Tipo de Monitoração" e "Impressão". Cada uma destas colunas, para cada trabalhador, apresenta um status de "Preenchido", no caso dos dados estarem completos de acordo com o item 4.2.3, ou "Preencher", se o campo não estiver preenchido. É possível ainda realizar a alteração dos dados da coluna, conforme mostrado na FIG. 5.4 para dados pessoais de trabalhador, FIG. 5.5 para dados da Instituição, FIG. 5.6 para dados sobre o Material Radioativo, FIG. 5.7 para dados sobre o radioisótopo, FIG. 5.8 para o tipo de monitoração e finalmente a FIG. 5.9 apresenta o formulário de impressão.

\section{Alteração dos Dados Pessoais de Trabalhadores}

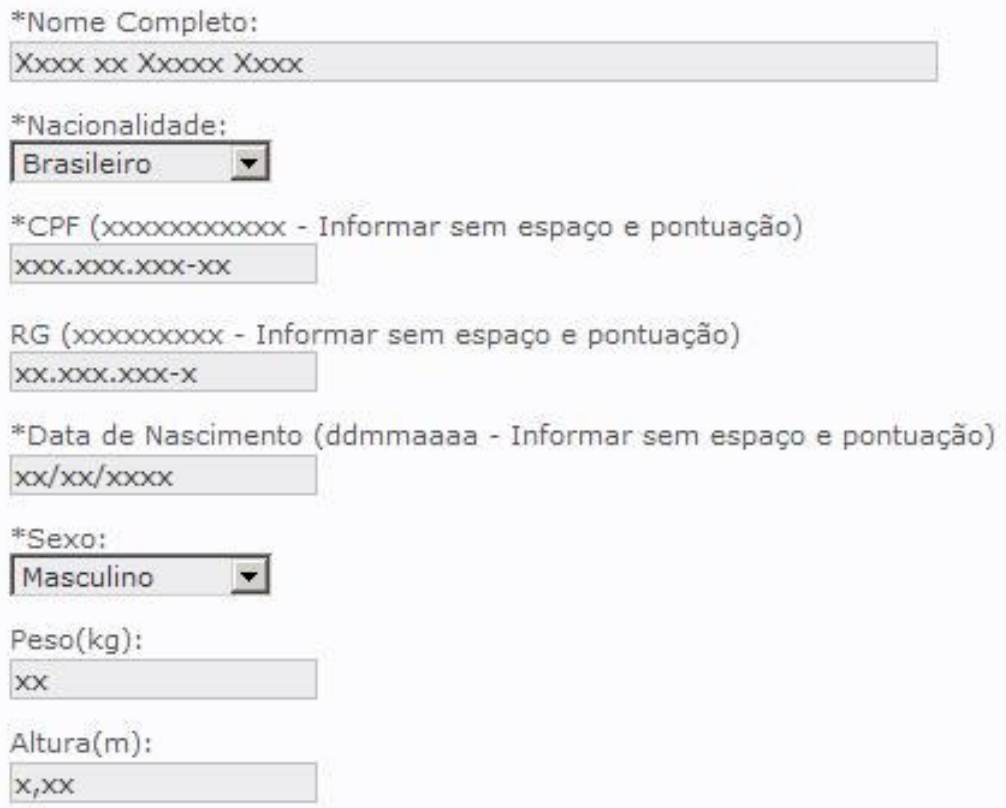

FIGURA 5.4 - Formulário para alteração de dados do trabalhador 


\title{
Atualização de Tabalhadores Instituição onde Trabalha Atualmente
}

\author{
Registro do(a) trabalhador(a) $\mathbf{X} \mathbf{x} \mathbf{x} \mathbf{x} \mathbf{x} \mathbf{x} \mathbf{X} \mathbf{x} \mathbf{x} \mathbf{x} \mathbf{X} \mathbf{X x \mathbf { x }}$ \\ *Intituição: \\ $\mathrm{Xxxx}$ \\ *Setor: \\ $x x x-x x x x$ \\ Função: \\ $X X X X X X X X$ \\ Início com a radiação (ddmmaaaa - Informar sem espaço e pontuação) \\ $x x / x x / x x x x$
}

\section{Salvar $\quad$ Voltar}

FIGURA 5.5 - Formulário para alteração de dados do trabalhador - instituição

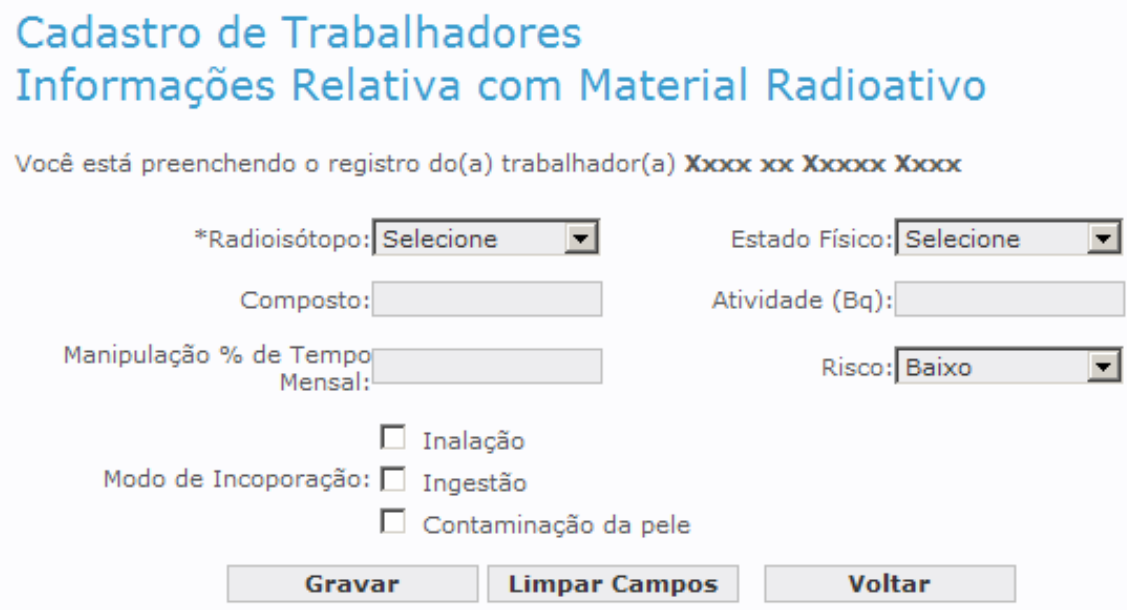

Registro(s) Encontrado(s)

1 registro(s) encontrado(s)

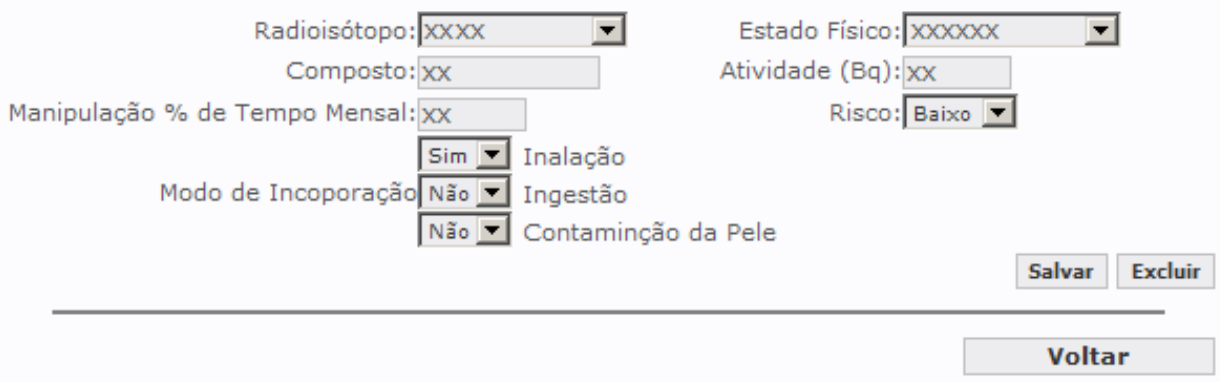

FIGURA 5.6 - Formulário para alteração de dados do trabalhador - material radioativo 


\section{Cadastro de Trabalhador}

Radioisótopo com os Quais Trabalhou (ou Trabalha)

Você está preenchendo o registro do(a) trabalhador(a) $\mathbf{X} \mathbf{x} \mathbf{x} \mathbf{x} \mathbf{x} \mathbf{x} \mathbf{X} \mathbf{x} \mathbf{x} \mathbf{x} \mathbf{x} \mathbf{X} \mathbf{x} \mathbf{x}$

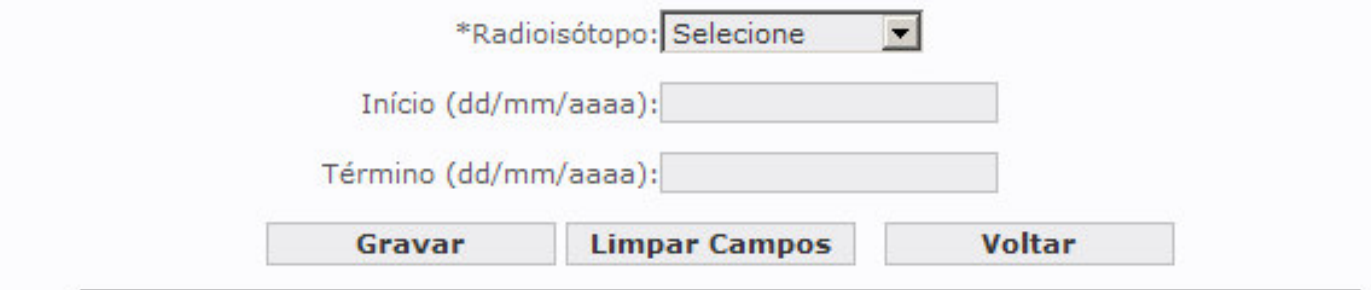

Radioisótopo(s) Encontrado(s)

1 registro(s) encontrado(s)

\begin{tabular}{|c|c|c|}
\hline Radioisótopo & Início & Término \\
\hline XXXXX & $\nabla \mathrm{xx} / \mathrm{xx} / \mathrm{x} \mathrm{x} \mathrm{x} \mathrm{x}$ & $x x / x x / x x x x$ \\
\hline
\end{tabular}

Voltar

FIGURA 5.7 - Formulário para alteração de dados do trabalhador - radioisótopo

Atualização de Trabalhador

Tipo de Monitoração

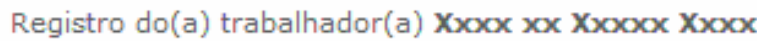

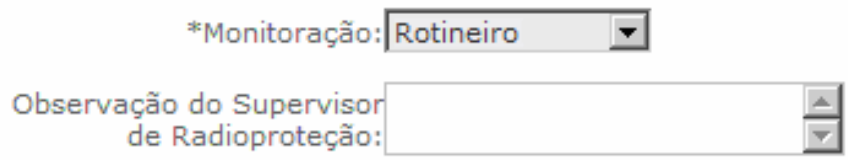

Salvar

Voltar

FIGURA 5.8 - Formulário para alteração de dados do trabalhador - tipo de monitoração 


\section{CADASTRO DE TRABALHADOR - DOSIMETRIA INTERNA}

Nome Completo: $X_{x x x} x x X_{x x x x} X_{x x x}$

CPF: $x x x \cdot x x x \cdot x x x-x x$

Sexo: $X X X X X X X X$

Intituição Completo: $x x x x$

Setor: $x \times x X$
$R G: X X . X X X . X X X-X$

Peso $(\mathrm{kg}): x X$
Nacionalidade: $x \operatorname{xx} x x x x x$

Data de Nascimento: $X X X X-X X-X x$ Altura $(m): x_{1} x x$

Informações relativas do trabalho com material radioativo:

\begin{tabular}{|l|c|c|c|c|c|c|}
\hline Radioisótopo & $\begin{array}{c}\text { Estado } \\
\text { Físico }\end{array}$ & Composto & Atividade (Bq) & $\begin{array}{c}\text { Manipulação } \\
\% \text { de } \\
\text { tempo mensal }\end{array}$ & $\begin{array}{c}\text { Incorporação } \\
\text { Modo } \\
\text { IG CP }\end{array}$ & Risco \\
\hline$X X X X X$ & $X X X X X X X$ & $X X$ & $X X$ & $X X$ & $S i m$ Não Não & Baixo \\
\hline
\end{tabular}

Indique os radioisótopos com os quais trabalhou (ou trabalha) em outras instalações:

\begin{tabular}{l|l|l|}
\hline Radioisótopo & Início & Término \\
\hline$X X X X$ & $X X / X X / X X X X$ & $X X / X X / X X X X$ \\
\hline
\end{tabular}

Tipo de Monitoração: Rotineiro

Observação do Supervisor de Radioproteção:

Local e Data:

\begin{tabular}{|l|l|l|l|}
\hline $\begin{array}{l}\text { Assinatura do } \\
\text { Usuário }\end{array}$ & $\begin{array}{l}\text { Assinatura e Carimbo da } \\
\text { Imediata } \\
\text { da Instalação }\end{array}$ & $\begin{array}{l}\text { Assinatura da } \\
\text { Chefia }\end{array}$ & $\begin{array}{l}\text { Assinatura e Carimbo do } \\
\text { Supervisor } \\
\text { de Proteção Radiológica }\end{array}$ \\
\hline & & \\
\hline
\end{tabular}

Método de Medida Sugerida:

Freqüência Sugerida:

Observações da Dosimetria:

Data

Carimbo/Assinatura

Centro de Metrologia das Radiações - CMR

1 a via - Cáculo de Dose Interna $2^{\mathrm{a}}$ via - Laboratório de Dosimetria Interna $3^{\mathrm{a}}$ via - Proteção Radiológica

FIGURA 5.9 - Formulário de impressão da ficha cadastral do trabalhador 


\subsubsection{Relação Supervisor x Setor}

No capítulo 4, item 4.2.2, foi visto como é realizado a relação entre supervisor e setor. A FIG. 5.10 mostra que é possível realizar a pesquisa pelo campo "Supervisor" e pelo campo "Setor", sendo possível realizar as alterações de setores por supervisor, tanto para alterar o setor ou excluir o mesmo da relação daquele supervisor especifico. O mesmo ocorre quando a pesquisa é realizada por setor. Vale ressaltar que a combinação nos campos Supervisor e Setor concatena as informações trazidas diretamente do banco de dados.

\section{Supervisor $x$ Setor}

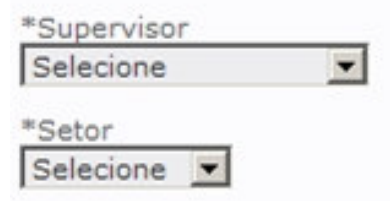

Gravar Pesquisar Supervisor Pesquisar Setor

Limpar Campos

4 registro(s) encontrado(s) para o Supervisor Supervisor 01

\begin{tabular}{|l|l|l|l|}
\hline CEN-R & Salvar & Excluir \\
\hline CTR-P & Salvar & Excluir \\
\hline CEN-SRP \\
\hline CR-GA
\end{tabular}

FIGURA 5.10 - Formulário de pesquisa relação supervisor x setor

\subsection{Monitoração In Vivo}

O acesso ao histórico da monitoração in vivo é realizado por meio do Menu Monitoração e do Sub Menu In Vivo da FIG. 4.6. Conforme citado anteriormente, somente possuem acesso ao histórico de monitoração in vivo o Laboratório de Monitoração In Vivo e o Grupo de Cálculo de Dose. A FIG. 5.11 mostra um histórico da monitoração individual in vivo, que teve suas informações inseridas conforme mencionado no item 4.2.4. 


\section{Histórico de Monitoração Individual Interna}

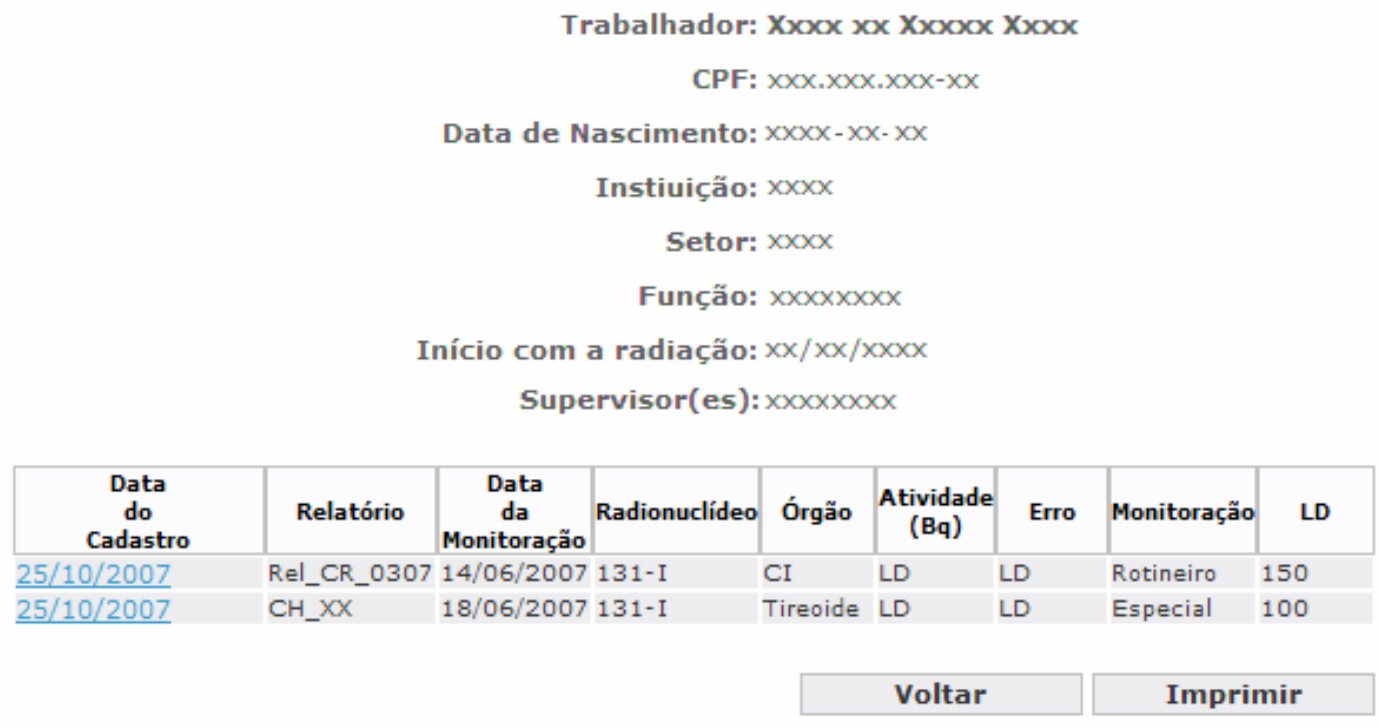

FIGURA 5.11 - Histórico de monitoração individual interna in vivo

Pode-se observar os dados pessoais do trabalhador e o histórico de medições por data, radionuclídeo, órgão, atividade (Bq), erro, tipo de Monitoração e o Limite de Detecção. Eventualmente a alteração dos dados pode ser realizada selecionando o campo "Data do Cadastro". Neste caso, o formulário de alteração é apresentado conforme na FIG. 5.12. Observa-se que o formulário também apresenta os dados pessoais do trabalhador. 


\title{
Atualização Monitoração Individual Interna In Vivo
}

\author{
Trabalhador: Xxxx $\mathbf{x x}$ Xxxxx $\mathbf{X x x x}$ \\ CPF: $x x x \cdot x x x . x x x-x x$
}

Data de Nascimento: $x x x x-x x-x x$

Instiuição: $x x x x$

Setor: $x x x x$

Função: $x x x x x \times x x$

Início com a radiação: $x x / x x / x x x x$

Supervisor(es): $x \times x \times x \times x x$

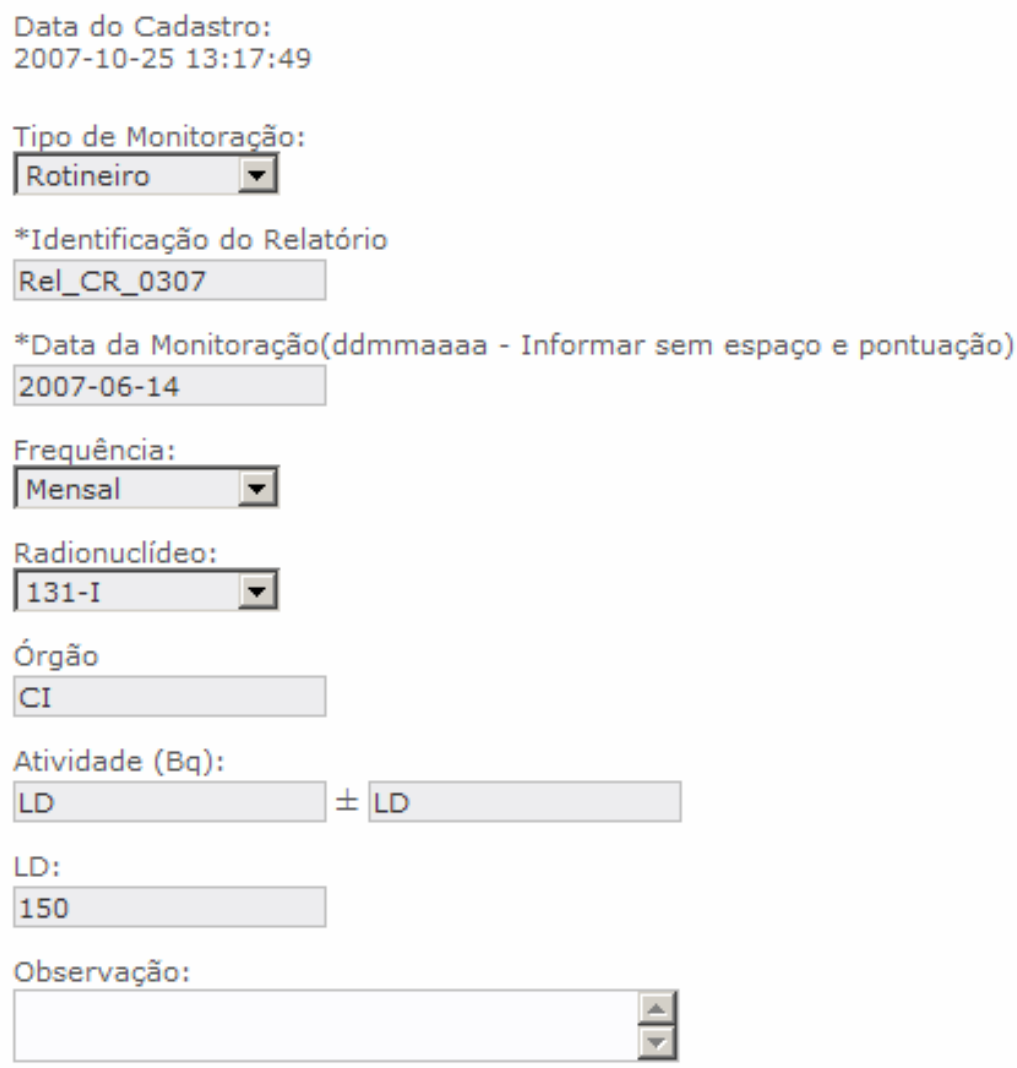

Salvar Voltar

FIGURA 5.12 - Formulário para alteração de dados da monitoração in vivo 


\subsection{Monitoração In Vitro}

O acesso ao histórico da Monitoração In Vitro é efetuado por meio do Menu Monitoração e do Sub Menu In Vitro da FIG. 4.7. Neste caso, somente possuem acesso ao Histórico de Monitoração In Vitro o Laboratório de Monitoração In Vitro e o Grupo de Cálculo de Dose. A FIG. 5.13 mostra um histórico da monitoração individual in vitro, que teve suas informações inseridas conforme mencionado no item 4.2.5.

\section{Histórico de Monitoração Individual Interna - In Vitro}
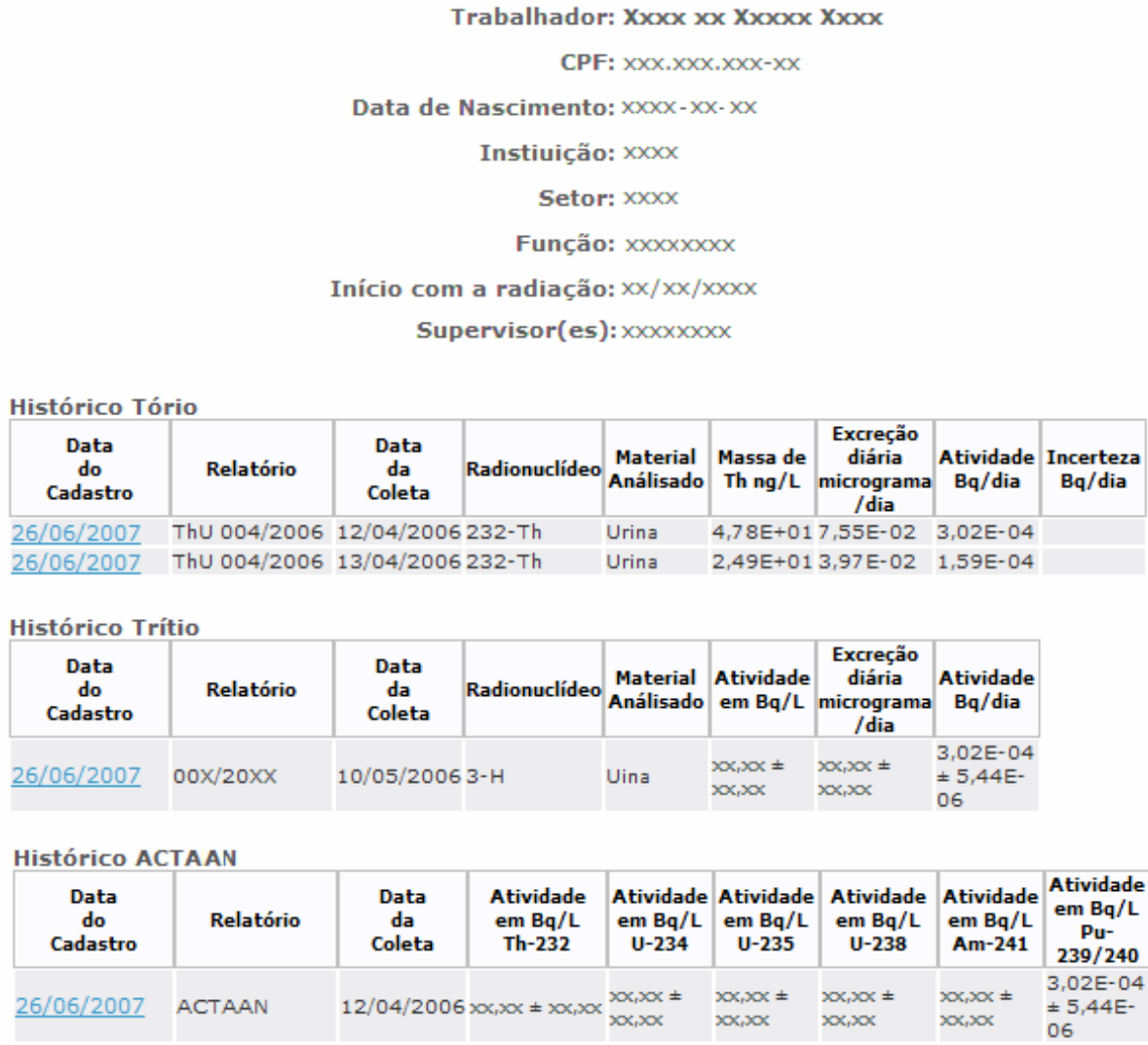

$$
\text { Voltar Imprimir }
$$

FIGURA 5.13 - Histórico da monitoração individual interna in vitro

Pode-se observar os dados pessoais do trabalhador e o histórico de análises de acordo com o método de análise, que são: Tório, Trítio e Actinídeos. 
Eventualmente a alteração dos dados pode ser realizada selecionando o campo "Data do Cadastro". O formulário de alteração é apresentado na FIG. 5.14. Por meio deste formulário é possível efetuar alterações da medida quando houver necessidade. Observa-se que o formulário também apresenta os dados pessoais do trabalhador. A título de exemplo, é apresentado o formulário de atualização da monitoração interna in vitro para o trítio.
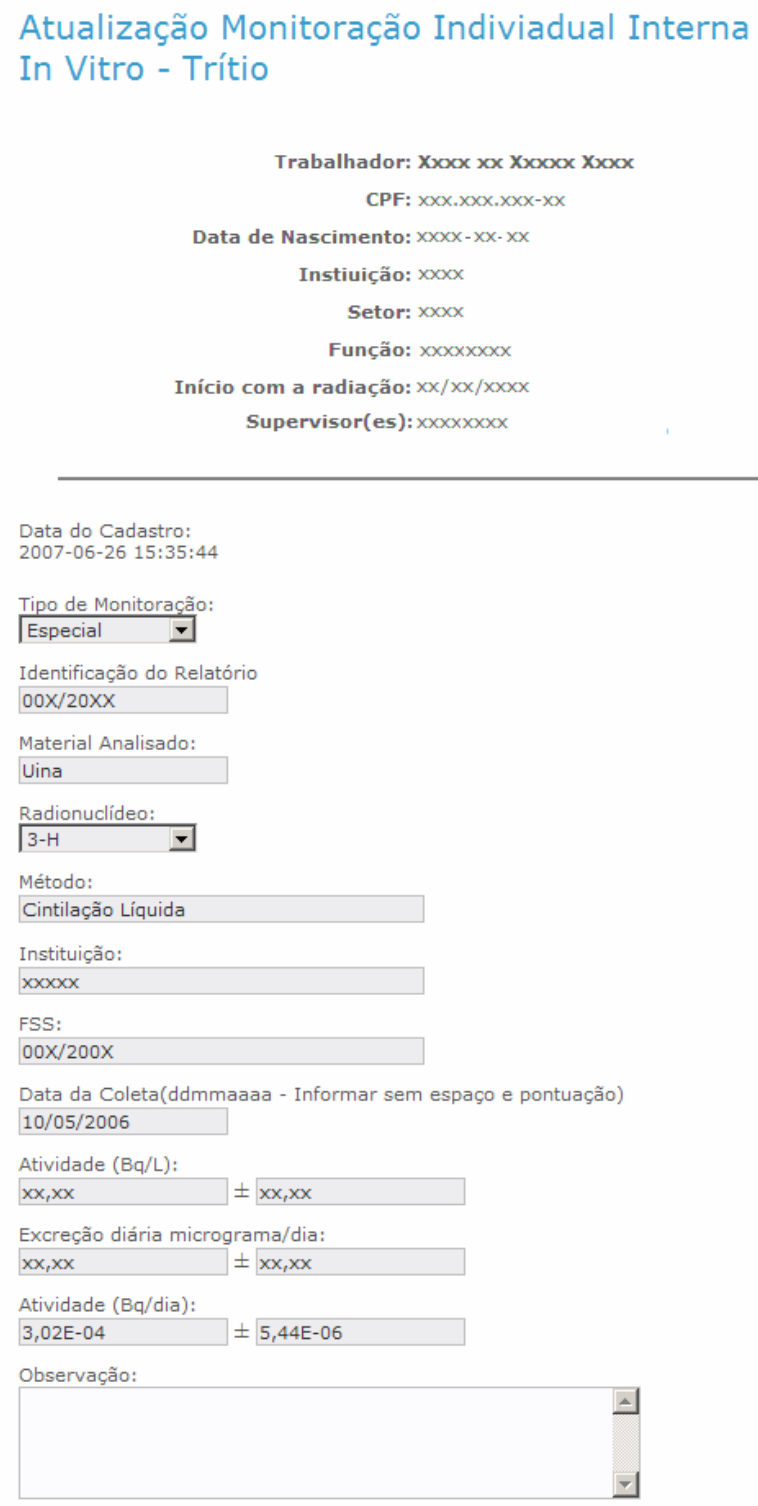

Salvar

Voltar

FIGURA 5.14 - Formulário para alteração de dados da monitoração in vitro - trítio 


\subsection{Cálculo de Dose}

\subsubsection{Relatório de Monitoração}

A FIG. 5.15 apresenta uma pesquisa efetuada por período, conforme mencionado no capítulo 4, item 4.2.6. Esta pesquisa tem por objetivo informar as monitorações para as quais ainda não foram efetuados os cálculos da dose.

\section{Pesquisa de Monitoração para Cálculo da Dose \\ *Data Inicial (ddmmaaaa - Informar sem espaço e pontuação) \\ *Data Final (ddmmaaaa - Informar sem espaço e pontuação) \\ Pesquisar Limpar Campos}

\begin{tabular}{|c|c|c|c|c|c|c|c|c|c|c|c|c|}
\hline $\begin{array}{l}\text { Cód. } \\
\text { Monit. }\end{array}$ & Relatório & $\begin{array}{c}\text { Cód. } \\
\text { Trabalhador }\end{array}$ & Trabalhador & $\begin{array}{c}\text { Data } \\
\text { Cadastro }\end{array}$ & Freq. & $\begin{array}{c}\text { Tipo } \\
\text { de } \\
\text { Monit. }\end{array}$ & Radionuclideo & Órgão & $\begin{array}{c}\text { Data } \\
\text { Monitoração }\end{array}$ & Atividade & $\begin{array}{c}\text { Erro } \\
\text { Atividade }\end{array}$ & LD \\
\hline 13 & Rel_CR_0307 & 1 & $\begin{array}{l}X_{000} \times x \\
X_{0000 \times} X_{000 x}\end{array}$ & $25 / 10 / 2007$ & Mensal & Rotineiro & $131-I$ & CI & $14 / 06 / 2007$ & LD & LD & 150 \\
\hline 14 & $\mathrm{CH}_{3} \mathrm{XX}$ & 1 & 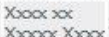 & $25 / 10 / 2007$ & Mensal & Especial & $131-I$ & Tireoide & $=18 / 06 / 2007$ & LD & LD & 100 \\
\hline
\end{tabular}

2 registro(s) encontrado(s) no período de 01/04/2007 a 30/06/2007 Histórico Tório

\begin{tabular}{|c|c|c|c|c|c|c|c|c|c|c|c|}
\hline Relatório & $\begin{array}{c}\text { Cód. } \\
\text { Trabalhador }\end{array}$ & Trabalhador & $\begin{array}{c}\text { Data } \\
\text { do } \\
\text { Cadastro }\end{array}$ & Relatório & $\begin{array}{c}\text { Data } \\
\text { da } \\
\text { Coleta }\end{array}$ & Radionuclideo & $\begin{array}{l}\text { Material } \\
\text { Análisado }\end{array}$ & $\begin{array}{c}\text { Massa de Th } \\
\mathrm{ng} / \mathrm{L}\end{array}$ & $\begin{array}{c}\text { Excreção } \\
\text { diária } \\
\text { micrograma } \\
\text { /dia }\end{array}$ & $\begin{array}{c}\text { Atividade } \\
\text { Bq/dia }\end{array}$ & $\begin{array}{c}\text { Incerteza } \\
\mathrm{Bq} / \mathrm{dia}\end{array}$ \\
\hline $\begin{array}{l}\text { Thu } \\
004 / 2006\end{array}$ & 1 & $\begin{array}{l}X_{1000}>0 \times \\
X_{0000} X_{100}\end{array}$ & & $\begin{array}{l}\text { ThU } \\
004 / 2006\end{array}$ & $12 / 04 / 200$ & $6232-T h$ & Urina & & $7,55 E-02$ & $\begin{array}{l}3,02 \mathrm{E}- \\
04\end{array}$ & $5,44-06$ \\
\hline $\begin{array}{l}\text { Thu } \\
004 / 2006\end{array}$ & 1 & $\begin{array}{l}X_{000 \times}>0 x \\
X_{0000 x} X_{000 x}\end{array}$ & $26 / 06 / 2007$ & $\begin{array}{l}\text { Thu } \\
004 / 2006\end{array}$ & $13 / 04 / 200$ & $6232-\mathrm{Th}$ & Urina & $2,49 E+01$ & $3,97 \mathrm{E}-02$ & $\begin{array}{l}1,59 \mathrm{E}- \\
04\end{array}$ & $\begin{array}{l}2,86 \mathrm{E}- \\
06\end{array}$ \\
\hline
\end{tabular}

1 registro(s) encontrado(s) no período de 01/04/2007 a 30/06/2007

\begin{tabular}{|c|c|c|c|c|c|c|c|c|c|c|c|}
\hline \multicolumn{12}{|c|}{ Historico I ritio } \\
\hline $\begin{array}{l}\text { Cód. } \\
\text { Monit. }\end{array}$ & Relatório & $\begin{array}{l}\text { Cód. } \\
\text { Trabalhador }\end{array}$ & Trabalhador & $\begin{array}{c}\text { Data } \\
\text { do } \\
\text { Cadastro }\end{array}$ & Relatório & $\begin{array}{c}\text { Data } \\
\text { da } \\
\text { Coleta }\end{array}$ & Radionuclídeo & $\begin{array}{c}\text { Material } \\
\text { Análisado }\end{array}$ & $\begin{array}{l}\text { Atividade } \\
\text { em Bq/L }\end{array}$ & $\begin{array}{c}\text { Excreção } \\
\text { diária } \\
\text { micrograma } \\
\text { /dia }\end{array} \mid$ & Atividade \\
\hline 2 & $00 x / 20 x x$ & 1 & $\begin{array}{l}X_{000 x} \times x \\
X_{0000 \times} X_{100}\end{array}$ & $26 / 06 / 200$ & $0 x / 20 x x$ & $10 / 05 / 200$ & $63-\mathrm{H}$ & Uina & $x, x, x$ & $x<x, x<x$ & $\begin{array}{l}3,02 \mathrm{E}- \\
04\end{array}$ \\
\hline
\end{tabular}

1 registro(s) encontrado(s) no período de 01/04/2007 a 30/06/2007 Histórico ACTAAN

\begin{tabular}{|c|c|c|c|c|c|c|c|c|c|c|c|}
\hline & \multirow{2}{*}{\multicolumn{2}{|c|}{ Data }} & \multirow{2}{*}{\multicolumn{6}{|c|}{ Atividade em $B q / L$}} \\
\hline & & & & & & & & & & & \\
\hline $\begin{array}{l}\text { Cód. } \\
\text { Monit. }\end{array}$ & Relatório & \begin{tabular}{c|} 
Cód. \\
Trabalhador
\end{tabular} & Trabalhador & Cadastro & Coleta & Th-232 & $U-234$ & $u-235$ & U-238 & Am-241 & $\begin{array}{c}\text { Pu- } \\
239 / 240\end{array}$ \\
\hline 3 & ACTAAN & 1 & 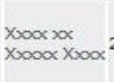 & $26 / 06 / 2007$ & $12 / 04 / 2006$ & 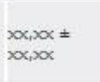 & $x x_{1}, x x=x x_{1}, x x$ & $\begin{array}{l}x x, x x= \\
x, x, x x\end{array}$ & 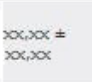 & $\begin{array}{l}x x, x<x= \\
x \alpha, x<x\end{array}$ & $\begin{array}{l}3,02 \mathrm{E}- \\
04 \pm \\
5,44 \mathrm{E}- \\
06\end{array}$ \\
\hline
\end{tabular}

Voltar Salvar

FIGURA 5.15 - Pesquisa de monitoração realizada para efetuar cálculo de dose

Quando houver a necessidade de guardar a referida pesquisa, o sistema oferece o e recurso para que a mesma seja salva em planilha Excel, 
como apresentado na FIG. 5.16. Para tanto basta pressionar o botão "Salvar" conforme apresentado na FIG. 5.15.

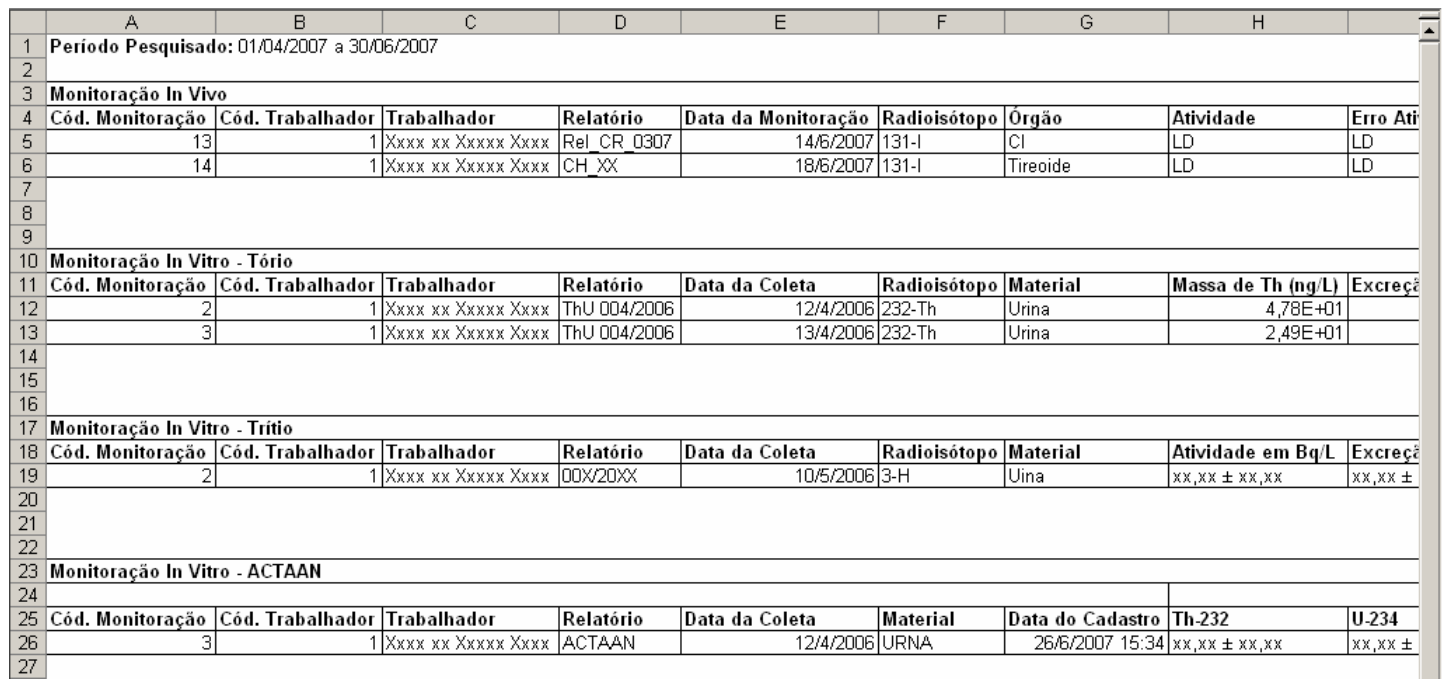

FIGURA 5.16 - Resultado da pesquisa de monitoração salva em planilha Excel

\subsubsection{Registro de Dose}

O item 4.2.6 apresenta como inserir os registros do cálculo da dose. Tais registros podem ser visualizados por meio da Pesquisa de Trabalhadores bastando para isso acessar o Menu Dose e o Sub Menu Registro de Dose, como pode-se observar na FIG. 5.17. Somente o Grupo de Cálculo de Dose tem acesso a esse menu.

\section{Registro de Dose}

\section{Pesquisar trabalhadores}

Nome:

Pesquisar

FIGURA 5.17 - Formulário de pesquisa registro de dose 
O resultado da pesquisa mencionada é apresentado na TAB. 5.3, onde podemos observar o nome do trabalhador, modo e a forma de incorporação, classe, AMAD, tempo, Incorporação, Dose e a data em que o cadastro foi realizado.

TABELA 5.3 - Resultado da pesquisa do registro de dose

Pesquisa de Trabalhadores

Registro de Dose

\begin{tabular}{|c|c|c|c|c|c|c|c|c|}
\hline Nome & $\begin{array}{c}\text { Modo } \\
\text { de } \\
\text { Incorporação }\end{array}$ & $\begin{array}{c}\text { Forma } \\
\text { de } \\
\text { Incorporação }\end{array}$ & Classe & AMAD & Tempo & Intake & Dose & $\begin{array}{l}\text { Data } \\
\text { do } \\
\text { Cadastro }\end{array}$ \\
\hline 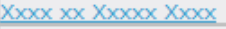 & Inalação & Agudo & $\mathrm{m}$ & 5 & 7 & $M \pm M$ & $M \pm M$ & $2007-10-25 \quad 13: 32: 53$ \\
\hline$x_{x x x} x x X_{x x} x x x X_{x x x}$ & Contaminação da Pele & Agudo & f & 5 & 7 & $M \pm M$ & $M \pm M$ & $2007-10-25$ 13:43:8 \\
\hline
\end{tabular}

Pode-se observar os dados pessoais do trabalhador, os dados da monitoração e os dados do cálculo da dose. Eventualmente pode-se alterar os dados do cálculo da dose, conforme observa-se na FIG. 5.18. 


\section{Registro de Cálculo de Dose}

Trabalhador: Xxxx $\mathbf{x x}$ Xxxxx Xxxx

CPF: $x x x \cdot x x x \cdot x x x-x x$

Data de Nascimento: $x x x x-x x-x x$

Instiuição: $x x x x$

Setor: $x x x x$

Função: $x x x x x x x x$

Início com a radiação: $x x / x x / x x x x$

Supervisor(es): $x x x x x x x x$

Cód. da Monitoração: 2

Relatório: ThU 004/2006

Material: Urina

Radionuclídeo: 232-Th

Metodo: Análise por Ativação Neutrônica

Tipo de Monitoração: Rotineiro

Data da Coleta: 12/04/2006

Massa: $4,78 \mathrm{E}+01$

Excreção: 7,55E-02

Atividade: $3,02 \mathrm{E}-04$

Incerteza: 5,44-06

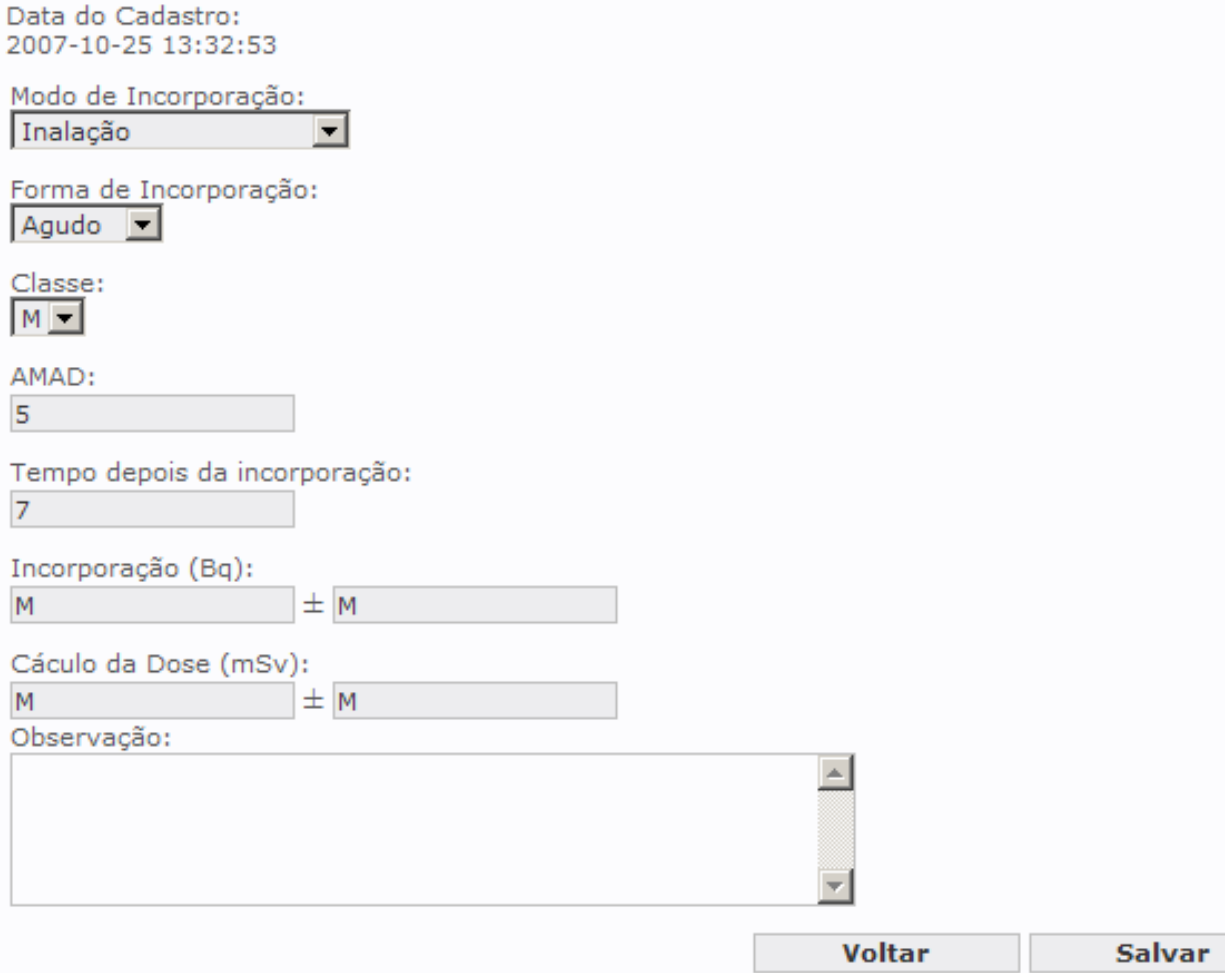

FIGURA 5.18 - Formulário para alteração de dados do registro de dose 


\subsection{Relatório}

\subsubsection{Relatório In Vivo}

O IntDosWeb permite emitir relatórios individuais ou para supervisor referente aos resultados do cálculo de dose para a monitoração in vivo, conforme descrito no capítulo 4, item 4.2.7.1.

A TAB. 5.4 apresenta o resultado do relatório para o supervisor. Nesta mesma tela o usuário poderá solicitar a emissão do relatório bastando pressionar o botão "Imprimir". A FIG. 5.19 apresenta a impressão deste relatório.

TABELA 5.4 - Relatório da monitoração interna in vivo para o Supervisor Relatório Monitoração Interna - In Vivo

Medidas: Laboratório de Monitoração In Vivo

Relatório: $x-x x .-x x x-x x \times x / x x x x x x$

Solicitante: $x \times x \times x \times x \times x \times x \times x$

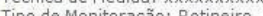

Periodicidade: Mensal

\begin{tabular}{|c|c|c|c|c|c|c|}
\hline Data & Nome & CPF & Órgão & $\begin{array}{l}\text { Atividade } \\
\text { Medida (Bq) }\end{array}$ & $\begin{array}{l}\text { Dose Efetiva } \\
\text { Comprometida (mSv) }\end{array}$ & obs \\
\hline yy/yy/yyyy & Yyyyyy Yyyyyy & $y y y \cdot y y y \cdot y y y-y y$ & CI & LD & LD & \\
\hline$x x / x x / x=2 x x$ & $x x x x x x=x x x x x x x x x$ & $x x x . x x x . x x y-x x$ & Tireóide & LD & LD & \\
\hline$x x / x x / x x x x$ & $\mathrm{Xxxx} \times \mathrm{xx}$ Xxxxx Xxxx & $x x x \cdot x x x \cdot x x x-x x$ & Tireóide & LD & LD & \\
\hline
\end{tabular}


Medidas: Laboratório de Monitoração In Vivo

Relatório: $\mathbf{x}-\mathbf{x x} . \mathbf{x} \mathbf{x x}-\mathbf{x} \mathbf{x} \mathbf{x} \mathbf{x} / \mathbf{x x} \mathbf{x} \mathbf{x} \mathbf{x} \mathbf{x}$

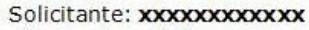

Técnica de Medida: $\mathbf{x x x x x x x x x x x x x}$

Nome: $\mathbf{X x x x} \mathbf{x x} \mathbf{X x x} \mathbf{x} \mathbf{x} \mathbf{X x x}$

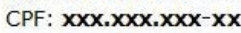

Setor: $\mathbf{x x}-\mathbf{x x x x}$

Tipo de Monitoração: Rotineiro

Periodicidade: Mensal

\begin{tabular}{llll}
\hline Data & Órgão & $\begin{array}{l}\text { Atividade } \\
\text { Medida }(B q) *\end{array}$ & $\begin{array}{l}\text { Dose Efetiva } \\
\text { Comprometida }(\mathbf{m S v}) * *\end{array}$ \\
$y y / y y / y y y y$ & LD & LD \\
$x x / x x / x x x x$ & CI & LD & LD \\
$x x / x x / x x x x$ & Tireóide & LD & LD \\
\hline
\end{tabular}

* Menor LD = Menor que o limite de detecção do método

LD - para I-131 (Tireoíde) $=110 \mathrm{~Bq}$

LD - para Co-60 (Corpo Inteiro) $=220 \mathrm{~Bq}$

** A dose efetiva comprometida é determinada somente quando incorporação apresentar valor maior que o Nível de Registro na frequê̂ncia de medida.

São Paulo, $x x$ de xxxxxxx de xxxx

Grupo de Cálculo de Dose

Instituto de Pesquisas Energéticas e Nucleares Departamento de Metrologia das Radiações - NM
Av. Prof. Lineu Prestes, 2242 - Cidade Universitária - CEP 05508-000
Fone: (0XX11) 3816-9217 Fax: (0XX11) 3816-9217

FIGURA 5.19 - Impressão do relatório monitoração interna in vivo para o Supervisor 
A TAB. 5.5 apresenta o resultado do relatório individual para o trabalhador. Analogamente, apresentada o usuário poderá solicitar a emissão do relatório, bastando pressionar o botão "Imprimir" na TAB. 5.5. A FIG. 5.20 apresenta a impressão deste relatório.

TABELA 5.5 - Relatório da monitoração interna in vivo para o Trabalhador Relatório Monitoração Interna - In Vivo

Medidas: Laboratório de Monitoração In Vivo

Relatório: $\mathbf{x}-\mathbf{x x} \cdot \mathbf{x x} \mathbf{x}-\mathbf{x} \mathbf{x} \mathbf{x x} / \mathbf{x} \mathbf{x} \mathbf{x} \mathbf{x} \mathbf{x} \mathbf{x}$

Solicitante: $\mathbf{x} \mathbf{x} \mathbf{x} \mathbf{x} \mathbf{x} \mathbf{x} \mathbf{x} \mathbf{x} \mathbf{x} \mathbf{x} \mathbf{x} \mathbf{x}$

Técnica de Medida: $\mathbf{x} \mathbf{x} \mathbf{x} \mathbf{x} \mathbf{x} \mathbf{x} \mathbf{x} \mathbf{x} \mathbf{x} \mathbf{x}$

Nome: $\mathbf{X x x} \mathbf{x} \mathbf{x} \mathbf{x} \mathbf{X} \mathbf{x} \mathbf{x} \mathbf{x} \mathbf{x} \mathbf{X x} \mathbf{x} \mathbf{x}$

CPF: $\mathbf{x} \mathbf{x} \mathbf{x} \cdot \mathbf{x} \mathbf{x} \mathbf{x} \cdot \mathbf{x} \mathbf{x} \mathbf{x}-\mathbf{x x}$

Setor: $\mathbf{x x}-\mathbf{x x x} \mathbf{x}$

Tipo de Monitoração: Rotineiro

Periodicidade: Mensal

\begin{tabular}{|l|l||c|c|c|}
\hline Data & Radionuclídeo & Órgão & $\begin{array}{l}\text { Atividade } \\
\text { Medida (Bq) }\end{array}$ & $\begin{array}{l}\text { Dose Efetiva } \\
\text { Comprometida (mSv) }\end{array}$ \\
\hline$x x / x x / x x x x$ & $x-x x$ & CI & LD & LD \\
\hline$y y / y y / y y y y$ & $y-y y$ & Tireóide & LD & LD \\
\hline
\end{tabular}




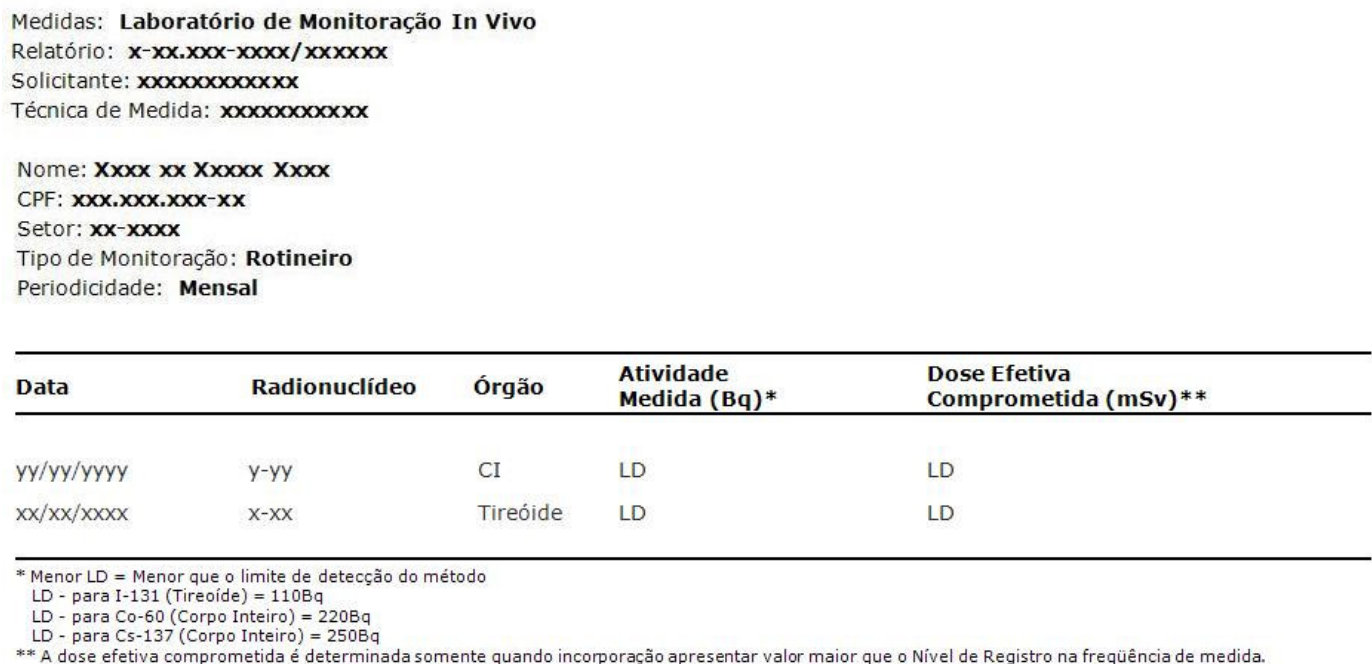

São Paulo, xx de xxxxxxx de xxxx

Grupo de Cálculo de Dose

Instituto de Pesquisas Energéticas e Nucleares Departamento de Metrologia das Radiações - NM

Av. Prof. Lineu Prestes, 2242 - Cidade Universitária - CEP 05508-000

FIGURA 5.20 - Impressão do Relatório Monitoração Interna In Vivo para o

Trabalhador

\subsubsection{Relatório In Vitro}

Assim como no relatório in vivo, o IntDosWeb é capaz de emitir relatórios individuais e relatórios para o supervisor referente aos resultados do cálculo de dose para monitoração in vitro, conforme descrito no capítulo 4, item 4.2.7.1. 
Um resultado do relatório para o Supervisor pode ser visto na TAB. 5.6. É possível ainda solicitar a emissão do relatório pressionando o botão "Imprimir". A FIG. 5.21 apresenta a impressão deste relatório.

TABELA 5.6 - Relatório da monitoração interna in vitro para o Supervisor Relatório Monitoração Interna - In Vivo

Medidas: Laboratório de Monitoração In Vivo

Relatório: $x-x x \cdot x x x-x x x x / x x x x x x$

Solicitante: $x x x x x x x x x x x x$

Técnica de Medida: xxxxxxxxxxx

Tipo de Monitoração: Rotineiro

Periodicidade: Mens

\begin{tabular}{|l|l|l|l|l|l|l|}
\hline Data & Nome & CPF & Órgão & $\begin{array}{l}\text { Atividade } \\
\text { Medida (Bq) }\end{array}$ & $\begin{array}{l}\text { Dose Efetiva } \\
\text { Comprometida (mSv) }\end{array}$ & Obs \\
\hline$y y / y y / y y y y$ & Yyyyyy Yyyyyy & $y y y \cdot y y y \cdot y y y-y y$ & CI & LD & LD & \\
\hline$x x / x x / x x x x$ & $X x x x x x X x x x x X x x x$ & $x x x \cdot x x x \cdot x x x-x x$ & Tireóide & LD & LD & \\
\hline$x x / x x / x x x x$ & $X x x x x x X x x x x X x x x$ & $x x x \cdot x x x \cdot x x x-x x$ & Tireóide & LD & LD & \\
\hline
\end{tabular}

Voltar Imprimir

\section{ipen}

Relatório de Monitoração Interna

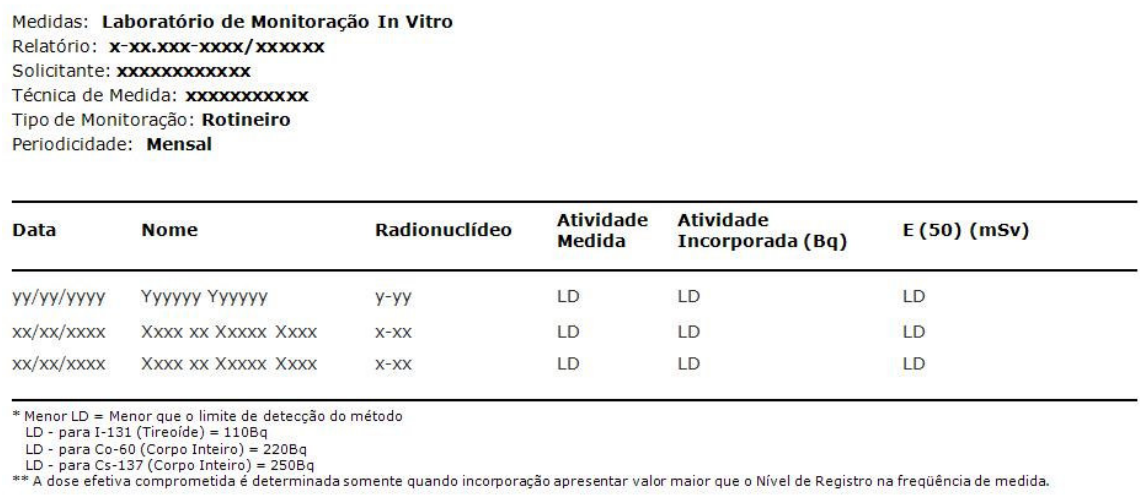

São Paulo, $x x$ de $x x x x x x x$ de $x x x x$

Grupo de Cálculo de Dose

Instituto de Pesquisas Energéticas e Nucleares Departamento de Metrologia das Radiações - NM
Av. Prof. Lineu Prestes, 2242- Cidade Universitária - CEP 05508-000
Fone: (0XX11) 3816-9217 Fax: (0XX11) 3816-9217 Fone: (0XX11) $3816-9217$ Fax: (0XX11) 38
São Paulo - Estado de São Paulo

FIGURA 5.21 - Impressão do Relatório Monitoração Interna In vitro para o Supervisor 
O resultado do relatório para o trabalhador pode ser visto na TAB. 5.7.

E a emissão do relatório na FIG. 5.22.

TABELA 5.7 - Relatório da monitoração interna in vitro para o Trabalhador Relatório Monitoração Interna - In Vitro

\begin{tabular}{|c|c|c|c|c|}
\hline \multicolumn{5}{|c|}{ 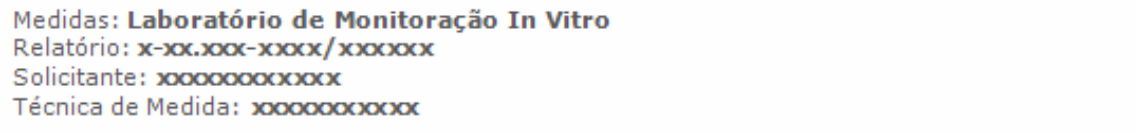 } \\
\hline \multicolumn{5}{|c|}{ 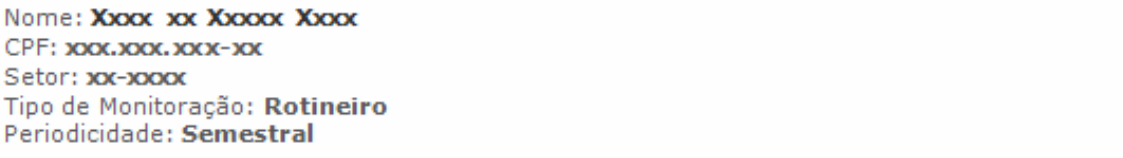 } \\
\hline Radionuclídeo & $\begin{array}{l}\text { Material } \\
\text { Biológico }\end{array}$ & $\begin{array}{l}\text { Atividade } \\
\text { Incorporada (Bq) }\end{array}$ & $E(50)$ (mSv) & Obs \\
\hline$x x / x x / x x x x=x-x x$ & Urina & LD & LD & \\
\hline yy/yy/yyyy y-yy & Urina & LD & LD & \\
\hline
\end{tabular}

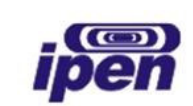

Relatório de Monitoração Interna

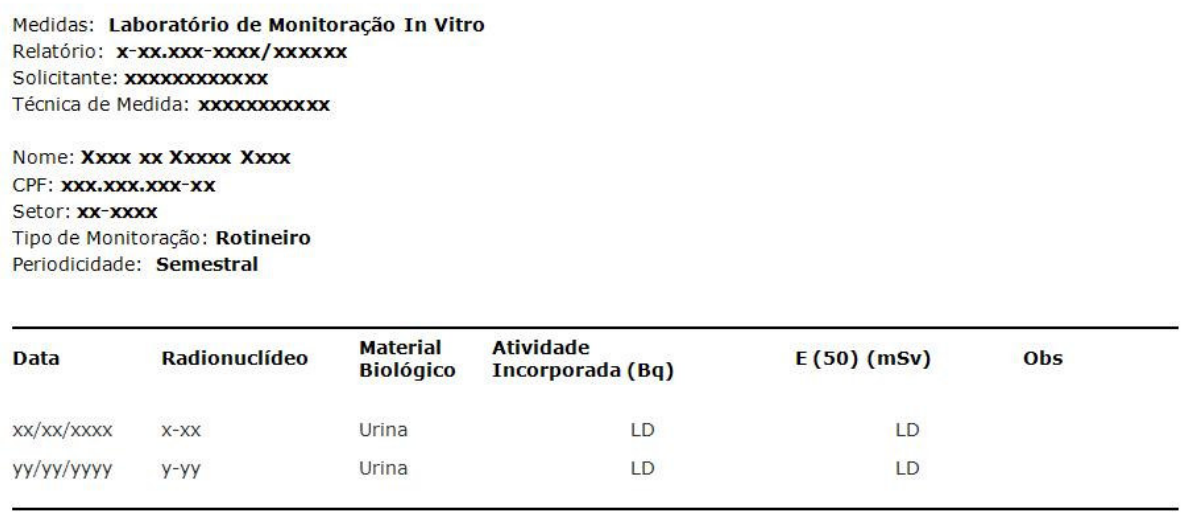

Grupo de Cálculo de Dose

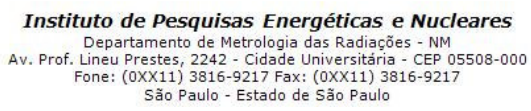

FIGURA 5.22 - Impressão do relatório monitoração interna in vitro para o Trabalhador 


\subsection{Discussões Finais}

O IntDosWeb passou por um estágio de avaliação operacional onde foram efetuados vários casos de simulação para conferir as capacidades funcionais, tais como, uniformização, agilização e racionalização do fluxo de informações, e também as não funcionais como confidencialidade e integridade do software. Os usuários podem ter acesso à informação dosimétrica de acordo com os seguintes parâmetros da base de dados: período de monitoração, tipo de monitoração, modo de incorporação, tipo de radionuclídeo, e também dados da monitoração dos trabalhadores para uma instalação específica ou dados de monitoração de cada trabalhador.

Este sistema foi testado acessando-o simultaneamente de vários computadores, por diversas categorias funcionais de usuários, para assegurar que a acessibilidade ao banco de dados e a segurança da informação estejam disponíveis nas mais variadas plataformas e sob as mais variadas condições de uso dentro da Intranet do IPEN.

É importante ressaltar que qualquer inserção, alteração ou exclusão dos dados informados no IntDosWeb será registrado para a segurança e confiabilidade dessa informação. É possível identificar o usuário, o momento da inserção, a alteração ou exclusão e o terminal (computador) onde foi gerado esse registro.

No que tange ao modelo de processo, percebeu-se que a prototipação incremental adequou-se de maneira eficaz às necessidades do Programa de Monitoração Interna. Este modelo possibilita o enriquecimento do software à medida que seus usuários verificam novas necessidades sem alterar a estrutura inicial do mesmo. 


\section{CONCLUSÃO}

Percebe-se ao longo do trabalho que o foco do software é proporcionar a avaliação integrada e pronta dos dados de monitoração ao permitir o acesso rápido e fácil às informações relativas às doses incorporadas.

Pode-se concluir que o uso do IntDosWeb nas áreas avaliadas ao longo da pesquisa poderá trazer benefícios nos processos de cada etapa do Programa de Monitoração Interna, à medida que padronizará o controle dos trabalhadores que manuseiam materiais radioativos na forma não selada.

A implementação do IntDosWeb no serviço de dosimetria interna irá proporcionar recursos adicionais que servirão como facilitadores para a análise dos resultados das medidas e para o estudo da distribuição de dose dos trabalhadores ocupacionais, avalia a tendência de exposição que um grupo coletivo de trabalhadores pode receber e aperfeiçoar a eficácia do programa de monitoração. 


\section{SUGESTÕES PARA TRABALHOS FUTUROS}

Durante 0 processo de pesquisa inicial para a realização deste trabalho, observou-se a possibilidade de se realizar a implantação de um controle informatizado para o Laboratório de Monitoração In vitro (LRT). Esta informatização facilitaria o controle dos resultados parciais e finais das análises realizadas pelo LRT.

Outro ponto importante é o conhecimento de que existem trabalhadores que fazem parte do programa de monitoração externa e interna do IPEN e que são cadastrados nos dois sistemas. Nesse sentido, a integração dos formulários de cadastramento dos trabalhadores do programa de monitoração externa com o Banco de Dados do IntDosWeb, uniformizaria as informações do trabalhador. 


\section{REFERÊNCIAS BIBLIOGRÁFICAS}

1 Raabe, O. G. Internal radiation dosimetry. Medical Physics Publishing, $1^{\text {st }}$ Edition, Madison, Wisconsin, 1994.

2 GABURO, J.C.C.; MESQUITA, S. A.; SANCHES, M.P.; TODO, A.S; LIMA, V. $R$. International monitoring of workers occupationally exposed to radionuclides in the brazilian radiological and nuclear facilities, 3rd Iberian Latin American and Caribbean Congress of Medical Physics and IX Brazilian Congress of Medical Physics - 26-29 September, 2004, Rio de Janeiro, Brasil, CD-Rom.

3 INTERNATIONAL ATOMIC ENERGY AGENCY. Occupational radiation protection. Vienna, 1999. (IAEA-RS-G-1.1).

4 INTERNATIONAL ATOMIC ENERGY AGENCY. Direct methods for measuring radionuclides in the human Body. Vienna, 1996. (IAEA-SS-114).

5 INTERNATIONAL ATOMIC ENERGY AGENCY. International basic safety standards for protection against ionizing radiation and for the safety of radiation sources. Vienna, 1996. (IAEA-SS-115).

6 GABURO, J.C.G.; SORDI, G.M.A.A. Radiobioanálise in vitro aplicada, São Paulo, nov. 1992. (IPEN-Pub-379).

7 INTERNATIONAL COMMISSION ON RADIOLOGICAL PROTECTION, Recommendations of the international commission on radiological protection. Oxford, 1977. (ICRP-26).

8 INTERNATIONAL COMMISSION ON RADIOLOGICAL PROTECTION. Human respiratory tract model for radiological protection. Oxford, 1995. (ICRP-66).

9 INTERNATIONAL COMMISSION ON RADIOLOGICAL PROTECTION. Human alimentary tract model for radiological protection. Oxford, 2007. (ICRP-100).

10 INTERNATIONAL COMMISSION ON RADIOLOGICAL PROTECTION. Individual monitoring for internal exposure of workers. Oxford, 1998. (ICRP-78). 
11 COMISSÃO NACIONAL DE ENERGIA NUCLEAR. Diretrizes básicas de radioproteção. Rio de Janeiro, 2005. (CNEN-NN-3.01).

12 INTERNATIONAL ATOMIC ENERGY AGENCY. Indirect methods for assessing intakes of radionuclides causing occupational exposure. Vienna, 2000. (IAEA-SRS-18).

13 KILLOUGH, G.G.; ECKERMAN, K.F. Internal dosimetry. In: TILL, J. E.; MEYER, H. R. (Ed.). Radiological assessment: a textbook on environmental dose analysis. Washington, D. C.: Nuclear Regulatory Commission, 1983. p. 7.1-7.98. (Nureg/CR-3332).

14 POSTON, J.W. Reference Man: a system for internal dose calculation. In: TILL, J. E.; MEYER, H. R. (Ed.). Radiological assessment: a textbook on environmental dose analysis. Washington, D. C.: Nuclear Regulatory Commission, 1983. p. 6.1-7.31. (Nureg/CR-3332).

15 INTERNATIONAL ATOMIC ENERGY AGENCY. Optimization of radiation protection in the control of occupational exposure. Vienna, 2002. (IAEA-SRS-21).

16 INTERNATIONAL ATOMIC ENERGY AGENCY. Assessment of occupational exposure due to intakes of radionuclides.

Vienna, 1999. (IAEA-RS-G-1.2).

17 INTERNATIONAL ATOMIC ENERGY AGENCY. Assessment of occupational exposure due to external sources of radiation. Vienna, 1999. (IAEA-RS-G-1.3).

18 INTERNATIONAL COMMISSION ON RADIOLOGICAL PROTECTION. Limits for intakes of radionuclides by workers. Oxford, 1979. (ICRP-30 part 1).

19 INTERNATIONAL COMMISSION ON RADIOLOGICAL PROTECTION. Limits for intakes of radionuclides by workers: part 4 (an addendum). Oxford and New York (1989). (ICRP-30)

20 INTERNATIONAL COMMISSION ON RADIOLOGICAL PROTECTION, General principles for monitoring of radiation protection of workers. Vienna, 1982. (ICRP-35).

21 INTERNATIONAL COMMISSION ON RADIOLOGICAL PROTECTION, Individual monitoring for intakes of radionuclides by workers: design and interpretation. Oxford, 1988. (ICRP-54). 
22 INTERNATIONAL COMMISSION ON RADIOLOGICAL PROTECTION. 1990 Recommendations of the international commission on radiological protection. Oxford, 1991. (ICRP-60).

23 INTERNATIONAL COMMISSION ON RADIOLOGICAL PROTECTION. Dose coefficients for intakes of radionuclides by workers. Oxford, 1995. (ICRP-68).

24 INTERNATIONAL COMMISSION ON RADIOLOGICAL PROTECTION. General principles for radiation protection of worker. Vienna, 1998. (ICRP-75).

25 Servidor Apache. Disponível em: $<$ http://pt.wikipedia.org/wiki/Engenharia de software $>$. Acesso em 05 set. 2007.

26 BAUER. L. F; HELMS. J. H.; Software engineering. Mishawaka: BetterWorld, 1998.

27 ROYCE, W.W, Managing the development of large software systems. Proceedings, IEEE Wescon, Agosto 1970.

28 Preece, J.; A Guide to Usability: Human factors in computing. Rowland Heights: Zillions OF, 1993.

29 Sommerville, I. Engenharia de software, 6.ed., São Paulo: Makron Books, 2003.

$30 \mathrm{SCHACH}$, R.S; Object-oriented and classical software engineering. 5.ed. São Paulo: McGraw-Hill, 2002

31 BOEHM, B.; A spiral model for software development and enhancement. Computer, vol.21, n. 5, Maio 1988, pp. 61-72.

32 PAULA FILHO, PÁDUA.W. Engenharia de software: fundamentos, métodos e padrões. 2.ed. Rio de Janeiro: LTC, 2003.

33 TITTEL, E.; GAITHER, M.; HASSINGER, S. World Wide Web com HTML e CGI: bíblia do programador. 1.ed. São Paulo: Berkeley do Brasil, 1996.

34 ALMEIDA, M.G.; ROSA, C.P.,Internet, intranet e redes corporativas. 1.ed. São Paulo: Brasport, 2000.

35 Servidor Apache. Disponível em: $<$ http://pt.wikipedia.org/wiki/Servidor Apache>. Acesso em 22 jun. 2007.

36 SILBERSCHATZ, A.; KORTH, H.; SUDARSHAN, S.

Sistema de banco de dados. 3.ed. São Paulo: Makron Books, 1999. 
37 RUMBAUGH, B. M., PREMERLANI W., EDDY F. \& LORENSEN W.; Object-Oriented modeling and design. New Jersy: Prentice Hall, 1991.

38 NIEDERAUER, J.; PHP para quem conhece PHP. 2.ed. São Paulo: Novatec, 2004.

39 GUTMANS, A.; BAKKEN.S.; RETHANS, D.; PHP 5 - programação poderosa. 1.ed. São Paulo: Alta Books, 2005.

40 NETO, P.A.; PostgreSQL - técnicas avançadas - versões open source 7.X. 4.ed. São Paulo: Érika, 2003.

41 phpPgAdmin. Disponível em: $<$ http://phppgadmin.sourceforge.net/?page=about $>$. Acesso em 22 jun. 2007

42 Criptografia. Disponível em: <http://pt.wikipedia.org/wiki/Criptografia>. Acesso em 27 jul. 2007.

43 L. Bertelli. Activity and internal dose estimates (AIDE). Instructions Manual, Version 2.0e (2004). 